Organizadores

Gissele Carraro Loise Cristina Passos Drumond Valmin Ramos-Silva

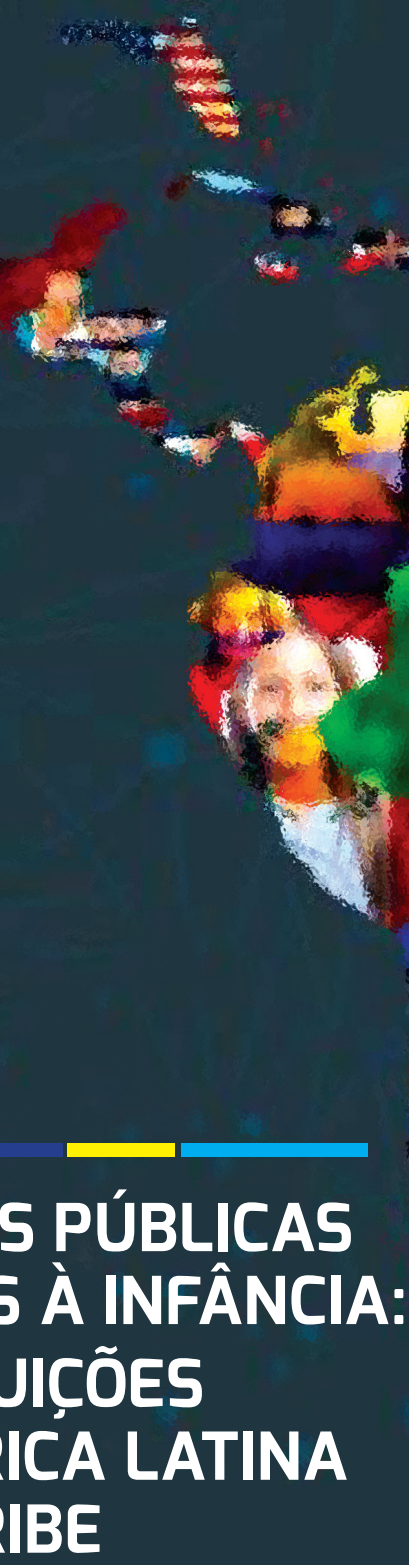

POLÍTICAS PÚBLICAS DIRIGIDAS À INFÂNCIA: CONTRIBUICOÕES DA AMÉRICA LATINA E DO CARIBE 

Gissele Carraro

Loise Cristina Passos Drumond

Valmin Ramos-Silva

Organizadores

\section{POLÍTICAS PÚBLICAS \\ DIRIGIDAS À INFÂNCIA: \\ CONTRIBUICÕ̃ES \\ DA AMÉRICA LATINA \\ E DO CARIBE}

DOI: 10.5935/978-65-88041-01-7.0001 (http://dx.doi.org)

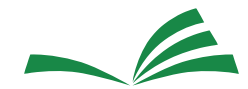

e ditora EMESCAM

Vitória, ES - 2020 
(C) 2020 Editora EMESCAM

Todos os direitos reservados. A reprodução de qualquer parte da obra, por qualquer meio, sem autorização da editora, constitui violação da LDA n 9.610/98

\section{Capa}

Setor de Comunicação da EMESCAM

\section{Revisão e preparação dos originais}

Valmin Ramos-Silva

\section{Editoração}

Edson Maltez Heringer | 27 98113-1826

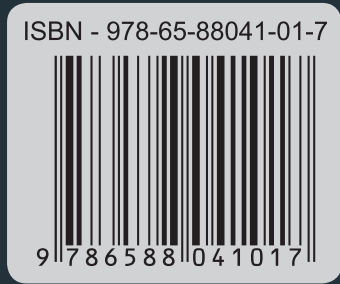

disponivel em https://www.editoraemescam.com.br/editora-2/

Dados internacionais de Catalogação na Publicação (CIP)

(Biblioteca Central da EMESCAM, Espírito Santo, ES, Brasil)

P769 Políticas públicas dirigidas à infância : contribuições da América Latina e do Caribe / Gissele Cassaro, Loise Cristina Passos Drumond e Valmin Ramos-Silva (organizadores). - Vitória: Emescam, 2020.

134 p. : il.

Inclui bibliografias

ISBN: 978-65-88041-01-7

1. Políticas públicas - crianças. 2. Crianças - aspectos sociais - América Latina Caribe. 3. Direitos das crianças. I. Carraro, Gissele, org. II. Drumond, Loise Cristina Passos, org. III. Ramos-Silva, Valmin, org. IV. Escola Superior de Ciências da Santa Casa de Misericórdia de Vitória, EMESCAM. V. Título. 


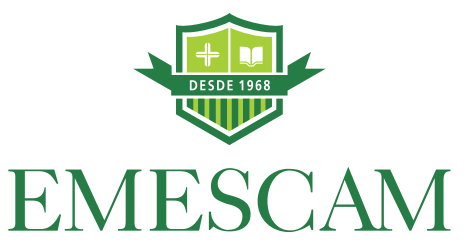

Irmandade da Santa Casa de Misericórdia de Vitória

Provedora

Maria da Penha Rodrigues D’Avida

Vice-provedor

Cláudio Medina da Fonseca

Escola Superior de Ciências da Santa Casa de Misericórdia de Vitória

\section{Diretor}

Cláudio Medina da Fonseca

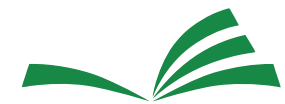

e d i t o r a

EMESCAM

Editora Universitária Emescam

Editor-Chefe

Valmin Ramos-Silva

Conselho Editorial

Jane Prates (PUCRS) - Presidente

Cristina Ribeiro Macedo - EMESCAM - Vitória/ES

Marcela Souza Lima Paulo - EMESCAM - Vitória/ES

Renato Lirio Morelato - EMESCAM - Vitória/ES

Roberta Ribeiro Batista - EMESCAM - Vitória/ES

Rubens José Loureiro - EMESCAM - Vitória/ES 


\section{Autores}

\section{Gissele Carraro}

Doutora em ServiçoSocial pelo Programa de Pós-Graduação em ServiçoSocial da Pontifícia Universidade Católica do Rio Grande do Sul (PUC-RS). Professora e Coordenadora do Programa de Pós-Graduação em Políticas Públicas e Desenvolvimento Local da Escola Superior de Ciências da Santa Casa de Misericórdia de Vitória (Emescam). Líder do Grupo de Estudos Capitalismo, Estado e Políticas Públicas na Sociedade Contemporânea (GECEPP). E-mail: gissele.carraro@emescam.bre gcarraro5@gmail.com ORCID https://orcid.org/0000-0002-3143-9708

\section{Loise Cristina Passos Drumond}

Graduação em Letras pela Universidade Federal do Espírito Santo; Especialização em Linguística Aplicada ao Texto pela Universidade Federal do Espírito Santo; Mestrado em Foreign e Formação em Psicanálise Clínica pela Universidade Iguaçu, RJ; Licenciatura em Pedagogia pela Faculdade de Educação Regional Serrana. Atualmente cursando Psicologia na Associação Vitoriana de Ensino Superior (FAVI). Professora dos cursos de Fisioterapia, Enfermagem e Medicina da Escola Superior de Ciências da Santa Casa de Misericórdia de Vitória (EMESCAM).

E-mail: loise.drumond@emescam.br

\section{Valmin Ramos-Silva}

Biólogo. Médico Pediatra. Mestre em Biologia Vegetal. Doutor em Pediatria. Pós- Doutorado em Educação. Docente do Programa de Pós-Graduação em Políticas Públicas e Desenvolvimento Local/Escola Superior de Ciências da Santa Casa de Misericórdia de Vitória/EMESCAM. Coordenador de Pesquisa e Pós-Graduação Stricto Senso/(EMESCAM). E-mail:valmin.ramos@emescam.br; Valmin.silva@gmail.com https://orcid.org/0000-0003-1574-0266 


\section{Autores colaboradores}

Adelma Alves de Figueirêdo (Brasil)

Amarilis Then-Paulino (República Dominicana)

Ana María Aguilar Liendo (Bolivia)

Ana María Lozano Alemán (Honduras)

Asha V. Badaloo (Jamaica)

Blenda Avelino García (Brasil)

Camilo Adauton Mariano da Silva (Brasil)

Carolyn Taylor-Bryan (Jamaica)

Daniel Thomas (Jamaica)

Denise Abreu Cavalcanti (Brasil)

Enrique O. Abeyá-Gilardon (Argentina)

Eugênia Aguilar Lema de Las Mercedes (Equador)

Faride Esther Rodríguez Díaz (Panamá)

Gerardo Weisstaub (Chile)

Gustavo Cediel (Colômbia)

Inocencia Palmira Peralta López (Paraguai)

Israel Ríos-Castillo (Panamá)

Janine Pereira da Silva (Brasil)

Joel Alves Lamounier (Brasil)

Maressa Cristiane Malini de Lima (Brasil)

María Elena Díaz Sánchez (Cuba)

Matilde Peguero Payano (República Dominicana)

Priscila Campos de Matos Lacerda (Brasil)

Shelley McFarlane (Jamaica)

Valmin Ramos-Silva (Brasil)

Wendell Costa Bila (Brasil) 


\section{Resumen}

Capítulo 1 O DUPLO FARDO DA DESNUTRIÇÃO, DA DESIGUALDADE E DO SISTEMA ALIMENTAR

Gerardo Weisstaub, Enrique O. Abeyá-Gilardon, Gustavo Cediel,

Ana María Aguilar Liendo y Israel Ríos-Castillo

Capítulo 2 DESAFIO E INOVAÇÃO EM POLÍTICAS PÚBLICAS PARA A INFÂNCIA EM SITUAÇÃO DE VIOLÊNCIA NO BRASIL: VIOLAÇÃO E DIREITOS

Adelma Alves de Figueirêdo, Blenda Avelino Garcia, Priscila Campos de Matos Lacerda y Denise Abreu Cavalcanti

Capítulo 3 DESAFIOS DAS POLÍTICAS PÚBLICAS PARA O CONTROLE DA OBESIDADE INFANTIL NA AMÉRICA LATINA E NO CARIBE

Asha V. Badaloo, Shelley McFarlane, Carolyn Taylor-Bryan y Daniel Thomas

Capítulo 4 POLÍTICA DE SEGURANÇA ALIMENTAR E NUTRICIONAL NO BRASIL: FOCO NO ENFRENTAMENTO DA DEFICIÊNCIA DE MICRONUTRIENTES 65

Wendell Costa Bila, Joel Alves Lamounier, Inocencia Palmira Peralta López, Ana María Lozano Alemán y Camilo Adauton Mariano da Silva

Capítulo 5 POLÍTICAS DE COMBATE À POBREZA INFANTIL NA AMÉRICA LATINA E NO CARIBE

Matilde Peguero y Amarilis Then-Paulino

Capítulo 6 POLÍTICAS PÚBLICAS DE NUTRIÇÃO NA AMÉRICA

LATINA E CARIBE: REFLEXÕES SOCIAIS E ANTROPOLÓGICAS

María Elena Díaz Sánchez

Capítulo 7 MORTALIDADE INFANTIL NA AMÉRICA LATINA E CARIBE: INTERFACE COM AS POLIITICAS PÚBLICAS E SOCIAIS

Maressa Cristiane Malini de Lima; Janine Pereira da Silva,

Eugenia de las Mercedes Aguilar Lema, Faride E. Rodríguez Díaz,

Helder Gomes, Valmin Ramos-Silva 


\section{Apresentação}

Trabalhamos pelas crianças, porque as crianças são as que sabem amar, porque as crianças são a esperança do mundo. [...] o que a gente quer é que os filhos sejam felizes, como os irmãozinhos da nossa gravura; e se alguma vez uma criança da América nos encontrar, em todo o mundo vai apertar muito a nossa mão, como um velho amigo, e dizer onde todos o ouvem: 'Este homem da Idade de Ouro era meu amigo!'. (José Martí, para as crianças que leram A Idade de Ouro).

A presente Coletânea é composta por textos de autores(as) brasileiros(as) e estrangeiros(as), produtos de reflexão conceitual, teórica e de indicadores da AméricaLatina e o Caribe, envolvendo análises de proposições na esfera das políticas públicas, possibilidades, entraves de desafios em seu processo de materialização nos países latino-americanos.

Cabe ressaltar que os autores(as) estrangeiros(as) e alguns brasileiros(as) integram um grupo de pesquisa que contempla as questões alimentares, nutricionais e outras que comprometem a infância, tira a oportunidade de acesso a bens e serviços, com prejuízos à saúde da criança. O grupo está vinculado a projetos de cooperação técnica internacional, com a participação de países da América Latina e Caribe, aprovado, coordenado e financiado pela Agência Internacional de Energia Atômica (IAEA) e pelas Agências de Energia Nuclear dos países envolvidos. Nestes projetos, participam docentes da Escola Superior de Ciências da Santa Casa de Misericórdia (EMESCAM) e do Programa de Pós-Graduação em Políticas Públicas e Desenvolvimento Local desta instituição, coordenados pelo Professor Valmin Ramos-Silva.

Estas produções de conhecimento resultam de investigações que articulam vários domínios de saber, por meio da interface entre diferentes áreas do conhecimento,em especial, Ciências da Saúde, Ciências Humanas e Ciências Sociais Aplicadas, contribuindo, desta forma, para amplas análises da realidade concreta e das políticaspúblicas dirigidas à infância em países da 
América Latina e Caribe. Frisa-se, queas políticas públicas possuem caráter interdisciplinar, à medida em que constituem campo de estudo e trabalho de pesquisadores(as) com diferentes formações, o que resulta em distintas concepções em relação a elas, convergentes e divergentes em determinados aspectos. A complementaridade e a construção de novos saberes, finalidades comuns, ações coletivas e integradas possibilitam produzir mudanças e respostas às demandas e necessidades sociais.

Reside aqui, um dos impactos desta produção bibliográfica para diferentes áreas em relação à divulgação do conhecimento, ao aprimoramento dos processos deformulação, execução e avaliação de políticas públicas, e contribuições para realizaçãode análises de fenômenos e processos histórico-sociais relevantes em âmbito local, regional, nacional e internacional, e na proposta de alternativas de intervenção aos problemas socioeconômicos que afetam a população, resguardando a diversidade de cada realidade concreta e formação social que interferem nos desenhos de ação, finalidades e meios especificados para a concretização de direitos e políticas, especialmente aquelas voltadas para à infância, delimitada como campo analítico nesta Coletânea.

O reconhecimento internacional do imperativo de proporcionar uma infância com proteção integral, visando ao desenvolvimento da autonomia e da personalidadede cada ser humano, tem exigido atenção especial e sistemática por parte do Estadoe da Sociedade Civil. Sua incorporação como prioridade no rol de direitos exigíveise políticas públicas dirigidas às crianças na América Latina e no Caribe e, no mundo resulta de lutas sociais e históricas travadas por movimentos coletivos reivindicatóriosem prol da constituição, defesa e materialização de direitos para a infância, que primem por ações cooperadas e intersetoriais, considerando necessidades socias e distintas demandas emergentes da realidade concreta de cada País.

A ampliação de desigualdades, da pobreza, da fome, obesidade e desnutrição,de violências que incidem sobre a infância em diferentes países, incluindo latino- americanos, têm acarretado sérios prejuízos ao processo de desenvolvimento cognitivo/linguístico, psicomotor, afetivo/social, apontam estudos e pesquisas de instituições e organismos nacionais e internacionais, tais como a Organização Mundial de Saúde (OMS), Organização Pan-Americana da Saúde (OPAS), o Fundo das Nações Unidaspara a Infância (UNICEF), 
a Organização das Nações Unidas para Alimentação e Agricultura (FAO), a Organização das Nações Unidas para a Educação, a Ciência ea Cultura (UESCO), o Sistema de Informação sobre a Primeira Infância na América Latina (SIPI).

Por constituir-se como uma responsabilidade pública de todas as pessoas e umdeveréticoquenãopodeserabdicado,comprometetantooEstadoquanto a Sociedadena garantia da satisfação das necessidades sociais, primordiais para a vida material esubjetiva de todo ser humano. Dessa forma, a luta pela afirmação da proteção à infânciacomo direito, bem como o reconhecimento de que são "sujeitos de direitos" e "pessoasem condição peculiar de desenvolvimento" requer o estabelecimento de parâmetros para sua regulação e asseguramento, por meio de instrumentos normativos, instânciaspúblicas, mecanismos de promoção, visando sua concretização.

Reside, nesse sentido, a importância dos tratados internacionais adotados e ratificados, ao longo do século XX, por diferentes países no mundo, em que os Estados-Partes assumiram um conjunto de compromissos políticos, que deveriam orientar a formulação e execução de políticas públicas destinadas à proteção da infância. Assim,destacam-se: Declaração de Genebra dos Direitos da Criança (1924); Declaraçãodos Direitos da Criança (1959); Declaração Universal dos Direitos Humanos (1948); Pacto Internacional de Direitos Civis e Políticos (1966); Pacto Internacional de DireitosEconômicos, Sociais e Culturais (1966); Pacto de São José da Costa Rica (1969); Convenção sobre os Direitos da Criança (1990).

Sem dúvidas, esses marcos históricos e normativos foram e continuam sendoimpulsionadores de avanços em diversos países do mundo, da América Latina e Caribe no que tange à proteção da infância, que se diferenciam e direcionam para: regulamentação de direitos na Constituição e instrumentos normativos específicos (leis, resoluções, decretos etc.); estabelecimento de marco conceitual, diretrizes e estratégias integrais no desenho e implementação de distintas políticas públicas; constituição de políticas públicas específicas para a infância, materializadas por meiode serviços, programas, projetos e benefícios. No entanto, ainda é preciso avançar qualitativamente para que essas iniciativas se transformem ações concretas, que permitam a todas as crianças usufruir do pleno desenvolvimento e uma infânciacom proteção integral. Isso depende da vontade política em priorizar recursos 
para políticas públicas em direção à universalidade de acesso e cobertura, integralidade, equidade e eficiência. O que constitui um dos maiores desafios, haja vista a crise do capital e as medidas de ajuste fiscal para seu enfrentamento, que geram inflexões namaterialização das políticas públicas.

Esta coletânea pretende ser impulsionadora de discussão a respeito das políticas públicas dirigidas à infância, que permita mostrar o atual estado da arte da questão, trocar lições aprendidas e reflexões para avançar nas árduas lutas que se tem pela frente, com o objetivo compartilhado por todos(as): que as crianças da regiãoda América Latina e Caribe possam desfrutar de uma infância plena em todos os aspectos da vida. Isso posto, apresenta-se os sete capítulos que compõem a produçãode conhecimento que em tela (?).

O primeiro capítulo, intitulado "o duplo fardo da desnutrição, da desigualdadee do sistema alimentar", dos autores(as): Gerardo Weisstaub, Enrique O. Abeyá- Gilardon, Gustavo Cediel, Ana María Aguilar Liendo, Israel Ríos-Castillo, discorre sobre a coexistência de desnutrição com excesso de peso e doenças crônicas vinculadas a dietas inadequadas, compostas por alimentos ultraprocessados e sedentarismo ao longo da vida, como resultado do modelo econômico de desenvolvimento. Chama a atenção para o avanço das formas de desnutrição nos países em desenvolvimento, que mais sofrem iniquidades vinculadas aos determinantes sociais.

O segundo capítulo, Desafio e inovação em políticas públicas para a infância em situação de violência no Brasil: violação de direitos, das autoras Adelma Alvesde Figueirêdo, Blenda Avelino Garcia, Priscila Campos de Matos Lacerda, Denise Abreu Cavalcanti, aborda as formas de violência infantil, com aportes de dadossobre a realidade internacional e brasileira e nesta pontuam alterações na visão e práticas envolvendo a infância, com relação ao texto constitucional e legislaçãoinfraconstitucional na realização de direitos de crianças eadolescentes, asseguradoresde proteção social. Neste texto, as autoras discorrem sobre as políticas públicas, particularizando concepções e normativas que instituem as mesmas, com exemplos de experiências concretas, explicitando desafios e inovações para o enfrentamento daviolência em suas diferentes configurações.

O terceiro capítulo Desafios das políticas públicas para o controle da obesidadeinfantil na América Latina e no Caribe, dos autores (as) Asha V. Badaloo, Shelley McFarlane, Carolyn Taylor-Bryan y Daniel Thomas, discorre sobre a 
obesidade infantil,suas expressões e implicações para a infância. Efetuam uma contextualização desta problemática na região estudada, com uso de indicadores para retratar a questãoda obesidade e estratégias e planos de ação para superação, em nível mundial,que envolvem diferentes políticas públicas, tais como saúde, educação, segurança alimentar e nutricional, além dos desafios postos a elas em seu processo de execução,monitoramento e avaliação, envolvendo governo, mercado, sociedade civil.

O quarto capítulo Política de Segurança Alimentar e Nutricional no Brasil: Focono enfrentamento da deficiência de micronutrientes, dos autores(as) Wendell Costa Bila, Joel Alves Lamounier, Inocencia Palmira Peralta López, Ana María LozanoAlemáne Camilo Adauton Mariano da Silva, centra-se na discussão das principais questões relacionadas às necessidade nutricionais e consequências da carência ou excesso demacro e micronutrientes na saúde, em especial para o crescimento e desenvolvimentoinfantil saudáveis, estabelecendo associação às desigualdades sociais e à pobreza. Traz ainda, as principais políticas públicas de segurança alimentar e nutricional na América Latina e Caribe para fazer frente à fome, desnutrição e obesidade.

O quinto capítulo Políticas de combate à pobreza infantil na américa latina e nocaribe, das autoras Matilde Peguero e Amarilis Then-Paulino, dedica-se às principais políticas públicas dirigidas à infância em países da região, tendo como foco a reduçãoda pobreza e iniquidades no desenvolvimento da primeira infância, e proteção ofertada na forma de sistemas, políticas, planos, programas, estratégias governamentais. Propõe-se explicitar seus objetivos, público contemplado, limites e desafios postos para sua concretização, em função das inflexões produzidas pela adesão à política neoliberal ditatorial de países e governos externos.

O sexto capítulo Políticas públicas de nutrição na América Latina e Caribe: reflexões sociais e antropológicas, da Antopóloga María Elena Díaz Sánchez, pauta sua análise sobre os entraves para a formulação e implementação de políticas públicasa partir dos contextos institucionais e socioculturais, da linguagem e do discurso dos formuladores, das decisões que são tomadas, as regras que as originam, o impacto e aforma como respondem às demandas que se propõem atender, incluindo alimentaçãoe nutrição. Em sua lógica de análise, aborda aspectos de cunho político, econômico, social que contribuem para a permanência da insegurança alimentar para a infância na 
região latino-americana. Pontua ainda, a importância da soberania alimentar comodireito dos povos na definição de políticas e estratégias de produção, distribuição e consumo de alimentos para toda a população.

Osétimo capítulo, Desafios das Políticas Públicas paraa redução damortalidadeinfantil na América Latina e Caribe, dos autores(as) Maressa Cristiane Malini de Lima;Janine Pereira da Silva, Helder Gomes, Eugênia Aguilar Lema de Las Mercedes, ValminRamos-Silva, traça um panorama da mortalidade infantil em alguns países da região, com discussão das causas deste problema. A abordagem desenvolvida leva em contasistemas políticos e políticas neoliberais implementadas a partir de orientações do Fundo Monetario Internacional, que tem resultado no aumento da mortalidade infantilAlém disso, são trazidos os paises com maiores frequências e ações para sua redução.

Brasil - Vitória (ES), novembro de 2020

Gissele Carraro Loise, Cristina Passos Drumond e Valmin Ramos-Silva (Organizadores) 


\section{Capítulo 1}

\section{O DUPLO FARDO DA DESNUTRIÇÃO, DA DESIGUALDADE E DO SISTEMA ALIMENTAR}

Gerardo Weisstaub ${ }^{1}$, Enrique O. Abeyá-Gilardon², Gustavo Cediel', Ana María Aguilar Liendo ${ }^{4}$, Israel Ríos-Castillo ${ }^{5}$

${ }^{1}$ Gerardo Weisstaub. Profesor Asistente. Instituto de Nutrición y Tecnología de los Alimentos (INTA). Departamento de Pediatría (Campus Centro). Universidad de Chile. gweiss@inta.uchile.cl

2 Enrique O. Abeyá-Gilardon. Médico pediatra y sanitarista, consultor independiente en nutrición y salud pública materno infantil. Argentina. enrique.abeya@gmail.com

${ }^{3}$ Gustavo Cediel. Doctor en Nutrición y Alimentos. Escuela de Nutrición y Dietética, Universidad de Antioquia, Medellín, Colombia. cedielgiraldo@gmail.com

${ }^{4}$ Ana María Aguilar Liendo. Docente investigadora Instituto de Investigación en Salud y Desarrollo - Facultad de Medicina Universidad Mayor de San Andrés. Bolivia. ana. aguilar@umsalud.edy.bo

${ }^{5}$ Israel Ríos-Castillo Oficial Regional de Nutrición. Organización de las Naciones Unidas para la Alimentación y la Agricultura (FAO). Oficina Subregional de la FAO para Mesoamérica. Ciudad de Panamá, Panamá. Israel.Rios@fao.org

Resumo

A dupla carga da desnutrição é caracterizada pela coexistência de desnutrição com sobrepeso, obesidade ou doenças crônicas não transmissíveis relacionadas à dieta ao longo do ciclo de vida. Como resultado do modelo econômico de desenvolvimento, urbanização, mudança demográfica e aumento do consumo de alimentos altamente processados, tem havido uma mudança significativa na qualidade dos alimentos. Esse tipo de doença pode se manifestar tanto em nível individual quanto populacional, desde a infância até vida adulta. Hoje, quase uma em cada três pessoas em todo o mundo sofre de pelo menos uma forma de desnutrição, especialmente nos países em desenvolvimento. A distribuição dos determinantes sociais, condicionantes da iniquidade, pode explicar a prevalência e combinação de doenças que coexistem no mesmo local e população. 0 acesso à alimentação saudável se 
baseia em um abastecimento adequado de alimentos que inclui formas de produção ambientalmente sustentáveis, canais adequados de comercialização e distribuição. Apesar da responsabilidade dos estados em regulamentar o consumo de alimentos, alguns programas de prevenção da desnutrição focam a maior parte da responsabilidade pela alimentação no indivíduo, uma visão que despolitiza a dificuldade que está por trás desse tipo de decisão. Desde os fatores que condicionam este tipo de desnutrição. sistemas alimentares subjacentes, ocorrem simultaneamente e interagem com aqueles que geraram as mudanças climáticas, ações sinérgicas serão essenciais para alcançar a saúde planetária, que definimos como a saúde e o bem-estar dos seres humanos e os ambientes naturais dos quais nós dependemos.

Palavras-chave: Desnutrição Proteica, Obesidade Pediátrica; Doença Crônica; Desenvolvimento Econômico; Desigualdade Social, Criança.

\section{Definição e epidemiologia da dupla carga de doenças}

O que entendemos por duplo fardo? A simultaneidade de duas ou mais condições, diferentes e muitas vezes contrárias à primeira vista, que ocorrem simultaneamente em um território, em uma casa ou na mesma pessoa.

A primeira publicação sobre dupla carga e desnutrição é de 1995 no Brasil, aplicada em lares de crianças desnutridas e mães obesas ${ }^{1}$. Nos últimos 10 anos, houve um aumento importante na bibliografia indexada no PubMed e o conceito foi estendido a grupos mais amplos, como comunidades e países ${ }^{2,3}$.

As realidades nutricionais representadas pela dupla carga costumam ser situações mais complexas do que na aparente dupla carga e que mesmo na literatura foram ampliadas para triplas e quádruplas cargas ${ }^{4}$. Numa primeira abordagem, o duplo fardo significou a continuidade das doenças infecciosas com elevada incidência nas taxas de mortalidade materna e infantil (diarreia, malária, pneumonia, sepses neonatal, entre outras) e desnutrição de macro e micronutrientes juntamente com as doenças crônica associada a um estilo de vida ocidental e ingestão excessiva de calorias, que tradicionalmente existia em países com grandes recursos ${ }^{5}$. 
No nível familiar, o duplo fardo da desnutrição foi descrito em quatro variedades: Individual: criança com retardo de crescimento e obesidade; e no mesmo domicílio; mãe com sobrepeso ou obesa e crianças menor de 5 anos com baixo peso; iii) mãe com sobrepeso ou obesidade e filho menor de 5 anos com retardo de crescimento; iv) mãe com baixo peso e menor de cinco anos com obesidade ${ }^{6}$. Este último tem uma frequência menor que $1 \%$; enquanto a terceira variedade é a mais frequente.

O denominador comum dessa diversidade de combinações é a ausência de uma alimentação saudável e a complexidade das interações metabólicas que podem afetar ao longo da vida. A maioria dos países, independentemente de sua renda, apresenta uma ou mais variedades, às quais se acrescenta a deficiência de micronutrientes, constituindo o que se denomina a nova realidade da nutrição. Conseguir uma alimentação saudável nos países é a realização bem-sucedida dos quatro componentes que a Organização para a Alimentação e Agricultura das Nações Unidas (FAO) reconhece como componentes da segurança alimentar: disponibilidade, acessibilidade/ consumo, utilização e estabilidade.

$\mathrm{Na}$ América Central, a FAO, também reconhece um quinto componente: a institucionalidade. Todos esses componentes têm implicações e relevância diferentes na causalidade da dupla carga dependendo do sistema alimentar de cada país para garantir uma alimentação saudável. Soma-se a isso o déficit de micronutrientes altamente prevalente em países de baixa e média renda?

A dupla carga de doenças não se manifesta da mesma forma em todos os lugares, portanto, para entender as diferentes formas de desnutrição que podem coexistir com prevalências mais elevadas, é importante conhecer a situação epidemiológica. Por exemplo, se o local (países e regiões dentro dos países) referido está em transição nutricional, este processo influencia a forma como a população se alimenta, bebe, se transporta, se diverte e se desloca para o trabalho, se no âmbito familiar afetou a distribuição da composição corporal e criou problemas nutricionais. A transição produziu grandes mudanças na atividade física e na dieta e um rápido aumento no sobrepeso, obesidade e doenças crônicas não transmissíveis. Para compreender como o contexto epidemiológico influencia a forma como a dupla carga se manifesta, é fundamental analisar o grau de desigualdade na sociedade. 


\section{Iniquidade no acesso a alimentos e desnutrição}

A iniquidade na dupla carga de doença pode ser explicada em grande parte pela - distribuição dos determinantes sociais na população $0^{8,9}$, o que permite identificar aquelas intervenções abrangentes ao longo da vida e com um olhar epigenético que melhoraria a situação?.

A presença simultânea de desnutrição e obesidade, no mesmo indivíduo ou em indivíduos da mesma família, tem sido amplamente documentada em países de baixa e média renda. Um aumento de 0,1 ponto no coeficiente de Gini está associado a um aumento de 8 a 12\% nas chances de um indivíduo ser obeso e estar abaixo do peso ${ }^{10}$.

Assim, você pode encontrar mães obesas com filhos desnutridos ou crianças com nanismo e obesidade. Lee $J$ et $\mathrm{al}^{11}$, em um estudo realizado na Guatemala, buscou identificar os fatores socioeconômicos associados a esta dualidade da desnutrição em uma amostra de quase 2.500 domicílios. Os resultados revelaram uma prevalência mais alta de nanismo na infância, mas uma prevalência mais baixa de excesso de peso materno entre os pobres em comparação com as famílias ricas. A desigualdade econômica na baixa estatura era maior do que a desigualdade econômica no excesso de peso materno. Além disso, constatou-se que uma díade mãe obesa / criança com baixa estatura era mais provável de ser encontrada em domicílios no quintil de consumo médio do que no primeiro quintil (melhor NSE). Em estudo realizado no Sri Lanka, em crianças de 5 a 10 anos, mostrou que a menor escolaridade das mães estava associada a maior magreza da criança $(\mathrm{OR}=$ 2,3 IC95\% 1,08-5,00) $)^{12}$.

Uma das recomendações para prevenir a obesidade é a realização de atividade física diária, principalmente de intensidade moderada ou vigorosa. Para colocar em prática esta recomendação, são necessários espaços públicos adequados. No entanto, sua distribuição também não é equitativa. Em Santiago do Chile, as quatro comunas de maior renda concentram um terço da área total de áreas verdes, enquanto as quatro comunas mais pobres apenas $4 \%$. No mesmo estudo observa-se que enquanto em uma comuna de baixa renda apenas $20 \%$ da população tem acesso a uma área verde de pelo menos $5.000 \mathrm{~m}^{2}$ perto de sua casa $(300 \mathrm{~m})$, o que contrasta com os $74 \%$ encontrados em uma comuna de alta renda ${ }^{13}$. A prática de 
exercícios físicos não está uniformemente distribuída entre os diferentes níveis socioeconômicos da sociedade.

Na última Pesquisa Nacional de Saúde realizada no Chile, observa-se que a maior prevalência de sedentarismo (90\%) ocorre em mulheres com menos de oito anos de estudo ${ }^{14}$. O mesmo fenômeno também pode ser observado em escolares.

No "Estudo Nacional de Educação Física" do Chile realizado em quase dez mil meninos e meninas em todo o país, observou-se que a condição física aeróbia avaliada pelo teste de Navette era satisfatória em apenas 31\% dos escolares que frequentavam as escolas municipal contra $41 \%$ dos que frequentavam escolas privadas pagas (de melhor nível socioeconômico ${ }^{15}$.

Avançar em um caminho de maior equidade e igualdade não é apenas um imperativo ético em uma região com lacunas sociais que se expressam em várias áreas. É preciso pensar em um novo estilo de desenvolvimento, ou seja, como uma sociedade se organiza para a produção, distribuição e consumo de alimentos e como o crescimento econômico se articula com a qualidade de vida $^{16}$.

\section{Dupla carga de doenças e produção de alimentos: sustentabilidade social e ambiental}

Uma alimentação saudável é fundamental para reduzir, prevenir e controlar as diferentes formas de desnutrição que coexistem com a dupla carga e as doenças crônicas não transmissíveis, que causam elevada morbimortalidade e incapacidades em todo o mundo ${ }^{17}$. Acesso a dietas saudáveis, principalmente frutas, verduras, legumes, peixes, nozes e sementes, parte de uma oferta adequada de alimentos que inclui formas de produção ambientalmente sustentáveis, canais adequados de comercialização e distribuição ${ }^{18,19}$. Apesar do exposto, alguns programas de prevenção focam grande parte da responsabilidade alimentar e nutricional no indivíduo, uma visão neoliberal das "seleções" que despolitiza a dificuldade que está por trás de cada uma ${ }^{20}$. Ao contrário, essa visão pode ser parte da causa da atual realidade epidemiológica das múltiplas formas de desnutrição, que afetam profundamente a população mais vulnerável ${ }^{21,22}$. Tentando gerar estratégias para superar a visão individual do problema, outra iniciativa surgiu, como a 
teoria dos ambientes alimentares com três elementos fundamentais: acesso físico e econômico aos alimentos (proximidade e acessibilidade); a promoção de alimentos, rotulagem, publicidade e informação (ambiente alimentar informativo); e a qualidade e segurança dos alimentos ${ }^{23}$.

Nesse cenário, atores como governos provinciais e nacionais e a indústria de alimentos são identificados como os dois grupos de interessados com maior capacidade de modificar os ambientes alimentares e dietéticos da população. Com essa visão, alguns países têm trabalhado para promover políticas e ações governamentais em ambientes alimentares saudáveis para reduzir a obesidade, as doenças crônicas não transmissíveis relacionadas à dieta e suas desigualdades associadas ${ }^{24}$. Essa alternativa, embora inédita e um avanço, ainda apresenta influências do nutricionismo, com regulamentação do acesso físico e econômico aos alimentos, baseada no conceito de alimentação adequada, que se reduz à presença ou não de nutrientes e à segurança dos alimentos apenas em termos de segurança ${ }^{25}$.

É sob este ponto de vista que a FAO enfatiza que dietas saudáveis e sustentáveis são padrões alimentares que devem ser promovidos a fim de atingir todas as dimensões da saúde e bem-estar das pessoas; têm baixa pressão e impacto ambiental; eles são acessíveis, baratos, seguros e equitativos; e são culturalmente aceitáveis ${ }^{19}$. Os programas de proteção social que incorporam a dimensão alimentar e nutricional, favorecem o acesso a alimentos saudáveis, especialmente para populações em maior vulnerabilidade ${ }^{26}$. Políticas e programas sociais devem permitir o acesso físico e econômico a dietas saudáveis, por exemplo, em escolas e centros de desenvolvimento da primeira infância ${ }^{26}$. Esses programas sociais devem se coordenar e se articular com o setor de alimentação, agricultura e saude para promover a produção, fornecimento e entrega de alimentos in natura, minimamente processados e naturais, de acordo com as diretrizes nacionais de alimentação saudável, como as Diretrizes Alimentares e os programas prevenção e controle da obesidade e doenças crônicas não transmissíveis ${ }^{27}$.

A dimensão da sustentabilidade deve, portanto, considerar as medidas necessárias para aumentar a resiliência dos sistemas alimentares para que possam facilitar a disponibilidade de alimentos saudáveis, mesmo em períodos de crises antropogênicas ou naturais ${ }^{18}$. No entanto, o sistema alimentar atual é caracterizado de alta disponibilidade e acesso a produtos 
processados e ultraprocessados, baratos, com alta percepção de conveniência e com grandes orçamentos para sua promoção e publicidade ${ }^{28,29}$. Bem como, a resistência do setor privado a medidas de saúde pública que promovam ambientes alimentares saudáveis, como leis de rotulagem frontal para advertência nutricional, impostos sobre bebidas açucaradas e comida não saudável; e a regulamentação de sua publicidade, entre outros ${ }^{30,31}$.

$\mathrm{Na}$ cadeia de abastecimento alimentar, a falta de insumos produtivos, mão-de- obra e dificuldades de transporte, armazenamento e distribuição afetam o cultivo e a comercialização de alimentos, especialmente frutas, verduras e legumes ${ }^{32}$. A falta de insumos agrícolas, por vários motivos, incluindo preços mais elevados, acarreta altos custos de produção, tornando as dietas saudáveis inacessíveis aos segmentos mais pobres da população. O transporte e distribuição de alimentos são especialmente relevantes para alimentos in natura e perecíveis, essenciais para a manutenção de dietas nutritivas, diversificadas e saudáveis. Portanto, é necessário ter soluções ao nível das políticas e programas de apoio à produção agrícola. Essa cadeia de abastecimento também deve garantir a qualidade e segurança dos alimentos ${ }^{33}$. Da mesma forma, outros atores na cadeia de abastecimento, como operações de bancos de alimentos, organizações não governamentais, grupos comunitários e instituições de caridade privadas, devem ser considerados. Além disso, são necessárias intervenções e iniciativas para reduzir as perdas e desperdícios de alimentos em diferentes elos da cadeia de abastecimento alimentar ${ }^{34}$. O comércio eletrônico é outro elemento disruptivo da cadeia alimentar, podendo facilitar o acesso a produtos perecíveis como frutas, verduras, laticínios e peixes; mas também para dietas não saudáveis, como comida não saudável e bebidas açucaradas. Portanto, é necessário ampliar a abordagem política para regulamentar o e-commerce móvel e o e-commerce social, de forma que dietas saudáveis sejam acessíveis a todos os segmentos sociais da população ${ }^{35}$.

Em alguns países, como a Argentina, o sistema alimentar é altamente dependente do agronegócio exportador com alta concentração oligopolística, que ele está interessado apenas no lucro, por isso é essencial regulamentar a coleta, a comercialização e a exportação ${ }^{36,37}$. A agricultura familiar e os pequenos e médios agricultores são atores-chave para aumentar a disponibilidade de dietas saudáveis ${ }^{38}$, principalmente 
camponesas e indígenas que vendem nos mercados locais ${ }^{39}$. Outro nó crítico da cadeia produtiva para maior disponibilidade de dietas saudáveis é a baixa participação dos agricultores familiares, pequenos e médios produtores nos mercados locais. Isso melhorará as economias locais e facilitará o acesso a dietas mais saudáveis. Outras iniciativas para aumentar a disponibilidade de alimentos saudáveis da cadeia de abastecimento alimentar incluem hortas domésticas escolares, comunitárias, urbanas e periurbanas, com o objetivo de aumentar a produção local de alimentos frescos ${ }^{40}$.

Portanto, ao nível do sistema alimentar, devem ser implementadas medidas práticas, inovadoras e seguras que mantenham a cadeia alimentar ativa, estimulem a produção local e garantam a disponibilidade de alimentos frescos e saudáveis para a população ${ }^{32}$. Ter políticas diferenciada para o segmento da agricultura familiar, pequenos e médios produtores agrícolas, por estimular a demanda constante por alimentos frescos e saudáveis. Em particular, possuem programas que facilitam a compra pública de alimentos saudáveis, socialmente e ambientalmente sustentáveis para diversos espaços institucionais como escolas, hospitais, orfanatos, lares de idosos, serviço militar, penitenciárias, entre outros, considerando também os sistemas tradicionais de produção de alimentos ${ }^{41}$. Mas o sistema alimentar não é um elemento isolado em nosso planeta, seu desenvolvimento e sustentabilidade impactam outros sistemas iguais ou mais complexos que este, como o sistema climático. A interação entre os dois gerou uma "Sindemia Global”.

\section{Carga dupla de doenças, sistema alimentar e mudanças climáticas}

A desnutrição, o sobrepeso, a obesidade e as "mudanças climáticas" representam sérios riscos ao bem-estar e à saúde da humanidade como um todo. Eles ocorrem simultaneamente, interagem, aumentam e compartilham fatores comuns e subjacentes nos sistemas alimentares, transporte, desenho urbano e uso do solo. A comissão da revista Lancet descreveu essa sinergia de pandemias como uma sindemia global que põe em risco as conquistas obtidas na área da saúde no último meio século.

Ambas as pandemias, desnutrição e mudanças climáticas, são causadas pelo alto uso de fontes de energia baratas. Na dieta consome alimentos 
altamente processados e carnes vermelhas que aumentam a desnutrição devido ao excesso e doenças relacionadas e geram cerca de um terço das emissões de gases de efeito estufa. O uso de fontes de energia derivadas de combustíveis fósseis para transporte ${ }^{42}$.

A prevalência de desnutrição e obesidade, somadas, tem aumentado nas últimas décadas, especialmente nos setores mais pobres da população onde coexistem os dois tipos de desnutrição. Do ponto de vista econômico, calculase que a perda econômica estimada com a obesidade represente $2,8 \%$ do produto interno bruto mundial. A isso se soma a perda econômica estimada devido às mudanças climáticas, que representa 5 a $10 \%$ do mesmo indicador.

Em termos ambientais, este tipo de alimento também tem um impacto negativ. Por exemplo, para produzir um quilo de tomate são usados 65 litros de água, mas para produzir um quilo de chocolate são 25 mil litros de água, sem considerar a produção de carbono, uso de agrotóxicos, desmatamento e mudança de uso do solo. Não só os seus longos processos, que muitas vezes incluem importação-processamento- exportação, consideram uma grande pegada, mas também os resíduos que geramos com a embalagem, principalmente produtos ultraprocessados.

Globalmente, a pandemia de COVID-19 já levou a aumentos significativos no desemprego e espera-se que leve a aumentos sem precedentes na pobreza e na insegurança alimentar, bem como problemas de saúde e nutrição ${ }^{43}$. O confinamento e a crise econômica afetam o setor alimentar e agrícola, colocando em risco a continuidade das cadeias de abastecimento alimentar. Além disso, os mesmos fatores afetam nossos ambientes e hábitos alimentares, especialmente nos grupos mais vulneráveis. Em alguns países, existem dados que mostram como a insegurança alimentar aumentou durante a pandemia. Na região metropolitana de Buenos Aires, o percentual de domicílios com crianças e adolescentes em que se reduziu a quantidade de alimentos aumentou de 26 para 30\%. No mesmo grupo, o aumento da insegurança alimentar grave foi ainda maior, uma vez que as situações de "fome" por falta de alimentos passaram de 6,5\% para $15 \% 44$. O contexto atual é adverso e a obesidade provavelmente também aumentará, devido ao aumento do sedentarismo e ao consumo de alimentos altamente processados e de baixo custo, condição também descrita como de maior risco para a gravidade da doença coronavírus ${ }^{45}$. 


\section{Conclusões}

A dupla carga da desnutrição aparece como a expressão mais clara de uma transição nutricional epidemiológica de um estágio com nítido predomínio de doenças infecciosas agudas para outro com predomínio de doenças crônicas não transmissíveis. Nessa transição há concomitância de ambas as situações expressas nas duas morbidades paradigmáticas, uma de desnutrição por deficiência de energia protéica e outra de sobrepeso por excesso calórico e desequilíbrio alimentar, esta última como consequência da maior acessibilidade a alimentos processados e bebidas açucaradas baratas e não saudáveis (alto em calorias, gordura saturada e sódio). Esse processo de dupla carga da desnutrição tem sido mais pronunciado em países de baixa e média renda, aumentando a desigualdade em saúde de acordo com os níveis socioeconômicos.

Muitas recomendações atuais para reduzir a obesidade e a desnutrição também são benéficas para a mitigação e adaptação às mudanças climáticas e vice- versa. Espera-se, para que o impacto em ambas as pandemias seja possível, que as intervenções realizadas levem em consideração o bemestar humano e a saúde, a equidade social, o respeito ao meio ambiente e o desenvolvimento econômico. As mudanças exigidas são tão complexas que devem incluir modificações profundas nos trâmites jurídicos, políticos e econômicos que definem os modelos de desenvolvimento de nossa sociedade. Na área de alimentos, alguns exemplos estão redirecionando os subsídios governamentais existentes para carne bovina, laticínios, açúcar, para uma agricultura sustentável (por exemplo, agricultura camponesa e familiar) de alimentos saudáveis. Somando a produção de carbono e o consumo de água por quilo para produzi-lo aos rótulos de advertências nutricionais e de saúde dos alimentos e, assim, estimular uma reformulação de produtos dentro da indústria.

Infelizmente, a grande maioria dos governos, até agora, teve uma resposta lenta e insuficiente a esses problemas e lidou com eles de forma independente. A inércia política para implementar políticas públicas eficazes, capazes de prevenir e mitigar os efeitos da "Sindemia”, é em grande parte consequência dos interesses comerciais em jogo. Um movimento social transformador é necessário, nos níveis local, nacional e global, para superar 
essa inércia. Ações sinérgicas serão essenciais para o alcance da saúde planetária, que definimos como a saúde e o bem-estar dos seres humanos e dos ambientes naturais dos quais dependemos. É responsabilidade de todos os setores da sociedade contribuir para a superação da crise gerada por nosso modelo de desenvolvimento.

\section{Referências}

1. Sawaya AL, Gerald D, Solymos G et al. Obesity and Malnutrition in a Shantytown Population in the City of Sao Paulo, Brazil. Obes Res 1995; 3 Suppl 2: 107s-115s.

2. Khor GL, Sharif ZM. Dual Forms of Malnutrition in the Same Households in Malaysia--a Case Study Among Malay Rural Households. Asia Pac J Clin Nutr 2003;12(4):427-37.

3. Gillespie, SR; Haddad, $\amalg$. The double burden of malnutrition in Asia. Causes, consequences, and solutions. Sage Publication. New Delhi, 2003.

4. Hickey $\mathrm{GM}$, Unwin N. Addressing the triple burden of malnutrition in the time of COVID-19 and climate change in Small Island Developing States: what role for improved local food production? Food Secur. 2020 Jul 9:1-5.

5. Wells JC, Sawaya AL, Wibaek R et al. The double burden of malnutrition: aetiological pathways and consequences for health. The Lancet 2020;395(10217):75-88.

6. Black RE, Victora CG, Walker SP, et al. Maternal and child undernutrition and overweight in low-income and middle-income countries.Lancet. 2013;382(9890):427- 451.

7. Batis C, Mazariegos M, Martorell R, Gil A, Rivera JA. Malnutrition in all its forms by wealth, education and ethnicity in Latin America: who are more affected? Public Health Nutr. 2020;23(S1):s1-s12.

8. Gubert MB, Spaniol AM, Segall-Corrêa AM, Pérez-Escamilla R. Understanding the double burden of malnutrition in food insecure households in Brazil. Matern Child Nutr 2017;13.e12347.

9. World Health Organization. The double burden of malnutrition. Policy brief: World Health Organization, 2017.

10. Hanandita W, Tampubolon G. The double burden of malnutrition in Indonesia: Social determinants and geographical variations. SSM Popul Health. 2015;1:16-25. Published 2015 Nov 18.

11. Lee J, Houser RF, Must A, de Fulladolsa PP, Bermudez OI. Socioeconomic disparities and the familial coexistence of child stunting and maternal overweight in Guatemala. Econ Hum Biol. 2012;10(3):232-241. 
12. Shinsugi C, Gunasekara D, Gunawardena NK, et al. Double burden of maternal and child malnutrition and socioeconomic status in urban Sri Lanka [published correction appears in PLoS One. 2020 Mar 19;15(3):e0230785]. PLoS One. 2019;14(10):e0224222.

13. Reyes Päcke S, Figueroa Aldunce M. Distribución, superficie y accesibilidad de las áreas verdes en Santiago de Chile. EURE 2010, 36: 89-110.

14. Encuesta Nacional de Salud. Ministerio de Salud. Chile. 2017. (Acceso en julio 2020. https://www.minsal.cl/wp-content/uploads/2017/11/ENS-2016-17_PRIMEROS- RESULTADOS.pdf).

15. Informe de Resultados Estudio Nacional de Educación Física 2013 Agencia de Calidad de la Educación. Ministerio de Educación de Chile. ( Acceso en Julio 2020 http://archivos.agenciaeducacion.cl/biblioteca_digital_historica/resultados/2013/result8b_edfisica_2013.pdf).

16. Comisión Económica para América Latina y el Caribe (CEPAL), La inefciencia de la desigualdad, 2018 (LC/SES.37/3-P), Santiago, 2018.

17. Branca F, Lartey A, Oenema S, Aguayo V, Stordalen GA, Richardson R, et al. Transforming the food system to fight non-communicable diseases. BMJ. 2019; 364:1296.

18. FAO. Nutrition-sensitive agriculture and food systems in practice. Options for intervention. Nutrition-sensitive agriculture and food systems in practice. Options for intervention. Roma: United Nations Food and Agriculture Organization (FAO); 2017. 102 p.

19. FAO, WHO. Sustainable healthy diets: Guiding principles. Sustainable healthy diets. Rome; 2019. 44 p.

20. Bedoya Hernández M. La gestión de sí mismo. Editorial Universidad de Antioquia, editor. 2018. 353 p.

21. Popkin BM, Corvalan C, Grummer-Strawn LM. Dynamics of the double burden of malnutrition and the changing nutrition reality. Lancet [Internet]. 2020 Jan 4 [cited 2020 Apr 10];395(10217):65-74. Available from: http://www.ncbi.nlm.nih. gov/ pubmed/31852602.

22. Cediel G, Perez E, Gaitán D, Sarmiento OL, Gonzalez L. Association of all forms of malnutrition and socioeconomic status, educational level and ethnicity in Colombian children and non-pregnant women. Public Health Nutr [Internet]. 2020 Mar 5 [cited 2020 Apr 12];1-8. Available from: http://www.ncbi.nlm.nih.gov/ pubmed/32131920.

23. High Level Panel of Experts on Food Security and Nutrition. HLPE Report on Nutrition and food systems [Internet]. [cited 2020 Apr 14]. Available from: http:// www. fao.org/fileadmin/user_upload/hlpe/hlpe_documents/HLPE_S_and_R/ HLPE_2017_Nutrition-and-food-systems_S_R-EN.pdf.

24. Sandevijvere S, Dominick C, Devi A, Swinburn B. The healthy food environment policy index: findings of an expert panel in New Zealand. Bull World Health Organ 
[Internet]. 2015 May 1 [cited 2020 Apr 15];93(5):294-302. Available from: http:// www. who.int/entity/bulletin/volumes/93/5/14-145540.pdf.

25. Scrinis G. Nutritionism : the science and politics of dietary advice [Internet]. First. Columbia Univers. Press (18 de junio de 2013), editor. Columbia University Press; 2013 [cited 2020 Apr 8]. 352 p. Available from: https://www.amazon.es/ Nutritionism-Politics-Traditions-Perspectives-Culinary/dp/0231156561.

26. FAO, OPS/OMS, PMA, UNICEF. Panorama de la Seguridad Alimentaria y Nutricional de América Latina y el Caribe. Santiago; 2019.

27. Wijesinha-Bettoni R, Khosravi A, Sherman J, Hernandez-Garbanzo Y, Vargas M, Ramos A. Implementing food-based dietary guidelines for policies, programmes and nutrition education. UNSCN News. 2017;42:77-89.

28. Popkin BM, Reardon T. Obesity and the food system transformation in Latin America. Obes Rev. 2018;1-37.

29. Monteiro C, Moubarac J, Cannon G, Ng SW, Popkin B. Ultra-processed products are becoming dominant in the global food system. Obes Rev. 2013;14(S2):21-8.

30. Hawkes C, Smith TG, Jewell J, Wardle J, Hammond RA, Friel S, et al. Smart food policies for obesity prevention. Lancet. 2015;385(9985):2410-21.

31. Mialon M, Gaitan Charry DA, Cediel G, Crosbie E, Scagliusi FB, Perez Tamayo EM. 'I had never seen so many lobbyists': food industry political practices during the development of a new nutrition front-of-pack labelling system in Colombia [published online ahead of print, 2020 Aug 21]. Public Health Nutr. 2020;1-9.

32. HLPE. Nutrition and food systems: A report by The High Level Panel of Experts on Food Security and Nutrition. Rome; 2017.

33. Grace D. Food safety in low and middle income countries. Int J Environ Res Public Health. 2015;12:10490-507.

34. Corrado S, Caldeira C, Eriksson M, Hanssen OJ, Hauser HE, van Holsteijn F, et al. Food waste accounting methodologies: Challenges, opportunities, and further advancements. Glob Food Sec. 2019; 20:93-100.

35. Beurskens F. The Economics of Dot.coms and E-commerce in the Agrifood Sector. Rev Agric Econ. 2003;25(1):22-8.

36. Mayet M, Greenberg S. Las tres megafusiones de agronegocios: macabros verdugos de la soberanía de las y los agricultores. Observatorio del Derecho a la Alimentación y a la Nutrición 2017;(7):76-85. (accesible en: https://www.righttofoodandnutrition.org/files/rtfanw-2017_spa.pdf).

37. Batis C, Mazariegos M, Martorell R, Gil A, Rivera JA. Malnutrition in all its forms by wealth, education and ethnicity in Latin America: who are more affected? Public Health Nutr. 2020;23(S1):s1-s12. doi:10.1017/S136898001900466X.

38. FAO. Smallholders and Family Farmers. Sustainability Pathways. Rome: United Nations Food and Agriculture Organization (FAO); 2012. p. 4.

39. Pinstrup-Andersen P. Nutrition-sensitive food systems: From rhetoric to action. Lancet. 2013;382(9890):375-6. 
40. Galhena DH, Freed R, Maredia KM. Home gardens: A promising approach to enhance household food security and wellbeing. Agric Food Secur. 2013;2:8.

41. Kanter R, Boza S. Strengthening Local Food Systems in Times of Concomitant Global Crises: Reflections From Chile. Am J Public Health. 2020;110:971_973.

42. Swinburn BA, Kraak VI, Allender S, et al. The Global Syndemic of Obesity, Undernutrition, and Climate Change: The Lancet Commission Lancet. 2019;393(10173):791846.

43. Pérez-Escamilla R, Cunningham K, Moran VH. COVID-19, food and nutrition insecurity and the wellbeing of children, pregnant and lactating women: A complex syndemic [published online ahead of print, 2020 May 26]. Matern Child Nutr. 2020;e13036.

44. Tuñón I, Sánchez ME. Las infancias en tiempos de cuarentena. Observatorio de la Deuda Social Argentina Universidad Católica Argentina. Mayo 2020. http:// wadmin. uca.edu.ar/public/ckeditor/Observatorio\%20Deuda\%20Social/Presentaciones/2020/2020_OBSERVATORIO_EDSA\%20COVID19_INFANCIA-V.pdf.

45. Qingxian C, Fengjuan C, Fang L, Xiaohui L, Tao W, Qikai W, et al. Obesity and COVID-19 Severity in a Designated Hospital in Shenzhen, China. Lancet Infect Dis. 2020; (202002073000001. 


\section{Capítulo 2}

\section{DESAFIO E INOVAÇÃO EM POLÍTICAS PÚBLICAS PARA A INFÂNCIA EM SITUAÇÃO DE VIOLÊNCIA NO BRASIL: VIOLAÇÃO E DIREITOS}

\section{Adelma Alves de Figueirêdo ${ }^{1}$, Blenda Avelino Garcia ${ }^{2}$, Priscila Campos de Matos Lacerda ${ }^{3}$, Denise Abreu Cavalcanti ${ }^{4}$}

${ }^{1}$ Gastroenterologista Pediátrica; Mestre em pediatria/UFMG; docente do curso de medicina da UFRR; Presidente da Sociedade Roraimense de Pediatria.

2 Pediatra. Docente do curso de Medicina/UFRR. Vice-presidente do CRM-RR

3 Priscila Campos de Matos Lacerda. Pediatra. Mestre em Ciências da Saúde pela UFRR. Doente do curso de Medicina/UFRR

${ }^{4}$ Denise Abreu Cavalcanti. Advogada. Presidente da Comissão de Direitos da Criança e do Adolescente da OAB/RR e do Instituto Brasileiro de Direito de Família em Roraima. Mestranda em Direito das Migrações Internacionais pela UNIVALI e pela Universidade de Perugia/Itália.

As crianças, quando bem cuidadas, são uma semente de paz e esperança

Zilda Arns Neumann

Resumo:

Este capítulo se utiliza da conceituação dos diferentes tipos de violência infantil definidos pela Organização Mundial da Saúde. No Brasil, um país reconhecido como de alta violência no mundo, grande número de crianças são vítimas de algum tipo de violência. Mas, apesar disso, existe grande mobilização nacional para garantir os direitos desse grupo vulnerável. Existem políticas públicas eficazes para o enfrentamento do problema, mas o reflexo de práticas autoritárias e de subjugação da criança, muitas vezes implementadas por quem deveria proteger, contribuem para a subnotificação dos casos o que faz desse um grave problema de saúde pública e de violação de direitos humanos, 
associados a taxas crescentes de abuso sexual doméstico e homicídios na adolescência. Nesse sentido busca-se refletir sobre as causas sociais da violência e sua associação com a violação de direitos da infância e adolescência, mostrando a evolução das políticas públicas e de todo o aparato jurídico para enfrentar a problemática, expondo o cenário de desafios e inovações.

Palavras-chave: Maus-tratos Infantis; Negligência com a Criança; Violência Infantil.

\section{Introdução}

No que tange a crianças e adolescentes, a Organização Mundial de Saúde (OMS) define violência como todas as formas de maus-tratos emocionais e/ou físicos, abuso sexual, negligência ou tratamento negligente, comercial, ou outras formas de exploração, com possibilidade de resultar em danos potenciais, ou reais à saúde das crianças, sobrevivência, desenvolvimento ou dignidade no contexto de uma relação de responsabilidade, confiança ou poder ${ }^{1}$.

Em todo o mundo, um bilhão de crianças, o que corresponde a mais de $50 \%$ delas, entre 2 e 17 anos de idade, sofreu violência psicológica, física ou sexual em 2016². No Brasil, um cenário desolador permeia essa realidade, sendo que o númerode notificações de casos de violência contra crianças e adolescentes vem crescendo exponencialmente ao longo dos anos. Apenas, no ano de 2017, o SINAN³ (Sistema de Informação de agravos de Notificação) registrou 126.230 casos de violência contramenores de 19 anos.

À vista disso, a violência contra crianças e adolescentes é tratada atualmente como um grave problema de saúde pública e de direitos humanos. No entanto, acredita-se que tais registros representem somente o princípio da problemática as violências cotidianas, pois um significativo número de ocorrências não alcança a visibilidade social e sua devida notificação4.

Essa realidade vivenciada, no Brasil, pode ser explicada devido ao comportamento da sociedade brasileira desde a sua formação histórica. A não cidadania das crianças brasileiras data desde o Período Colonial e se perpetuou até a instalação da República. 
Há poucas décadas, a população infanto-juvenil era vista dentro da ótica adultocêntrica marcada, sobretudo, pela desvalorização e pelo desconhecimento da própria existência. Muitas práticas autoritárias, coercitivas e até mesmo castigos físicos eram realizados e justificados pelo exercício do pátrio poder, sob o qual os menores eram completamente subjugados 5 .

Tais práticas só foram revistas no Brasil no final da década de 1980, a partir da promulgação da Constituição da República em 1988 e, logo em seguida, do Estatuto da Criança e do Adolescente (Lei $\left.n^{\circ} 8.069 / 90\right)^{6}$. O país passou a adotar o princípio da proteção integral, pelo qual crianças e adolescentes transformaram-se efetivamente em sujeitos de direitos.

Dessa forma, a doutrina da proteção integral surgiu como uma tentativa de articular uma política para resguardar os direitos sociais da criança e do adolescente, a partir da ação conjunta entre governo e sociedade. Com isso, a família, a sociedade, a União, os Estados e os Municípios, solidariamente, tornaram-se obrigados a garantir e assegurar o amplo acesso aos direitos fundamentais: Saúde, Convivência Familiar e Comunitária, Educação, Esporte e Lazer, Dignidade, Respeito, Liberdade, Preparação e Proteção ao Trabalho. E, por conseguinte, qualquer violação desses direitos passou a ser considerada como prática de violência?.

A passos lentos, o Brasil vem alcançando conquistas em relação à proteção das crianças e adolescentes. A redução da mortalidade infantil foi um dos grandes marcos atingidos segundo os Objetivos de Desenvolvimento do Milênio, propostos pela ONU, em 2015. Porém, evidenciam-se taxas crescentes de homicídios na adolescência8.

O homicídio é a forma mais extrema de violência e de violação de direitos. Estatísticas apontam uma elevação importante das taxas de homicídios dos adolescentes, desde 2012, cujo trágico desfecho é, proporcionalmente, maior nessa faixa etária do que noutros segmentos da população. Além disso, o gênero masculino e a raça negra destacam-se em meio às notificações ${ }^{9}$.

Não é à toa que o Brasil aparece como o quinto país mais violento do mundo, com taxa de homicídio maior do que a de países em guerra. Para combater e enfrentar esse fenômeno da "juventude perdida", torna-se necessário analisar minuciosamente as causas sociais da violência, o fortalecimento de medidas que visem à educação, a oferta de emprego para 
os adolescentes mais vulneráveis e o compromisso firmado de extinguir a impunidade de cada caso de homicídio contra esse grupo social ${ }^{10}$.

A proposta deste capítulo é situar o leitor na temática, contextualizando-a como importante questão de saúde pública e de direitos humanos. Além disso, intencionou- se fazer um breve levantamento das políticas públicas direcionadas para enfrentar a problemática, expondo o cenário de desafios e inovações.

\section{Formas de violência contra crianças e adolescentes}

Ao retomar a amplitude do conceito de violência contra crianças e adolescentes,torna-se necessário distingui-la em suas diferentes formas. Parte-se do princípio que aviolência praticada ultrapassa os limites de agressões físicas, tornando a caracterizaçãomais abrangente; classificando-se em estrutural, psicológica, física e sexual, incluídasas subdivisões, mas não raro uma forma está agregada a outras ${ }^{11}$.

\section{Violência estrutural}

Talvez seja a menos percebida ou a mais disfarçada das violências. Esse tipo refere-se às injustiças sociais que as crianças sofrem historicamente, mesmo antes do nascimento, como a falta de políticas públicas voltadas para sua proteção. Certas situações ilustram o caminho histórico de vulnerabilidade social associada a este tipode violência, como o nascimento em lares mal estruturados, onde a criança é fruto deuma gestação não planejada, os vínculos familiares são frágeis, há desigualdades sociais e o analfabetismo parental. Segundo Minayo (2001)12 essa forma de violênciaparece naturalizada no Brasil, quer pela perenidade de seu caráter, quer por não se visualizar rapidamente o binômio autor-ação. Ou seja, os autores políticos das ações socioeconômicas que geraram tal violência.

\section{Violência psicológica}

Humilhar, abandonar emocionalmente, criticar excessivamente, controlar, envergonhar ou fazer sentir culpa são formas de violência psicológica contra criançase adolescentes. Quantos mais traumas o indivíduo sofre na 
infância, menor será sua capacidade adaptativa emocional e maiores serão os impactos sobre a personalidade,além de um risco 17 vezes maior de suicídio na vida adulta ${ }^{13}$.

\section{Violência física}

Diz respeito à violência causada pelo uso da força física, podendo resultarem dor sem lesão, ferimentos de leve a severa gravidade, ou, até mesmo, em óbito. Infelizmente, apesar das ruas e instituições serem locais de grande vulnerabilidade para este tipo de violência, os lares das crianças e adolescentes também o são. Um estudo realizado pela UNICEF (2014)14, demonstrou que a violência física está presente no cotidiano de crianças entre 2 e 14 anos em todo o mundo. Os resultadosevidenciam que cerca de 6 em cada 10 menores são submetidos a castigos físicos regularmente como forma de instituir disciplina.

No Brasil, dados do SINAN (2017) ${ }^{15}$ demonstram um aumento do número de notificações a cada ano por violência física em menores de 19 anos. Os resultados demonstrados na Tabela 1 correspondem a uma série histórica entre os anos de 2009a 2017.

Além do aumento progressivo do número de notificações, com o passar dos anos, ressalta-se como faixa etária mais acometida por agravos físicos, no Brasil, a de adolescentes entre 15 e 19 anos. No entanto, as autoras inferiram que os casos de violência física contra crianças menores são mais subnotificados, pelo receio da própria criança em relatar o ocorrido, assim como o temor de outras punições. Além disso, dificuldades de notificação podem perpassar tanto falhas diagnósticas quanto falta de dispositivos padronizados e efetivos, durante a condução dos casos, pelo sistema de saúde. 
Tabela 1 - Número de Notificações por violência física registrados por faixa etária entre os anos de 2009 a 2017 no Brasil

\begin{tabular}{|r|r|r|r|r|r|}
\hline \multirow{2}{*}{ ANO } & \multicolumn{5}{|c|}{ IDADE (ANO) } \\
\cline { 2 - 6 } & $<\mathbf{1}$ & $\mathbf{1}$ a $\mathbf{4}$ & $\mathbf{5}$ a $\mathbf{9}$ & $\mathbf{1 0}$ a $\mathbf{1 4}$ & $\mathbf{1 5}$ a $\mathbf{1 9}$ \\
\hline $\mathbf{2 0 0 9}$ & 472 & 884 & 1291 & 2279 & 4164 \\
\hline $\mathbf{2 0 1 0}$ & 837 & 1450 & 2016 & 4117 & 7437 \\
\hline $\mathbf{2 0 1 1}$ & 1339 & 1917 & 2709 & 6136 & 12668 \\
\hline $\mathbf{2 0 1 2}$ & 1774 & 3028 & 3975 & 8575 & 18992 \\
\hline $\mathbf{2 0 1 3}$ & 1705 & 2885 & 3922 & 9669 & 22368 \\
\hline $\mathbf{2 0 1 4}$ & 1511 & 3329 & 4182 & 10215 & 24426 \\
\hline $\mathbf{2 0 1 5}$ & 1742 & 3442 & 4522 & 10140 & 25577 \\
\hline $\mathbf{2 0 1 6}$ & 1643 & 3699 & 4696 & 10741 & 27307 \\
\hline $\mathbf{2 0 1 7}$ & $\mathbf{2 8 8 6}$ & 4247 & 5235 & 13372 & 33553 \\
\hline TOTAL & $\mathbf{1 3 . 9 0 9}$ & $\mathbf{2 4 . 8 8 1}$ & $\mathbf{3 2 . 5 4 8}$ & $\mathbf{7 5 . 2 4 4}$ & $\mathbf{1 7 6 . 9 4 2}$ \\
\hline
\end{tabular}

Fonte: Ministério da Saúde - Sistema de Informação de Agravos de Notificação - SINAN Net15

Alguns autores como Gawryszewski et al (2009) ${ }^{16}$, Mascarenhas et al. (2010) ${ }^{17}$ eGarbin et al. (2011) ${ }^{18}$ encontraram nos seus estudos maus-tratos, por agravos físicos,em crianças como a forma mais frequente de violência. Tais registros podem estar associados à existência de lesões corporais facilmente identificáveis, favorecendo a ocorrência por denúncias.

\section{Violência sexual}

A violência sexual contra crianças e adolescentes é definida como todo ato ou jogo sexual com intenção de estimular sexualmente a criança ou o adolescente, cujo objetivo é submeter a uma prática para obter satisfação sexual, em que os autores daviolência estão em estágio de desenvolvimento psicossexual mais adiantado que as vítimas ${ }^{19}$.

A Lei $n^{\circ} 12.015 / 2009^{20}$ alterou o Código Penal brasileiro, criando a figura do estupro de vulnerável. Dessa forma, considera-se que pessoas menores de 14 anos estão em vulnerabilidade absoluta, e que o ato sexual - por si só - já configura crime, independentemente se houve consentimento do menor e/ ou de seus responsáveis, compleição física e, ainda, se a vítima tenha tido experiência sexual pregressa. 
Como as crianças e os adolescentes são seres em desenvolvimento, a violência sofrida por eles causará impacto muito maior que em adultos, pois, além deafetar o ser humano à época do agravo, influencia negativamente o desenvolvimentobiopsicossocial desse cidadão. Quanto mais jovem, maior e mais prolongada for essaviolência, mais agravos atuais e futuros ocorrerão. Recentemente, essa ideia passou a ser mais bem esclarecida e demonstrada como "estresse tóxico"21.

Desta feita, o neurodesenvolvimento é compreendido como um processo complexo no qual o cérebro, para alcançar seu potencial genético, necessita de uma boa nutrição, de segurança afetiva e de estimulação psicomotora. Ou seja, para um bom desenvolvimento, é necessária para a integração qualitativa entre condicionantesneurobiológicas e ambientais. Lactentes criados com afeto, estímulos, educação e nutrição adequada e que não vivenciam experiências traumáticas, terão melhordesempenho cognitivo e de habilidades emocionais na vida adulta. Traumas cerebraisna infância podem resultar em alterações no desenvolvimento com repercussões paraa vida adulta.

Assim, toda criança que passa por estresse, como uma doença, nascimento de um irmão, adversidades familiares, dentre outros, mas recebe um bom acompanhamento familiar e/ou institucional será capaz de dirimir esse estresse, impedindo que se torne tóxico. Caso isso não aconteça, ocorrerão alterações estruturantes cerebrais e perdas de habilidades emocionais e cognitivas irreparáveis ${ }^{21}$.

\section{Os direitos das crianças e dos adolescentes assegurados por lei}

Conforme a Constituição Federal do Brasil (1988) ${ }^{22}$, assim são garantidos os direitos da criança:

Art. 227: É dever da família, da sociedade e do Estado assegurar à criança, ao adolescente e ao jovem, com absoluta prioridade, o direito à vida, à saúde, à alimentação, à educação, ao lazer, à profissionalização, à cultura, à dignidade, ao respeito, à liberdade e à convivência familiar e comunitária, além de colocá-los a salvo de toda forma de negligência, discriminação, exploração, violência, crueldade e opressão.

Art. 228: São penalmente inimputáveis os menores de dezoito anos, sujeitos àsnormas da legislação especial. 
Nesse sentido, com a Lei n. $8.069^{6}$, de 13 de julho de 1990, criou-se o Estatuto da Criança e do Adolescente (ECA), em contraposição ao antigo Código de Menores e em consonância com a Convenção sobre o Direito da Criança, adotada pela Assembleia Geral das Nações Unidas. Assim, a família, a sociedade, a União, os Estados e os Municípios, solidariamente, devem garantir e assegurar o amplo acesso aos direitos fundamentais elencados na Constituição e no ECA.

Em 1991, foi instituído por meio da Lei n. 8.242/199123 o Conselho Nacional dos Direitos da Criança e do Adolescente - CONANDA, visando, dentre outros, à elaboração de normas gerais de atendimento dos direitos da criança e do adolescente, para fiscalizar as ações de execução, observando-se o Estatuto.

A Lei $13.431 / 2017^{24}$ criou o sistema de garantia de direitos dos menores vítimasou testemunhas de violência e alterou a Lei no $8.069 / 1990^{6}$ que regulamentava o ECA.

\section{Das políticas públicas}

A Lei n. $13.257 / 2016^{25}$, alterou o artigo $8^{\circ}$ do ECA, assegurando que todas as mulheres e gestantes tenham acesso às políticas públicas no âmbito do Sistema Único de Saúde. Mas, questiona o que venham ser tais medidas e como se aplicam. Na forma da Lei, "São ações e programas desenvolvidos pelo Estado para garantir e colocar em prática direitos que são previstos na Constituição Federal e em outras leis. São medidas e programas criados pelos governos dedicados a garantir o bem-estar da população. Definições recentes consideram que a política pública ultrapassa uma decisão governamental, uma vez que pode transcorrer de decisões e ações de outros atores, como a sociedade civil $^{26}$.

No caso em análise, os sujeitos de direitos (crianças e adolescentes), em conformidade com a legislação pátria, fazem jus a políticas públicas pensadas e executadas pelo Estado, de acordo com suas especificidades e que, por sua natureza, são políticas públicas sociais.

Hofling (2001)27, assevera que "políticas sociais se referem a ações que determinam o padrão de proteção social implementado pelo Estado, vol- 
tadas, em princípio, para a redistribuição dos benefícios sociais visando à diminuição das desigualdades estruturais produzidas pelo desenvolvimento socioeconômico".

Nesse sentido, a já citada Lei n. 13.257/2016 25 trouxe importante inovação, instituindo o Estatuto da Primeira Infância e prevendo políticas públicas para atender crianças de 0 a 6 anos de idade. Cada Estado desenvolve as próprias políticas públicas, em acordo com as normas legais vigentes e com as especificidades.

Contudo, é sabido que existe uma grande discrepância entre as políticas públicas sociais e a efetiva implementação. Para fundamentar esse estudo, recorreu- se às políticas que envolvem a segurança alimentar no âmbito es$\operatorname{colar}^{28}$, no Estado de Roraima e em seus municípios. O PNAE - Programa Nacional de Alimentação Escolar (2013)29 - prevê, dentre outros, que o cardápio das escolas "deve respeitar as referências nutricionais, os hábitos alimentares, a cultura alimentar da localidade". Também destaca que deve "atender as especificidades culturais das comunidades indígenas e/ou quilombolas".

Outro exemplo legal a que se recorreu refere-se à Lei $13.431 / 2017^{24}$, que instituiu a obrigatoriedade da escuta qualificada de crianças e adolescentes, em ambiente adequado e com profissionais qualificados. Mas, nem todos os Estados criaram tal estrutura, que deveria contar com as delegacias especializadas para apurar crimes em que crianças e adolescentes sejam vítimas ou testemunhas, evitando, como já dito alhures, a revitimização e seus consequentes abusos.

Embora a lei tenha avançado, muitas famílias, a sociedade e o poder público ainda demonstram dificuldade em acompanhar as novas diretrizes. As descobertas da ciência que estudam os reflexos da violência sobre as crianças precisam imprimir mudanças profundas no tratamento dispensado à infância e à juventude, refletindo-se, inclusive, no próprio sistema de justiça criminal brasileiro. Apesar dessas constatações, a luta pelas crianças é muito importante, devendo ser exaustiva para que se estabeleçam os direitos, reconhecidos e valorizados os ganhos alcançados para que se reproduzam. 


\section{a. Desafios}

Como proteger uma população que é física e emocionalmente dependente? Como identificar a violência, haja vista que, muitas vezes, ela é sutil, culturalmente aceita e ocorre no ambiente domiciliar? Como fazer crianças pequenas falarem que são violentadas ou, até mesmo, os adolescentes, já que $\mathrm{o}$ agressor com frequência tem ascendência familiar sobre a vítima? $\mathrm{E}$, ainda, como criar a cultura da não violência, no Brasil, um país tão amplo, diverso e cruelmente desigual? São perguntas retóricas que convergem para os desafios constantes, os quais devem ser ininterruptos todos os esforços de enfrentamento.

Relativo a isso, atualmente, no Brasil, há alguns projetos, planos e estratégias. Alguns incipientes e outros bem sedimentados, porém, não alcançam toda a população- alvo. Atribui-se a não total abrangência à falta de coordenação das ações, por meio de uma política pública de estado que transpasse longitudinalmente os governos. Os esforços são, portanto, pouco efetivos.

Quiçá, mais que criar novos projetos, seja necessário fazer um levantamento daqueles que existem, dos que deram melhores resultados em curto e longo prazo para fazê-los funcionar. Logo, é fundamental que haja uma coordenação central, com integração de diversas pastas atreladas - saúde, educação, segurança, seguridade social, entre outros -, pois a violência tem interface nos mais variados segmentos da sociedade.

\section{b. Inovações}

Em 2018, o Brasil tornou-se membro da Parceria Global pelo Fim da Violência contra Criança e Adolescentes, liderada pela ONU, cujo objetivo é contribuir para o cumprimento dos Objetivos de Desenvolvimento Sustentável (ODS), sobretudo aqueles que se destinam a acabar com todas as formas de violência e de tortura contra crianças. Ao ingressar nessa Parceria Global, o Brasil assumiu o compromisso de desenvolver um Roteiro Nacional (Roadmap) de ações integradas e se comprometeu a desenvolver um sistema de indicadores de violações dos direitos das crianças e dos adolescentes.

O país criou a Secretaria Nacional dos Direitos da Criança e do Adolescente (SNDCA), atrelada ao Ministério dos Direitos Humanos, órgão responsável pela articulação das políticas públicas de combate às manifestações de violência contra crianças e adolescentes ${ }^{30}$. Para isso, criou o disque 100, 
que recebe denúncias de violação dos direitos humanos; em parceria com a Unicef, desde 2013, ampliou com o aplicativo "Proteja Brasil”, que facilita e fortalece as denúncias de violência. Em 2016, foi lançada nova versão, ampliando suas funcionalidades e fazendo a sua integração ao Disque $100^{31}$.

Ademais, firmou parceria com a Sociedade Brasileira de Pediatria (SBP), com o Conselho Federal de Medicina (CFM) e com o Ministério dos Direitos Humanos para buscar soluções contra agressões a crianças e adolescentes. Um dos exemplos desse feito foi a elaboração do Manual de Atendimento às Crianças e Adolescentes Vítimas de Violência, destinado aos profissionais de saúde ${ }^{32}$.

\section{c. Inspire}

Refere-se ao Projeto de medidas elaborado pela OPAS/OMS e por diversas outras entidades, como o Centro de Controle e Prevenção de Doenças dos Estados Unidos, o Fundo das Nações Unidas para a Infância (UNICEF), o Banco Mundial, entre outras. O INSPIRE é composto por sete estratégias e orienta atividades transversais que, em seu bojo, contribuem para conectar e fortalecer as setes estratégias, bem como para avaliar os seus progressos ${ }^{33}$. Não se trata de um novo programa, mas de estratégias bem definidas que devem ser adaptadas a cada realidade para que funcionem. Tais estratégias estão descritas na Tabela 2:

Tabela 2 - Estratégias do INSPIRE para prevenir e enfrentar a violência na infância Inserir as linhas na tabela

\begin{tabular}{|l|l|}
\hline Estratégia & Medidas \\
\hline $\begin{array}{l}\text { Implementação } \\
\text { e vigilância do } \\
\text { cumprimento } \\
\text { das leis }\end{array}$ & $\begin{array}{l}\text { Leis que proíbem pais, mães, professores ou outros } \\
\text { cuidadores de aplicar castigos violentos a crianças. } \\
\text { - Leis que criminalizam o abuso sexual e a exploração } \\
\text { de crianças. }\end{array}$ \\
\hline Normas e valores & $\begin{array}{l}\text { Leis que previnem o uso indevido de álcool. } \\
\text { - } \begin{array}{l}\text { Leis que limitam o acesso de jovens a armas de fogo e } \\
\text { sejam restritivas. }\end{array}\end{array}$ \\
& $\begin{array}{l}\text { Programas de mobilização da comunidade. } \\
\text { Intervenções junto a testemunhas. }\end{array}$ \\
\hline
\end{tabular}




\begin{tabular}{|c|c|}
\hline Estratégia & Medidas \\
\hline $\begin{array}{l}\text { Segurança do } \\
\text { ambiente }\end{array}$ & $\begin{array}{l}\text { - Redução da violência por atuação em "áreas críticas". } \\
\text { - Interrupção da propagação da violência. } \\
\text { - Melhoria do espaço urbano. }\end{array}$ \\
\hline $\begin{array}{l}\text { Pais, mães e } \\
\text { cuidadores } \\
\text { recebem apoio }\end{array}$ & $\begin{array}{l}\text { - Por meio de visitas domiciliares. } \\
\text { - Por meio de grupos nas comunidades. } \\
\text { - Por meio de programas integrais. }\end{array}$ \\
\hline $\begin{array}{l}\text { Incremento } \\
\text { de renda e } \\
\text { fortalecimento } \\
\text { econômico }\end{array}$ & $\begin{array}{l}\text { - Transferência de renda. } \\
\text { - Associações de poupança e empréstimo combinadas } \\
\text { à educação para a equidade de gênero. } \\
\text { - Microfinanciamento combinado à educação sobre } \\
\text { normas de gênero. }\end{array}$ \\
\hline $\begin{array}{l}\text { Resposta de } \\
\text { serviços de } \\
\text { atenção e apoio }\end{array}$ & $\begin{array}{l}\text { - } \text { Aconselhamento e apoio terapêutico. } \\
\text { - Rastreamento de casos combinado a intervenções. } \\
\text { - } \text { com a lei no sistema de justiça criminal. } \\
\text { - Intervenções de acolhimento familiar, com } \\
\text { participação dos serviços de bem-estar social. }\end{array}$ \\
\hline $\begin{array}{l}\text { Educação e } \\
\text { habilidades para } \\
\text { a vida }\end{array}$ & $\begin{array}{l}\text { - Aumento da taxa de matrículas na pré-escola e nas } \\
\text { escolas primária e secundária. } \\
\text { - Criação de um ambiente escolar seguro e estimulante. } \\
\text { - Melhoria do conhecimento das crianças sobre o } \\
\text { - Fobuso sexual e maneiras de se proteger. } \\
\text { - Pormação de habilidades sociais e para a vida } \\
\text { da violência infigidos a adolescentes para prevenção } \\
\text { digla pelo parceiro íntimo. }\end{array}$ \\
\hline
\end{tabular}

Fonte: OPAS, $2017^{33}$

\section{d. Projeto Primeira Infância Melhor - Porto Alegre/RS}

Política pública para a infância, socioeducativa, preventiva, pioneira no Brasil, de promoção do desenvolvimento integral, que incrementa vínculos afetivos e fortalece a identidade familiar, desde a gestação até os seis anos de idade. Envolve três secretarias Municipais, de Educação, da Saúde e de Cultura no atendimento às famílias em situação de vulnerabilidade social ${ }^{34}$. 


\section{e. Programa Cresça Com Seu Filho - Fortaleza/CE}

Esse programa é realizado em conjunto com a Estratégia de Saúde da Família na cidade de Fortaleza - CE. Seu principal objetivo é apoiar as famílias em situação de vulnerabilidade social, promovendo o desenvolvimento integral de crianças, da gestação até os 3 anos. Durante as visitas semanais às famílias cadastradas, o agente comunitário de saúde realiza atividades de acordo com a faixa etária da criança, com o intuito de fortalecer os domínios do desenvolvimento cognitivo, afetivo, motor e da linguagem, estimulando e capacitando os cuidadores na participação destas atividades lúdicas ${ }^{35}$.

\section{f. Programa Família que Acolhe - Boa Vista/RR}

É uma política pública integrada destinada à Primeira Infância, que busca garantir o desenvolvimento integral da criança, fortalecendo laços de afeto e estabilidade entre as famílias. Envolve várias secretarias, desde a criação de espaços físicos planejados para as crianças e sua família até a integração de todos os serviços oferecidos com foco na Primeira Infância. A gestante ingressa no programa até a $20^{\text {a }}$ semana gestacional, terá acompanhamento durante o pré-natal, orientação para cuidados após o nascimento do bebê, receberá o enxoval e terá acompanhamento médico- psicossocial, além de vaga garantida na creche, em período integral, a partir dos dois anos (Figuras 1 e 2) ${ }^{36}$.

Figura 1 - Universidade do bebê: grupos temáticos familiares

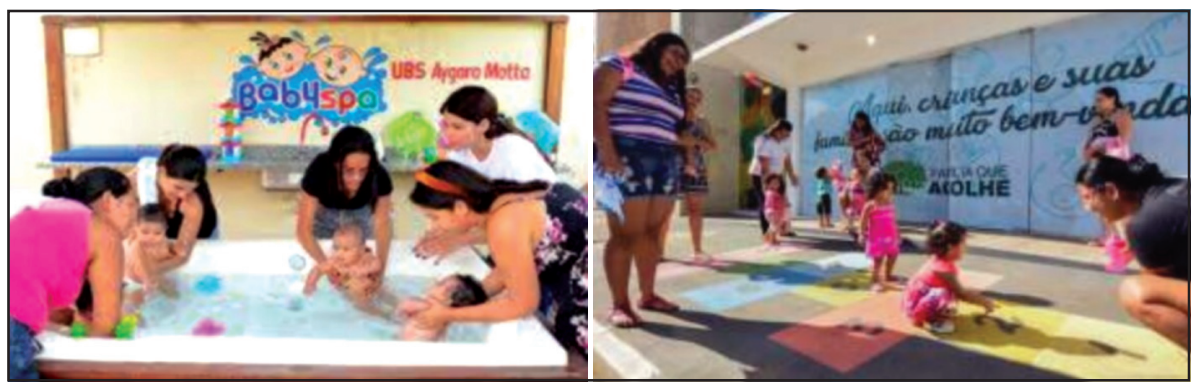

Fonte: Prefeitura de Boa Vista - RR 
Figura 2 - Caminhos da Primeira Infância - Adaptação de percursos que compreendem a unidade Básica de Saúde, o Centro de Assistência Social, escolas, creches, a Casa Mãe e uma praça; para que as crianças possam se divertir com suas famílias e fortalecer os vínculos.

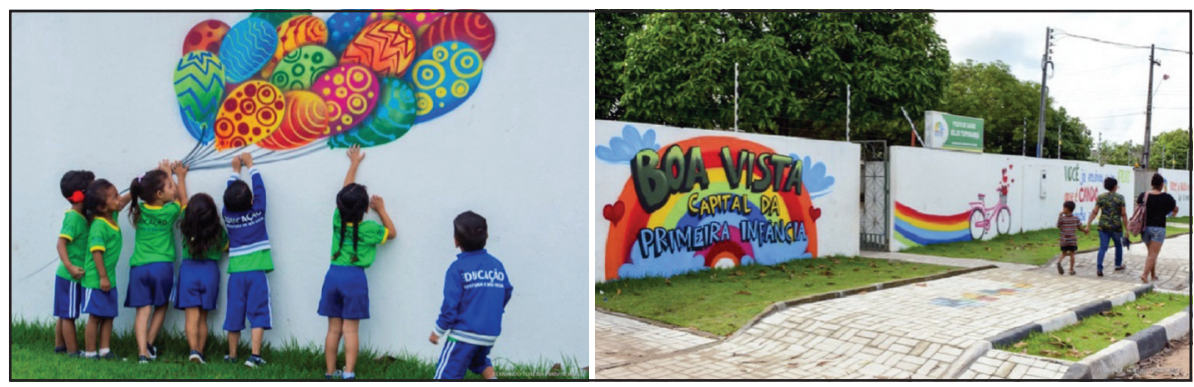

Fonte: Prefeitura de Boa Vista- RR

\section{Considerações finais}

As autoras avaliam os programas como importantes iniciativas de assistência e, consequentemente, de enfrentamento e combate à violência, haja vista o entendimento de que, com o planejamento familiar, geram-se filhos desejados e esperados. Tal consciência coíbe a violência da gravidez na adolescência para os pais, a violência física e psíquica do aborto clandestino e a negligência dos cuidados para com um bebê não desejado. Garante, ainda, a qualidade dos primeiros mil dias de vida e se evitam as podas neuronais excessivas, que impedem não só o crescimento cognitivo adequado, mas também a aquisição de habilidades psicoafetivas, como a empatia, tão importante para a não perpetração da violência.

Outrossim, registra-se que, ao empreenderem a revisão bibliográfica para a produção do presente capítulo, as autoras depararam-se com significativo acervo de classificações, estratégias, programas e projetos elaborados para prevenir e dirimir a desgraça provocada pela violência contra a população infanto-juvenil. Destacam- se importantes e complexas propostas, como o INSPIRE, da Organização Mundial da Saúde, e as demais existentes no Brasil e citadas neste trabalho. Porém, devido à persistência de tamanha crueldade para com as crianças, deduzimos que as boas ideias não são plenamente executadas, ou o são para ínfima parcela da população- alvo, deixando a 
maioria à margem dessa proteção vital, a qual deveria ser regra. Contraditoriamente, enquanto a humanidade no século $X X I$ já se desenvolveu a ponto criar soluções, utilizando-se de inteligência artificial, os direitos das crianças e dos adolescentes continuam sendo violados e a depender de políticas retrógradas. É preciso, pois, reivindicar semelhante modernização.

\section{Referências}

1. KRUG E.G., DAHLBERG L.L.; MERCY J.A.; ZWI A.B.; LOZANO R. World report on violence and health. Geneva: World Health Organization; 2002

2. HILLIS S, MERCY J, AMOBI A, et al. Global prevalence of past-year violence against children: a systematic review and minimum estimates. Pediatrics. 2016;137(3): e20154079.

3. SINAN. Sistema de Informação de Agravos de Notificação. 2017 Disponível em http://tabnet.datasus.gov.br/cgi/tabcgi.exe?sinannet/cnv/violebr.def. Acesso 04 MAI 2020.

4. UNICEF. Hidden in plain sight: a statistical analysis of violence against children New York: UNICEF; 2014.

5. RIZZINI I., PILOTTI F et al. A arte de governar crianças. Rio de Janeiro: Amais, Santa Úrsula; 1996.

6. BRASIL. Lei $\mathbf{8 . 0 6 9}$ de $\mathbf{1 3}$ de julho de $\mathbf{1 9 9 0}$. Dispõe sobre o Estatuto da Criança e Adolescente e dá outras providências. Diário Oficial da União, Brasília, DF, 13 jul. 1990. Disponível em: http://www.planalto.gov.br/ccivil_03/leis/l8069.htm. Acesso 05 ABR 2020.

7. CONTINI, M. L. (2002). Prefácio - a adolescência e psicologia: práticas e reflexões críticas. In M. L. J. Contini, S. H. Koller \& M. N. S. Barros (Orgs.). Adolescência e psicologia: concepçōes, práticas e reflexōes críticas (pp.11-14). Brasília, DF: Conselho Federal de Psicologia

8. ATLAS DA VIOLÊNCIA 2018. IPEA - Instituto de Pesquisa Econômica Aplicada. Brasília, DF, 5. jun. 2018. Disponível em: http://www.ipea.gov.br/portal/images/ stories/PDFs/relatorio_institucional/180604_atlas_da_violencia_2018.pdf. Acesso em 06 mai. 2020.

9. BRASIL. Ministério da Saúde. Departamento de Informática do SUS. Informações de Saúde, Epidemiológicas e Morbidade: banco de dados. Disponível em: http:// www2.datasus.gov.br/DATASUS/index.php?area=02. Acesso em 08 mai. 2020

10. UNICEF. Mais que promessas: compromissos reais com a infância e a adolescência no Brasil, 2018. Disponível em : https://www.unicef.org/brazil/ media/3051/file/ Mais_que_promessas.pdf. Acesso em 08 mai. 2020. 
11. KOIFMAN, L., MENEZES, R. M., BOHRER, K. R. (2012). Abordagem do tema “Violência contra a criança" no curso de Medicina da Universidade Federal Fluminense. Revista Brasileira de Educação Médica, 36(2), 172-179. Disponível em: http://www. scielo.br/pdf/rbem/v36n2/04.pdf. Acesso em 06 mai. 2020.

12. MINAYO, Maria Cecília de Souza. Violência contra crianças e adolescentes: questão social, questão de saúde. Rev. Bras. Saude Mater. Infant., Recife , v. 1, n. 2, p. 91-102, Aug. 2001.

13. ARAÚJO, R. M. F. et al. Mais do que palavras: a associação do abuso emocional na infância com o comportamento suicida. 2015. Dissertação de Mestrado em Medicina e Ciências da Saúde. Faculdade de Medicina. Pontifícia Universidade Católica do Rio Grande do Sul, RS.

14. UNICEF. Hidden in plain sight: a statistical analysis of violence against children New York: UNICEF; 2014.

15. SINAN. Sistema de Informação de Agravos de Notificação. 2017 Disponível em http://tabnet.datasus.gov.br/cgi/tabcgi.exe?sinannet/cnv/violebr.def. Acesso em 04 mai. 2020.

16. GAWRYSZEWSKI, Vilma Pinheiro et al . Maus-tratos contra a criança e o adolescente no Estado de São Paulo, 2009. Rev. Assoc. Med. Bras., São Paulo , v. 58, n. 6 , p. 659-665, Dez. 2012.

17. MASCARENHAS, M. D. M. et al . Violência contra a criança: revelando o perfil dos atendimentos em serviços de emergência, Brasil, 2006 e 2007. Cad. Saúde Pública, Rio de Janeiro , v. 26, n. 2, p. 347-357, Feb. 2010.

18. GARBIN, Cléa Adas Saliba et al. Violência denunciada: ocorrências de maus- tratos contra crianças e adolescentes registradas em uma unidade policial. Rev. bras. enferm., Brasília , v. 64, n. 4, p. 665-670, Aug. 2011.

19. BRASIL. Linha de cuidado para a atenção integral à saúde de crianças, adolescentes e suas famílias em situação de violências: orientação para gestores e profissionais de saúde. (2010). Brasília :MS; 2010.

20. BRASIL. Lei $\mathbf{n}^{\circ} \mathbf{1 2 . 0 1 5}$ de 7 de agosto de 2009. Altera o Título VI da Parte Especial do Decreto-Lei n 2.848, de 7 de dezembro de 1940 - Código Penal, e o art. $1^{\circ}$ da Lei no 8.072, de 25 de julho de 1990, que dispõe sobre os crimes hediondos, nos termos do inciso XLIII do art. $5^{\circ}$ da Constituição Federal e revoga a Lei $n^{\circ} 2.252$, de 10 de julho de 1954, que trata de corrupção de menores. Diário Oficial da União 2009, Brasília, DF 10 ago.2009, Disponível em: http://www.planalto.gov. br/ ccivil_03/_ato2007-2010/2009/lei/l12015.htm. Acesso em 09 mai. 2020.

21. SBP. Departamento Científico de Pediatria do Desenvolvimento e Comportamento. Manual de Orientação. O papel do pediatra na prevenção do estresse tóxico na infância. Rio de Janeiro: SBP, n 3; 2017.

22. BRASIL. Constituição da República Federativa do Brasil. Diário Oficial da União, 5 de outubro de 1988 
23. BRASIL, 1991. Lei $\mathbf{n}^{\circ} \mathbf{8 . 2 4 2}$ de 12 de Outubro de 1991. Cria o Conselho Nacional dos Direitos da Criança e do Adolescente (Conanda) e dá outras providências. Diário Oficial da União . Brasília, DF, 16 de outubro de 1991. Disponível em: http:// www.planalto.gov.br/ccivil_03/leis/l8242.htm. Acesso em 10 mai. 2020.

24. BRASIL, 2017. Lei $\mathbf{n}^{\circ} \mathbf{1 3 . 4 3 1}$ de $\mathbf{4}$ de Abril de 2017. Estabelece o sistema de garantia de direitos da criança e do adolescente vítima ou testemunha de violência e altera a Lei n 8.069, de 13 de julho de 1990 (Estatuto da Criança e do Adolescente). Diário Oficial da União, Brasília, DF, 05 abr 2017. Disponível em http:// www.planalto.gov.br/ccivil_03/_ato2015-2018/2017/lei/l13431.htm. Acesso em 06 mai. 2020.

25. BRASIL, 2016. Lei $\mathbf{n}^{\circ} \mathbf{1 3 . 2 5 7}$ de 8 De Março de 2016. Dispõe sobre as políticas públicas para a primeira infância e altera a Lei $n^{\circ} 8.069$, de 13 de julho de 1990 (Estatuto da Criança e do Adolescente), o Decreto-Lei n 3.689, de 3 de outubro de 1941 (Código de Processo Penal), a Consolidação das Leis do Trabalho (CLT), aprovada pelo Decreto-Lei $n^{\circ} 5.452$, de $1^{\circ}$ de maio de 1943 , a Lei $n^{\circ} 11.770$, de 9 de setembro de 2008, e a Lei $n^{\circ}$ 12.662, de 5 de junho de 2012. Diário Oficial da União 2009, Brasília, DF 09 mar.2016, Disponível em: http://www.planalto.gov.br/ ccivil_03/_ato2015-2018/2016/lei/l13257.htm. Acesso em 07 mai. 2020.

26. HOWLETT,M.;RAMESH,M.;PERL,A. Política pública: seusciclos esubsistemas - uma abordagem integral. Rio de Janeiro: Elsevier, 2013.

27. HOFLING, E. M. Estado e políticas (públicas) sociais. Cad. CEDES, Campinas, v.21, n. 55, p. 30-41, Nov. 2001.

28. BRASIL. Lei $\mathbf{n}^{\circ} \mathbf{1 1 . 9 4 7}$, de 16 de junho de 2009. Dispõe sobre o atendimento da alimentaçãoescolar e do Programa Dinheiro Direto na Escola aos alunos da educação básica;altera as Leis nos 10.880, de 9 de junho de 2004, 11.273, de 6 de fevereiro de 2006, 11.507, de 20 de julho de 2007; revoga dispositivos da Medida Provisóriano 2.178-36, de 24 de agosto de 2001, e a Lei 8913, de 12 de julho de 1994; e dáoutras providências. Diário Oficial da União. Brasília, DF, 17 de junho de 2009.

29. BRASIL. RESOLUÇÃO N 26 DE 17 DE JUNHO DE 2013. Dispõe sobre oatendimento da alimentação escolar aos alunos da educação básica no âmbito doPrograma Nacional de Alimentação Escolar - PNAE.

30. BRASIL. Secretaria Especial de Direitos Humanos (2009). Programa Nacional de Enfrentamento da Violência Sexual Contra Crianças e Adolescentes: Disque Denúncia Nacional DDN 100. Brasília: SEDH.

31. PROTEJA BRASIL. UNICEF. 2016. Disponível em http://www.protejabrasil.com.br/ br/. Acesso em 07 mai. 2020.

32. WAKSMAN, R. D.; HIRSCHHEIMER, M.R. Manual de atendimento às crianças e adolescentes vítimas de violência. Núcleo de Estudos da Violência Doméstica contra a Criança e o Adolescente. Brasília, DF, 2011. Disponível em: https://portal. cfm.org.br/images/stories/biblioteca/manual\%20atendimento\%20crianca\%20 adolescente.pdf. Acesso em 06 mai. 2020. 
33. OPAS. INSPIRE. Sete estratégias para por fim à violência contra crianças. Washington, D.C. : OPAS, 2017.

34. SECRETARIA DE SAÚDE - RS. Programa Primeira Infância Melhor. https://saude. rs.gov.br/programa-primeira-infancia-melhor-pim)

35. PREFEIRURA DE FORTALEZA. Cresça com seu filho. https://www.fortaleza. ce.gov.br/noticias/tag/cres\%C3\%A7a\%20com\%20seu\%20filho

36. PREFEITURA DE BOA VISTA/RR. PROGRAMA FAMÍLIA QUE ACOLHE. https://www. boavista.rr.gov.br/canal-do-cidadao-projetos/familia-que-acolhe-fqa 


\title{
Capítulo 3
}

\section{DESAFIOS DAS POLÍTICAS PÚBLICAS PARA O CONTROLE DA OBESIDADE INFANTIL NA AMÉRICA LATINA E NO CARIBE}

Asha V. Badaloo ${ }^{1}$, Shelley McFarlane ${ }^{2}$, Carolyn Taylor-Bryan ${ }^{3}$, Daniel Thomas ${ }^{4}$

Resumo

\begin{abstract}
${ }^{1}$ B.Sc. (Química e Bioquímica), Mestrado e Doutorado (Nutrição Humana). Professor de Metabolismo Nutricional, Unidade de Pesquisa de Metabolismo Tropical, Instituto Caribenho de Pesquisa em Saúde, Universidade das Índias Ocidentais.

${ }^{2}$ M. Phil. (Bioquímica e Diabetologia), Doutorado (Epidemiologia). Professor de Epidemiologia, Unidade de Pesquisa do Metabolismo Tropical, Instituto Caribenho de Pesquisa em Saúde, Universidade das Índias Ocidentais.

${ }^{3}$ B.Sc. (Química e Bioquímica), MBBS, MD (Pediatria), PhD (Nutrição). Professor de Nutrição, Unidade de Pesquisa do Metabolismo Tropical, Instituto Caribenho de Pesquisa em Saúde, Universidade das Índias Ocidentais.

${ }^{4}$ B.Sc. (Hon) (Ciências Médicas Básicas), MBBS. Bolsista de Pesquisa Clínica.
\end{abstract}

A obesidade é uma epidemia global caracterizada por alta morbimortalidade, associada a Doenças Não Transmissíveis que se manifestam na infância e persistem ao longo do ciclo vital até a idade adulta. Este capítulo analisa os desafios das políticas públicas no controle da obesidade na infância e na adolescência na América Latina e no Caribe. São fornecidas informações básicas sobre o contexto da obesidade infantil na região, destacando a importância do tema em nível regional e internacional e apresentando uma perspectiva histórica sobre os avanços que foram feitos até agora para lidar com a obesidade infantil. É apresentada uma análise das principais políticas e ações implementadas na região, incluindo as políticas de alimentação e nutrição, bem como aquelas voltadas para a promoção de hábitos de vida saudáveis, incluindo a atividade física. Os autores apresentam uma discussão sobre os desafios multifacetados que enfrentam não só a criação, mas também a implementação dessas políticas de saúde 
e o enfoque multissetorial que é importante para combater de forma adequada esta crescente ameaça à saúde de nossa população.

Palavras-chave: Controle da obesidade; Sistemas de Manejo da Obesidade; Obesidade pediátrica; Iniquidade social.

\section{Introdução}

Nas últimas décadas, a prevalência de obesidade em crianças aumentou dramaticamente. Essa epidemia mundial tem consequências importantes, incluindo transtornos psiquiátricos, psicológicos e psicossociais na infância e maior risco de desenvolvimento de doenças crônicas não transmissíveis (DCNT) mais tarde na vida ${ }^{1}$ O tratamento da obesidade é difícil e as crianças com excesso de peso tendem a se tornar adultos com obesidade 2 . Desde 2016, a Organização Mundial da Saúde (OMS) classificou a obesidade infantil como um dos mais sérios desafios de saúde pública do século $21^{3}$. O aumento global do excesso de peso na população tem demandado ações governamentais voltadas à prevenção dos impactos à saúde gerados pela obesidade. Essas tendências levaram os estados membros da OMS ${ }^{4}$ a endossar a meta de Nenhum aumento da obesidade na infância até 2025.

Geralmente, a obesidade infantil é impulsionada pela interação da nutrição e atividade física influenciada por fatores socioecológicos. Essa interação apresenta diferentes desafios e oportunidades de ação ao longo do curso de vida. Fatores bem reconhecidos relacionados à inatividade física e ao gasto energético reduzido que contribuíram para a epidemia global de obesidade incluem uma redução da caminhada devido ao maior uso de transporte motorizado, um declínio nas atividades físicas ocupacionais como consequência do aumento da automação e uso de tecnologia, e um aumento no tempo de lazer despendido com comportamentos sedentários. O estilo de vida sedentário é alto na América Latina e no Caribe (ALC). Um estudo de coorte de nascimentos em Pelotas, Brasil, mostrou 58\% de estilos de vida sedentários entre os jovens, caracterizados por excesso de TV e falta de atividade física ${ }^{5,6,7}$. De forma alarmante, $43 \%$ dos adultos e adolescentes da América Latina foram classificados como inativos, indicando que a região 
é a mais inativa do mundo,10. Resultados semelhantes foram observados por Gaskin et al8 em um estudo escolar com crianças de 9-11 anos de idade em Barbados. De forma alarmante, $43 \%$ dos adultos e adolescentes da América Latina foram classificados como inativos, indicando que a região é a mais inativa do mundo, 90

Mudanças na dieta têm ocorrido em paralelo e em causalidade bidirecional, com mudanças no amplo sistema alimentar - o conjunto de cadeias de abastecimento das fazendas, através dos segmentos intermediários de processamento, atacado e logística, aos segmentos downstream de varejo e food service (restaurantes e redes de fast food) ${ }^{11}$. Isso se reflete em maiores quantidades e variedade de alimentos densos em energia disponíveis; níveis crescentes de promoção e comercialização de alimentos com alto teor de energia; oportunidades de compra de alimentos mais frequentes e difundidas; aumento do uso de restaurantes e lojas de fast food; Porções maiores de alimentos oferecendo melhor "valor" pelo dinheiro; maior frequência de ocasiōes de comer; aumento do uso de refrigerantes para substituir a água, por ex. nas escolas ${ }^{7,8}$.

\section{Contexto da obesidade infantil na América Latina e no Caribe}

Atualmente, a região da América Latina e do Caribe, com a maior prevalência de sobrepeso e obesidade do mundo, enfrenta uma combinação de importantes problemas de saúde e sedentarismo relacionados à dieta acompanhados de enormes custos econômicos e sociais. As mudanças na dieta são profundas, com mudanças rápidas observadas em direção a níveis muito altos de sobrepeso e obesidade em todas as idades, juntamente com, em alguns países, altas cargas de atraso de crescimento. Embora os países latino-americanos tenham avançado na redução da desnutrição e das deficiências de micronutrientes, faltam políticas abrangentes e intersetoriais para enfrentar a obesidade..$^{12}$

A prevalência estimada de obesidade em 2014 foi de $21,7 \%$ em crianças latino-americanas com menos de 20 anos ${ }^{13,14,15}$. Níveis mais baixos de excesso de peso em crianças menores de cinco anos foram relatados pela $\mathrm{OMS}^{15} \mathrm{em}$ 2013 nas regiões da América Latina e Caribe, com pouca mudança nos 13 anos anteriores; mas países com grandes populações, como Argentina, Brasil, Chile, 
Peru e Bolívia, observaram níveis de aumento de $7 \%$ ou mais ${ }^{16}$. No final de 2010, a prevalência relatada de $14 \%$ em crianças caribenhas na faixa etária abaixo de cinco anos era ainda maior do que para a América Latina; e chegava a $27 \%$ nas meninas e $33 \%$ nos meninos em crianças de 11 a 13 anos $^{17}$.

Para prevenir e controlar especificamente a obesidade em crianças menores de cinco anos, a Assembleia Mundial da Saúde em 2012 aprovou um plano de implementação abrangente para a nutrição materna, infantil, compreendendo seis metas nutricionais para 2025; a quarta meta é "nenhum aumento no excesso de peso na infância em $2025^{\prime 18}$. Nesse contexto, a força-tarefa forneceu várias informações e recomendações claras ao consumidor, tais como:

a) rotulagem de alimentos;

b) encorajando as empresas de alimentos a fornecer alimentos mais nutritivos e com menos energia para crianças e a desenvolver critérios para publicidade que promovam uma alimentação mais saudável;

c) para melhorar a nutrição materna e incentivar a amamentação de bebês;

d) projetar instalações recreativas seguras e bairros com locais mais seguros;

e) incentivar as escolas a promulgar políticas coerentes de alimentação, nutrição e atividade física;

f) encorajar todos os profissionais de Saúde a participarem do desenvolvimento de programas de saúde pública.

Em conformidade com essas recomendações de diretrizes, a LAC tem trabalhado em conjunto para implementar essas políticas de saúde pública. Foi na década seguinte que a Organização Pan-Americana da Saúde (OPAS, 2014) publicou um Plano de Ação para a prevenção da obesidade em crianças e adolescentes nas Américas (disponível em https://www.paho.org/bra/images/ stories/ UTFGCV/planofactionchildobesity-por.pdf?ua=1). Também em 2014, um plano de ação complementar foi publicado pela Agência Caribenha de Saúde Pública (CARPHA), disponível em https://www.paho.org/nutricionydesarrollo/wp-content/uploads/2014/09/ Plano-de-Acao-para-Prevencao-da-Obesidade-em-Criancas-e-Adolescentes.pdf. Esses dois documentos seguiram as recomendações da Força-Tarefa de Obesidade Interna de 2004. Mas por que demorou uma década para que essas políticas fossem adotadas pelas regiões? Quais foram os desafios encontrados para chegar a esse ponto? Onde estamos agora? Este capítulo tentará abordar essas questões. 


\section{Políticas Públicas para Enfrentar a Obesidade Infantil na Região da América Latina.}

Altos níveis de obesidade infantil na América Latina ( $A L)$ são impulsionados por altos níveis de urbanização, cerca de $80 \%{ }^{19}$, limitação de espaço e tempo para atividades físicas, e a transição nutricional que é caracterizada pelo aumento da ingestão de alimentos densos em energia e açúcar Sweetened Beverages (SSB) desde 1900. Isso é acompanhado por acesso fácil e conveniente a alimentos altamente processados e com alto teor de gordura e açúcar. Foi demonstrado que a insegurança alimentar, que é uma proxy das disparidades econômicas, está associada à prevalência da obesidade na $\mathrm{AL}$, com os países da AL apresentando algumas das maiores disparidades de renda do mundo, apesar de um desenvolvimento econômico significativo 19,20,21. No entanto, a América Latina tem liderado a implementação de programas para reduzir a obesidade infantil14,19,22,23. Esses programas podem ser agrupados em duas categorias: dieta, nutrição e programas de atividade física.

\section{Políticas Relacionadas à Dieta e Nutrição na América Latina}

A seguir estão algumas políticas fiscais e não fiscais proeminentes na América Latina que mostraram reduzir a ingestão de alimentos ricos em energia e pobres em nutrientes ${ }^{12,23}$.

1. O imposto especial sobre bebidas adoçadas com açúcar (SSBs) no México

2. Requisitos para embalagem frontal no Chile, Equador e México

3. Políticas que restringem a comercialização de SSBs não alcoólicos com alimentos de alto teor calórico e baixo teor de nutrientes para crianças na Bolívia, Brasil, Chile, Colômbia, Equador, México, Peru e Uruguai;

4. Incentivos econômicos para o consumo de alimentos saudáveis no Chile, Colômbia, Costa Rica, Equador, Peru e Uruguai;

5. Remoção de ácidos graxos trans de alimentos processados na Argentina, Brasil, Chile, Costa Rica, México.

O imposto especial de consumo sobre o SSBs foi baseado em pesquisas importantes que mostram que a alta densidade energética da dieta infantil e 
que o SSBs são as principais fontes de adição de açúcar ${ }^{24}$. Estudos de pesquisa também criaram suporte baseado em evidências para a tributação de SSBs, especificamente que um aumento de $10 \%$ no preço estava associado a uma redução de $11,6 \%$ na demanda, onde os principais substitutos eram água e leite. Esses resultados foram divulgados em conferências, publicações e apresentados a órgãos como Congresso e Ministério da Fazenda e estão em fase de monitoramento e avaliação $0^{23}$.

Embora vários países tenham criado políticas relacionadas à rotulagem de alimentos, muitos outros ainda precisam desenvolver qualquer forma de política ou regulamentação. Mesmo entre aqueles em que existe alguma forma de diretrizes regulatórias, nem todos possuem padrões de rotulagem nutricional obrigatórios. No Chile e no Equador, as políticas de rotulagem na frente da embalagem mostraram- se eficazes, com 95\% das mães de crianças e adolescentes em idade pré-escolar entrevistados concordando que o Ministério da Saúde está ajudando os consumidores a identificar alimentos não saudáveis. Outras Diretrizes para Rotulagem da Frente de Embalagem, como no caso do México, mostraram falta de clareza e transparência?.

Embora a remoção de ácidos graxos trans (TFAs) do suprimento de alimentos tenha sido identificada pela OMS como uma intervenção de saúde pública 'best-buy' para países de baixa e média renda ${ }^{23}$, muitos países da América Latina ainda não o fizeram a inclusão da remoção de TFAs como uma meta de monitoramento global devido a preocupações sobre a viabilidade, alcançabilidade e efeito de saúde pública de removê-los do abastecimento alimentar. A Argentina é um dos poucos países da América Latina que criou regulamentos de políticas eficazes para restringir os TFAs na dieta. O governo iniciou regulamentações obrigatórias que especificam que os TFAs em alimentos não devem exceder $2 \%$ do total de gorduras em óleos vegetais e margarinas para consumo direto e $5 \%$ do total de gorduras em outros alimentos. A Argentina também tem pesquisado e fiscalizado com eficácia a conformidade da indústria com essas regulamentações. A política foi avaliada posteriormente por um estudo de modelagem que previu os benefícios traduzíveis para a saúde, dessa intervenção, criando evidências científicas adicionais para apoiar essa política²3. 


\section{Programas de atividade física na América Latina}

Na América Latina, as intervenções de Atividade Física (AF) nas escolas e as Ciclovias (ruas abertas) têm sido as principais estratégias para combater a inatividade física e aumentar o gasto de energia. Um Guia de Intervenção Útil para Atividades na AL (GUIA) foi iniciado desde 2005 para examinar e promover estratégias baseadas em evidências com o objetivo de aumentar a $A F$ na $A L^{6,25}$. A AF na escola foi identificada como uma intervenção e um corpo de evidências forte o suficiente para fazer uma recomendação de prática.

Em 2010, foi realizada uma revisão sistemática de 5 intervenções em escolas6. Um estudo foi realizado no Brasil, dois estudos no Chile e dois foram realizados na fronteira dos EUA/México. Três estudos usaram desenho de grupo randomizado e dois não usaram randomizado com um grupo de comparação. A revisão demonstrou aumentos positivos consistentes em PA em todos os três estudos randomizados. Os autores concluíram que os resultados fornecem ímpeto para implementar intervenções de AF em escolas de alta qualidade na região; e que a melhoria da qualidade da AF nas escolas depende de capacitação e treinamento para professores e instrutores de Educação Física (EF), mudanças apropriadas no currículo de EF, infraestrutura adequada incluindo equipamentos e materiais, e ajustes a várias características políticas, culturais e socioeconômicas .

Quase oito anos após o início do GUIA, outras revisões ${ }^{25,26}$ ainda estavam no estágio de fazer recomendações de que as intervenções na escola deveriam ser promovidas como um componente importante para programas integrados, políticas e estruturas de monitoramento projetadas para reverter a infância obesidade na região.

A estratégia Ciclovías (ruas abertas) tem sido a política de AP dominante na região da $\mathrm{AL}$. Isso envolve o fechamento temporário de ruas ao trânsito motorizado para transformá-las em espaços seguros para atividades como lazer de bicicleta, caminhada, corrida e participação em eventos sociais, de promoção da saúde e culturais. Com base no sucesso das Ciclovías em Bogotá, este programa se espalhou para 461 cidades em LA, conforme mostrado na Figura $1^{23}$. 
Figura 1 - Crescimento exponencial das Ciclovías ao longo do tempo nas cidades latino-americanas.

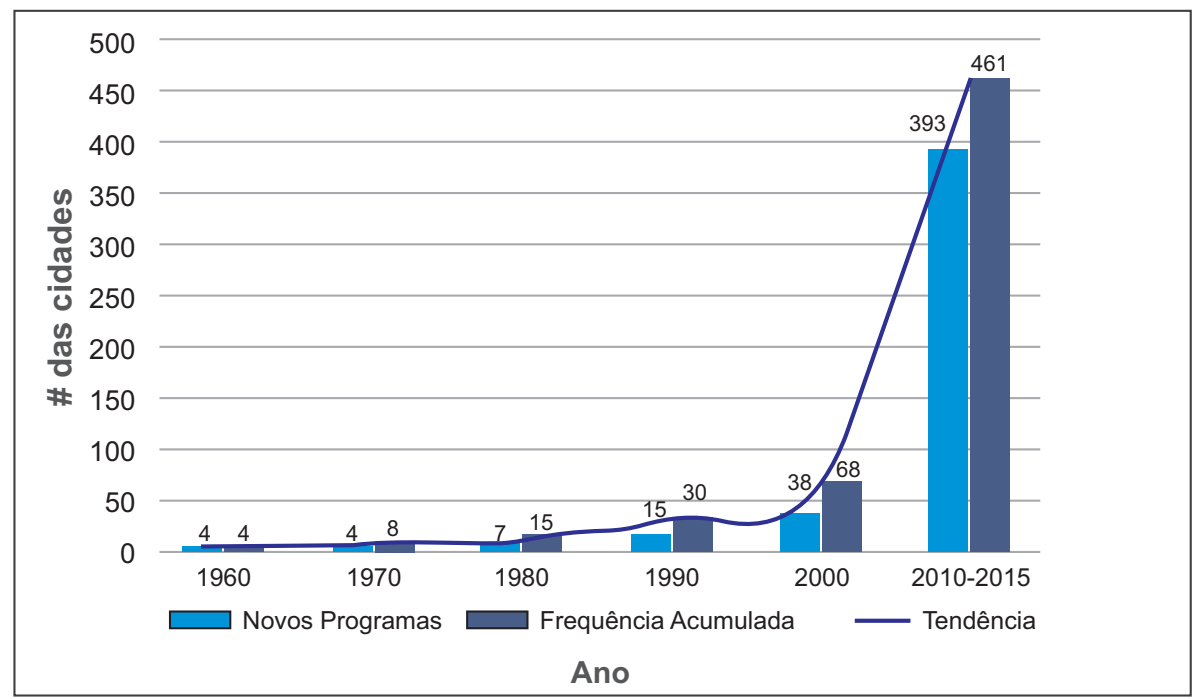

Fonte: Adaptado de Pérez-Escamilla et $a^{23}$.

\section{Políticas públicas para lidar com a obesidade infantil na região do Caribe}

Em uma reunião da CARICOM em 2013, a região do Caribe definiu um plano de ação alinhado com o Plano de Ação Global para a Prevenção e Controle de Doenças Crônicas Não Transmissíveis 2013-2020 e um Plano de Implementação Abrangente anterior sobre Nutrição Materna, Infantil e Infantil 2012. Ambos consideraram o uso de impostos e subsídios como políticas básicas de base populacional para permitir escolhas alimentares saudáveis e combater a obesidade e o diabetes ${ }^{27,28}$. A partir dessa reunião de líderes da CARICOM, foi desenvolvido um Plano de Ação de 6 pontos. Este Plano de Ação para a Promoção de Pesos Saudáveis no Caribe: Prevenção e Controle da Obesidade Infantil (2014-2019), estabeleceu metas para a região do Caribe e desenvolveu scorecards para monitorar e avaliar cada ilha caribenha no cumprimento das metas ${ }^{29,30}$.

A maioria das políticas implementadas na região do Caribe foi baseada na nutrição. A aplicação de estratégias fiscais é muito menor no Caribe em 
comparação com a AL. Alguns dos principais programas de políticas dos países do Caribe em resposta à epidemia de obesidade infantil são:

a) O Padrão Regional da CARICOM: Especificação para rotulagem de alimentos pré-embalados: Não há informações disponíveis sobre se a política foi implementada em algum país do Caribe ${ }^{27}$.

b) Plano Estratégico Nacional de Prevenção e Controle de Doenças Crônicas Não Transmissíveis (DCNT): Um dos objetivos desta política é reduzir a prevalência de obesidade em crianças e adolescentes. As áreas de ação incluem a promoção da nutrição materna e infantil, que inclui a promoção do aleitamento materno exclusivo por seis meses, programas de saúde e nutrição nas escolas e a inclusão da nutrição no currículo escolar. Essa política foi adotada na Jamaica. Embora exista uma política semelhante disponível em Trinidad e Tobago, Bahamas, Guiana, Barbados, Granada, São Vicente, Granadinas, São Cristóvão e Névis, não há informações disponíveis sobre se esses programas foram implementados com êxito ${ }^{27}$.

c) Plano Nacional de Ação para Prevenção e Controle da Obesidade Infantil: Esta política foi elaborada para operacionalizar as atividades de prevenção da obesidade do Plano Estratégico e de Ação Nacional para a Prevenção e Controle de DNTs. Foi adotado em Barbados. A Jamaica também tem essa política, mas não há informações disponíveis sobre sua implementação. O objetivo desta política é reverter a tendência de aumento da obesidade por meio da promoção do aleitamento materno exclusivo por 6 meses, reduzindo a prevalência de baixa atividade física em adolescentes e implementando programas de saúde e nutrição na escola e também incluindo nutrição no currículo escolar ${ }^{27}$.

d) Política Nacional de Alimentação de Bebês e Crianças Pequenas: Esta política foi adotada na Jamaica. Serve para aumentar o acesso ao apoio à amamentação nas comunidades e no local de trabalho e para alcançar o status de Hospital Amigo da Criança em todas as instituições que oferecem serviços de maternidade e saúde infantil. Cinco outros países também implementaram a Iniciativa Hospital Amigo da Criança (IHAC) e têm políticas de nutrição nas escolas, e vários estavam em processo de implementação de legislação sobre a comercialização de substitutos do leite materno ${ }^{27}$. São Vicente e Granadinas tem 
um Plano de Ação Nacional para Bebês e Crianças Pequenas e uma Política Nacional de Amamentação, e a Dominica também tem uma política de amamentação (Política de Amamentação da Comunidade de Dominica), que foi adotada desde 1993 e posteriormente revisada em 1999. Grenada tem uma Política de Nutrição Escolar com metas semelhantes às listadas acima27.

e) Defesa da Sociedade Civil - Plano de Ação 2017-2021 da Coalizão Caribenha Saudável (HCC): Prevenção da Obesidade Infantil no Caribe (CSAP): O HCC é uma organização não governamental que compreende membros de todas as associações e sociedades que defendem a prevenção da obesidade em crianças. A coalizão tem atuado como elo entre a sociedade civil, o setor privado e o governo em um esforço para ter uma abordagem coesiva multissetorial para a epidemia de obesidade infantil. Esse tipo de cidadania no Caribe exemplifica o papel das parcerias público-privadas na luta contra a obesidade infantili29.

f) Intervenções fiscais: em 2015, Barbados foi o primeiro país do Caribe e o décimo país do mundo a implementar um imposto especial sobre bebidas açucaradas. Eles introduziram um imposto especial de consumo de $10 \%$ sobre todas as bebidas adoçadas com açúcar ${ }^{29}$. Poucos meses depois, Dominica aplicou um imposto especial de consumo de $10 \%$ sobre bebidas açucaradas e alimentos com alto teor de açúcar, como chicletes e barras de chocolate ${ }^{31}$. Vários países também implementaram subsídios para frutas e vegetais locais ${ }^{27}$. No entanto, até o momento, não há países do Caribe com regulamentos em vigor que proíbam a comercialização de alimentos não saudáveis para crianças ${ }^{27}$.

\section{Desafios de políticas públicas na América Latina e no Caribe}

Todas as políticas de nutrição estão disponíveis para cada país pela OMS: Banco de dados global sobre a implementação de ações nutricionais (GINA)27. Uma olhada neste site mostra que muitas das políticas, incluindo aquelas destinadas a reduzir a obesidade infantil na ALC, não foram adotadas ou não há informações disponíveis. Isso aponta para a fraqueza na implementação, monitoramento e avaliação, conforme destacado em um workshop recente realizado em 2014 com o apoio do Instituto Nacional de Saúde dos EUA. No 
workshop, uma agenda para pesquisa regional e parceria estratégica para prevenir a obesidade infantil na AL foi examinada. Muitas lacunas e oportunidades foram reveladas em quatro publicações ${ }^{14,19,22,23}$ dos anais do workshop. Isso é quase 12 anos após o GUIA e cinco anos após definir a meta da OMS de "Nenhum aumento da obesidade infantil em 2025"18. Não é surpresa que os membros do workshop resumiram o progresso para abordar a crescente epidemia de obesidade infantil como lento e inconsistente.

\section{Lacunas de pesquisa}

Apesar da implementação bem-sucedida de alguns programas de políticas para prevenir e reduzir a obesidade infantil na América Latina, evidências científicas limitadas impedem o desenvolvimento e implementação de intervenções eficazes mais inovadoras em toda a região ${ }^{19}$. As evidências locais, culturalmente apropriadas, que levem em consideração as particularidades do ambiente alimentar e de atividade física da região, são necessárias para determinar as ações mais eficazes para a prevenção da obesidade ${ }^{32}$.

Muitos países têm disponibilidade limitada de dados devido à falta de sistemas sistemáticos de informação nutricional. Em muitos países da região, as informações sobre indicadores do estado nutricional, como indicadores antropométricos e bioquímicos, bem como biomarcadores do estado de micronutrientes, estão desatualizadas ou inexistentes ${ }^{12}$. Isso inibe o processo de tomada de decisão informada e oportuna e a formulação de intervenções nutricionais direcionadas entre as populações vulneráveis. Os inquéritos de saúde e nutrição disponíveis são representativos a nível nacional, usando metodologias padronizadas e amostras probabilísticas. No entanto, por não serem realizados de forma sistemática e, muitas vezes, em intervalos de tempo diferentes, há dificuldade em fazer comparações e tirar conclusões a partir dos dados ${ }^{12}$.

A capacidade de pesquisa para prevenção da obesidade infantil em LA foi revisada por Parra et al ${ }^{14}$. Os autores notaram que o número muito baixo de estudos de intervenção de publicação e quase ausência de pesquisa de política sugere uma falta de capacidade de pesquisa relevante. Da mesma forma, nos países do Caribe, a escassez de literatura publicada sobre algumas intervenções torna difícil traduzir essas descobertas em políticas. Dado que a pesquisa é fundamental para compreender, monitorar e implementar 
estratégias, políticas e programas para enfrentar a epidemia de obesidade, recomenda-se que haja uma demanda para aumentar a capacidade de pesquisa e incluir mais pesquisa translacional e implementação nos portfólios do país ${ }^{13}$. Por exemplo, embora haja fortes evidências que apoiam a intervenção de AF nas escolas para prevenir a obesidade infantil em LA desde 2005, isso não se tornou uma política. Os desafios para alcançar essa ação podem estar relacionados à necessidade de pesquisas futuras para identificar outros elementos-chave práticos, como legislação, política, barreiras e facilitadores para a promoção da EF nas escolas ${ }^{6}$. Além disso, as publicações de pesquisas mostram poucas colaborações aparentes entre os países da $\mathrm{AL}^{14}$, o que também observamos no Caribe. Outra área sobre a qual há muito pouca informação para a região é o efeito da nutrição materna e do baixo crescimento intrauterino predispondo ao desenvolvimento de obesidade na prole $^{33}$. A intervenção antes e durante a gravidez tem o potencial de reduzir a prevalência de obesidade em crianças ${ }^{34}$.

\section{Tabelas de Composição de Alimentos}

Na América Latina e no Caribe, há uma necessidade específica de medição detalhada dos alimentos e atividades e do gasto/composição alimentar ou energética subjacente para esses itens para informar os programas e o planejamento de políticas para a prevenção da obesidade infantil. As bases de dados atuais fornecem dados limitados e em alguns casos questionáveis sobre a qualidade dos macronutrientes, nutrientes e ingredientes, especialmente para muitos alimentos e bebidas produzidos localmente. Para criar medidas precisas de composição de alimentos, pesquisas dietéticas nacionais e tabelas de composição de alimentos atualizadas são necessárias. O projeto INFORMAAS ${ }^{22}$ está documentando e criando bancos de dados limitados de alimentos e bebidas com código de barras no Brasil, Chile, México e outros países da América Latina e em países selecionados, como México, Brasil, Colômbia e Chile e esforços de avaliação estão coletando bancos de dados completos de todos os alimentos processados embalados. Embora todos os países da região coletem dados de receita e despesa, existem apenas alguns países em que os estudiosos usam esses dados para análises nutricionais, o que se deve em parte aos dados limitados que fornecem. Análises químicas dos alimentos são necessárias para validar alguns desses dados ${ }^{22}$. 
A vigilância aprimorada por meio de pesquisas representativas em nível nacional ou subnacional, em combinação com tabelas aprimoradas de composição de alimentos, permitiria aos pesquisadores compreender melhor as dietas na América Latina ao longo do ciclo de vida e em diferentes subgrupos demográficos. Como resultado, a análise poderia determinar quais alimentos nas dietas locais são os mais responsáveis pela ingestão excessiva de energia e os impactos de vários alimentos e outros fatores, incluindo o contexto e o momento da ingestão de alimentos e bebidas, no apetite e na saciedade. Tecnologias para diminuir o tempo e despesas necessários para a coleta de dados dietéticos são urgentemente necessárias; assim como os dados de atividade física, as medidas agregadas são inadequadas para desenvolver políticas e programas de prevenção da obesidade infantil22.

\section{Monitoramento e avaliação das políticas implementadas}

Os programas implementados precisam ser monitorados e avaliados continuamente. Este tem sido um ponto fraco na maior parte da ALC. Essa falta de monitoramento impede a identificação precoce de barreiras relacionadas à implementação, acesso e utilização dos serviços de saúde, bem como ao cumprimento e cobertura. As informações sobre recursos humanos e financeiros para a implementação de ações de nutrição são escassas na região e há uma flagrante falta de relatórios abrangentes e artigos revisados por pares sobre a avaliação dessas políticas. Na maioria dos países da ALC, o monitoramento de programas ou vigilância do estado nutricional como parte dos esforços para avaliar a implementação de ações de nutrição é uma parte fraca ou ausente dos sistemas de informação em saúde ${ }^{12}$.

Há também uma falta geral de informações publicadas sobre a implementação e avaliação de políticas e programas e sobre recursos humanos e financeiros para as metas de nutrição. Recentemente, Ribeiro et al ${ }^{6}$ apontaram que muitas intervenções promissoras de AF estão sendo realizadas na $A L$, mas sua eficácia geralmente não foi avaliada. No Caribe, o desenvolvimento do scorecard caribenho sobre obesidade infantil (COPS) buscou fornecer monitoramento e vigilância de vários programas escolares e de obesidade infantil que foram iniciados. No entanto, a eficácia dos programas também não foi avaliada ${ }^{30}$. 


\section{Governo e partes interessadas}

As políticas e ações de nutrição são apoiadas por estruturas regulatórias, mas os países não têm capacidade para monitorar e fazer cumprir sua implementação. Em grande parte, isso se deve à falta de conscientização ou de "adesão" dos sucessivos governos da região. Esta falta geral de conscientização dos governos e agências de cooperação quanto à importância e necessidade de identificar e alocar financiamento adequado para a implementação de sistemas de informação sustentáveis resulta em ambientes com poucos recursos para a ampliação de intervenções comprovadas e limitada aceitação e promoção de iniciativas de políticas. Consequentemente, isso resultou em longos atrasos na transferência de programas e iniciativas para documentos de política. A falta de vontade política é um grande impedimento na implementação e monitoramento de políticas. Além disso, existe uma percepção por parte do governo de uma alta carga regulatória para a implementação de políticas, resultando na falta de financiamento para atividades de monitoramento e avaliação de políticas. Isso é particularmente desafiador para a América Latina e a região do Caribe, que compreende países de baixa e média renda. Digno de nota é que os países da América Latina apresentam algumas das maiores disparidades de renda do mundo, apesar do desenvolvimento econômico significativo ${ }^{19,20,21}$. Portanto, não é surpreendente que a insegurança alimentar tenha sido associada à obesidade em alguns países da América Latina. A insegurança alimentar pode levar à obesidade não apenas pelo consumo do excesso de energia de alimentos ricos em energia baratos e facilmente disponíveis, mas também em relação à desnutrição prévia ${ }^{16}$.

Embora a maioria dos países da AL e do Caribe tenha estabelecido políticas nacionais de segurança alimentar e nutricional, os mecanismos de coordenação entre os níveis nacional, regional e local devem ser fortalecidos. As metas e ações nutricionais não foram totalmente incorporadas às políticas de desenvolvimento nacional ou de redução da pobreza ${ }^{12}$.

\section{Desafios do setor privado}

O lobby de entidades que se opõem às mudanças nas políticas, como a indústria de alimentos, representa um dos maiores desafios para a criação de políticas públicas em todo o mundo e a ALC não é exceção. Grupos de interesses especiais jogaram com os temores do público, particularmente o medo da perda de oportunidades 
econômicas, como munição contra a implementação de muitas políticas. Em particular, a indústria de bebidas é um parceiro vital na redução do teor de açúcar das bebidas vendidas no mercado. Globalmente, a indústria de bebidas tem resistido aos esforços para implementar impostos sobre o açúcar e isso tem influenciado muito os mercados da América Latina e do Caribe. Com base na experiência, Barbados recomenda que os formuladores de políticas procurem envolver as partes interessadas, como os setores agrícola e manufatureiro, antes da implementação da política para abordar as preocupações e dissipar os temores em setores que se opõem à introdução de impostos sobre bebidas adoçadas com açúcar ${ }^{29}$.

De maneira semelhante, a introdução das Ciclovias encontrou alguma resistência de empresas e outros setores, incluindo empresas de transporte que foram afetadas pelo fechamento de estradas ${ }^{23}$. Na maioria dos casos, esses desafios foram superados pelo fornecimento de práticas recomendadas baseadas em evidências para a implementação das Ciclovias, juntamente com a forte participação da sociedade civil, destacando novas oportunidades de desenvolvimento econômico para proprietários de pequenos negócios ${ }^{23}$.

\section{Advocacia da sociedade civil}

Há também o desafio de criar, no nível da comunidade, uma atitude consciente com a saúde e mudanças de comportamento. Enquanto no Caribe o HCC atua como um defensor civil vibrante e cão de guarda, na América Latina, tem havido dificuldade em angariar o apoio de defensores informados e apoiadores de alcance público em nível regional que podem influenciar a percepção pública por meio da difusão de informações e mensagens concisas ${ }^{23}$. Os governos e as partes interessadas precisam promover 0 engajamento da sociedade civil para fortalecer a responsabilidade social ${ }^{12}$.

\section{Considerações finais}

Aqui, muitas tentativas de abordar a obesidade infantil na ALC foram discutidas, mostrando resultados variados, enquanto a prevalência permanece alta. Os desafios para abordar este grande problema de saúde incluem a falta de evidências robustas para informar os programas de implementação 
e, mesmo quando implementados, muitas vezes há monitoramento e avaliação inadequados, o que é uma barreira para se traduzir em políticas. A pesquisa de políticas prospectivas pode ser útil para o avanço da tradução do conhecimento ${ }^{23}$. Geralmente, em cada etapa do processo, mais publicações de pesquisa são necessárias não apenas para informar a implementação, mas para fornecer conhecimento dos programas implementados, ampliados para a política e seus exitos.

Além disso, é importante a influência de fatores socioecológicos, indicando que é necessária uma abordagem multissetorial. Em 2018, na 39ª Cúpula, Chefes de Governo e de Estado da CARICOM, o coordenador residente da ONU indicou que, para uma abordagem multissetorial bem-sucedida de combate à obesidade, é necessário que haja os 3Ps - Vontade política, a política pública certa e parceiros intersetorial. Esse princípio também é enfatizado na $\mathrm{AL}$, conforme destacado por Mariachiara et al ${ }^{4}$, que o trabalho de governos, sociedade civil, empresas privadas e outras partes interessadas importantes deve ser bem coordenado para enfrentar a epidemia. Se essa abordagem for implementada em todos os níveis, haverá menos barreiras para lidar com a obesidade infantil na região. A colaboração entre os países em regiões separadas também pode ser uma vantagem.

\section{Referências}

1. Gupta N, Goel K, Shah P, Misra A. Childhood obesity in developing countries: epidemiology, determinants, and prevention. Endocr Rev. 2012;33(1):48-70).

2. Guo SS, Wu W, Chumlea WC, Roche AF. Predicting overweight and obesity in adulthood from body mass index values in childhood and adolescence. Am J Clin Nutr. 2002;76(3):653-8.

3. Organization WH. Childhood overweight and obesity. 2016.

4. Di Cesare M, Sori M, Bovet P, Miranda JJ, Bhutta Z, Stevens GA, et al. The epidemiological burden of obesity in childhood: a worldwide epidemic requiring urgent action. BMC Med. 2019 Dec;17(1):212.

5. Hallal PC,Wells JCK, Reichert FF, Anselmi L, Victora C. Early determinants of physical activity in adolescence prospective birth cohort study. BMJ: doi:10.1136/ bmj.38776.434560.7C.)

6. Ribeiro IC, Parra DC, Hoehner CM, Soares J, Torres A, Pratt M, et al. School - based physical education programs: evidence-based physical activity interventions for youth in Latin America. Glob Health Promot. 2010 Jun;17(2):05-15. 
7. Lobstein et al The International Association for the Study of Obesity. Obesity reviews 5 (Suppl. 1), 4-85.

8. Gaskin PS, Lai P, Guy D, Knight J, Jackson M, Nielsen AL. Diet, Physical Activity, Weight Status, and Culture in a Sample of Children from the Developing World. Journal of Nutrition and Metabolism. 2012; 2012:1-8.

9. Cominato L, Di Biagio GF, Lellis D, Franco RR, Mancini MC, de Melo ME. Obesity Prevention: Strategies and Challenges in Latin America. Curr Obes Rep. 2018 Jun;7(2):97-104.

10. Ng SW, Popkin BM. Time use and physical activity: a shift away from movement across the globe. Obes Rev. 2012;13(8):659-80

11. Popkin BM, Reardon T. Obesity and the food system transformation in Latin America: Obesity and food system transformation. Obesity Reviews. 2018 Aug;19(8):1028-64.

12. Galicia L, Grajeda R, de Romaña DL. Nutrition situation in Latin America and the Caribbean: current scenario, past trends, and data gaps. Rev Panam Salud Publica. 2016 Aug;40(2):104- 13. Galicia L, de DL, Harding KB, De-Regil M, Grajeda R. Tackling malnutrition in Latin America and the Caribbean: challenges and opportunities. Rev Panam Salud Publica. 2016;9.

13. Rivera JA, González de Cossío T, Pedraza LS, Aburto TC, Sánchez TG, and Martorell R. Childhood and adolescent overweight and obesity in Latin America: a systematic review. The Lancet Diabetes-Endocrinology 2014; 2: 321-332. http:// www.thelancet.com/pdfs/journals/landia/PIIS2213-8587(13)70173-6.pdf.)

14. Parra DC, Vorkoper S, Kohl HW, Caballero B, Batis C, Jauregui A, et al. Research capacity for childhood obesity prevention in Latin America: an area for growth: Childhood obesity prevention. Obesity Reviews. 2017 Jul; 18:39-46.

15. Ng M, Fleming T, Robinson M et al. Global, regional, and national prevalence of overweight and obesity in children and adults during 1980-2013: a systematic analysis for the Global Burden of Disease Study 2013. Lancet 2014; 384: 766-781.

16. Published by the Food and Agriculture Organization of the United Nation and the Pan American Health Organization, Santiago de Chile, 2017.

17. Henry F. Obesity prevention: The key to noncommunicable disease prevention and control. http://caribbean.scielo.org/scielo.php?pid=S0043$31442011000400014 \&$ script=sci_arttext\&tlng=en. West Indian Medical Journal, 2011; 60 (4): 446-451.

18. WHO. Global nutrition targets 2025: childhood overweight policy brief (WHO/ NMH/ NHD/14.6). Geneva: World Health Organization; 2014.

19. Caballero B, Vorkoper S, Anand N, Rivera JA. Preventing childhood obesity in Latin America: an agenda for regional research and strategic partnerships: Childhood obesity in Latin America. Obesity Reviews. 2017 Jul;18:3-6.

20. Su D, Esqueda OA, Li L, Pagan JA. Income inequality and obesity prevalence among OECD countries. J Biosoc Sci. 2012; 44(4):417-32. [PubMed: 22214551] 
21. Schlussel MM, Silva AA, Perez-Escamilla R, Kac G. Household food insecurity and excess weight/obesity among Brazilian women and children: a life-course approach. Cad Saude Publica. 2013; 29(2):219-26. [PubMed: 23459802]

22. Kline L, Jones-Smith J, Jaime Miranda J, Pratt M, Reis RS, Rivera JA, et al. A research agenda to guide progress on childhood obesity prevention in Latin America: Child obesity research guide Latin Am. Obesity Reviews. 2017 Jul;18:19-27.

23. Pérez-Escamilla R, Lutter CK, Rabadan-Diehl C, Rubinstein A, Calvillo A, Corvalán C, et al. Prevention of childhood obesity and food policies in Latin America: from research to practice: Obesity research to practice in Latin America. Obesity Reviews. 2017 Jul;18:28-38.

24. Sánchez-Pimienta TG, Batis C, Lutter CK, Rivera JA. Sugar-Sweetened Beverages Are the Main Sources of Added Sugar Intake in the Mexican Population. The Journal of Nutrition. 2016; 146(9): 1888S-1896S. [PubMed: 27511931]

25. Hoehner CM, Ribeiro IC, Parra DC, Reis RS, Azevedo MR, Hino AA, et al. Physical Activity Interventions in Latin America. American Journal of Preventive Medicine. 2013 Mar;44(3):e31-40.

26. Holub CK, Elder JP, Arredondo EM, Barquera S, Eisenberg CM, Sánchez Romero LM, et al. Obesity Control in Latin American and U.S. Latinos. American Journal of Preventive Medicine. 2013 May;44(5):529-37.

27. World Health Organization, Global Database on the Implementation of Nutrition Action (GINA). [Accessed on 15 July 2020]. Available at https://extranet.who.int/ nutrition/gina/en/policies/summary.

28. WHO | Fiscal policies for diet and the prevention of noncommunicable diseases [Internet]. WHO. [cited 2020 July 2020]. Available from: http://www.who. int/ dietphysicalactivity/publications/fiscal-policies-diet-prevention/en/)

29. HCC Brief: A Closer Look, The Implementation of Taxation on Sugar-Sweetened Beverages by the Government of Barbados [Internet]. Healthy Caribbean Coalition. 2016 [cited 12 July 20202]. Available from: http://www.healthycaribbean. org/hcc- brief-taxation-sugar-sweetened-beverages-barbados/)

30. www.healthycaribbean.org > cop > cop-scorecard

31. Commonwealth of Dominica. Excise Tax (Amendment) Order, 2015. [Accessed 12 July 2020]. Available from: https://untobaccocontrol.org/impldb/wp-content/ uploads/reports/dominica_2016_annex6_excise_tax_2015.pdf

32. Banna J. Obesity Prevention in Children in Latin America Through Interventions Using Technology. American Journal of Lifestyle Medicine. 2019 Mar;13(2):138-41.

33. Schroeder DG, Martorell R, Flores R. Infant and child growth and fatness and fat distribution in Guatemalan adults. Am J Epidemiol. 1999;149(2):177-185.

34. James WP. The epidemiology of obesity: the size of the problem. J Intern Med. 2008;263(4):336-352. 


\section{Capítulo 4}

\section{POLÍTICA DE SEGURANÇA ALIMENTAR E NUTRICIONAL NO BRASIL: FOCO NO ENFRENTAMENTO DA DEFICIÊNCIA DE MICRONUTRIENTES}

Wendell Costa Bila ${ }^{1}$, Joel Alves Lamounier ${ }^{2}$, Inocencia Palmira Peralta López ${ }^{3}$, Ana María Lozano Alemán ${ }^{4}$, Camilo Adauton Mariano da Silva ${ }^{5}$

${ }^{1}$ Educador Físico. Doutor em Ciências da Saúde. Docente Faculdade Pitágoras - Unidade Divinópolis, Minas Gerais, Brasil. Docente Universidade UNIFENAS, Brasil.

2 Pediatra. Nutrólogo. Mestre em Bioquímica e Imunologia e Doutor em Saúde Pública e Nutrição. Chefe do Departamento de Medicina. Universidade Federal de São João Del Rei, Minas Gerais, Brasil.

${ }^{3}$ Inocencia Palmira Peralta López. Bioquímica. Docente/Investigadora. Centro Multidisciplinario de Investigaciones Tecnológicas - CEMIT-UMA. Facultad de Ciencias Químicas, Universidad Nacional de Asunción - FCQ, UNA

${ }^{4}$ Ana María Lozano Alemán, Docente/Pesquisador da Universidade Nacional Autônoma de Honduras, Mestre em Saúde Pública, Coordenador Nacional IBFAN Honduras.

${ }^{5}$ Nutricionista. Mestre em Demografia e Doutor em Ciências. Professor Associado da Universidade Federal de Ouro Preto, Minas Gerais, Brasil. Ex-Coordenador de Pesquisa, Avaliação e Monitoramento do Centro Colaborador em Alimentação e Nutrição Escolar (CECANE/UFOP/FNDE).

Resumo:

Neste capítulo, são abordadas as principais questões relacionadas às carências de micronutrientes, no contexto das políticas públicas de enfrentamento da fome e suas consequências para saúde de populações da América Latina e do Caribe (ALC). Descreve as necessidade nutricionais e as consequências da carência ou excesso de macro e micronutrientes na saúde, em especial para o crescimento e desenvolvimento infantil. Discute a questão social vinculada a esses deficiências e a sua associação às desigualdades sociais e a pobreza na América Latina Caribe, países que enfrentam grandes violações de direitos. Aborda as principais políticas de segurança alimentar e nutricional e 
da alimentação saudável na região, além dos programas de governo que atuam no combate a fome.

Palavras-chave: Segurança Alimentar e Nutricional; Direitos nutricionais; Ação integrada de Saúde

\section{Introdução}

\section{Macro e Micronutrientes}

Os macronutrientes são nutrientes que ajudam a fornecer energia necessária em grande quantidade pelo organismo. Água, carboidratos, gorduras e proteínas são classificados como macronutrientes. As proteínas são necessárias para o crescimento, construção e reparação dos tecidos e estão presentes também na constituição das células. Os carboidratos evitam que as proteínas dos tecidos sejam utilizadas para o fornecimento de energia. As gorduras protegem os órgãos contra lesões, ajuda a manter a temperatura do corpo, a absorver algumas vitaminas e sensação de saciedade ${ }^{1-3}$.

Os micronutrientes são os minerais e as vitaminas. O organismo precisa dos micronutrientes em quantidade menor se comparado aos macronutrientes. São nutrientes necessários para a manutenção do organismo, embora sejam requeridos em pequenas quantidades, de miligramas a microgramas. Por serem nutrientes essenciais, devem estar presentes na alimentação diariamente. $\mathrm{O}$ déficit pode provocar doenças ou disfunções e, o excesso, intoxicações. Por isso, a dieta deve ser sempre equilibrada e variada ${ }^{1,2}$.

A principal função é facilitar as reações químicas que ocorrem no corpo. As vitaminas, por exemplo, são essenciais para o funcionamento do metabolismo e regulação da função celular. No grupo das vitaminas, a vitamina B está presente nos vegetais de folhas verdes. A vitamina $C$ é encontrada nas frutas cítricas. Já as vitaminas A, D, E e K estão no leite, produtos lácteos, óleos vegetais e vegetais de folhas verdes. Na categoria dos minerais estão cálcio, potássio, ferro, sódio, magnésio, cobre, zinco, cobalto, cromo e flúor. Os micronutrientes são necessários em todas as etapas e ciclos da vida ${ }^{1,2}$. Neste capítulo, são abordadas as principais questões relacionadas com as carências de micronutrientes na população brasileira, no contexto de políticas públicas de enfrentamento da fome e suas consequências para saúde das pessoas. 


\section{Micronutrientes e necessidades nutricionais}

Os minerais de maior importância para o homem, além do ferro, são o cálcio, fósforo, magnésio, sódio, cloro, potássio, enxofre, zinco, iodo, selênio, cobre, manganês, flúor, cromo, molibdênio e cobalto.

As deficiências desses nutrientes têm consequências para o organismo, podendo, entre outras repercussões, comprometer o crescimento e o desenvolvimento normais. ${ }^{2}$ Além disso, a deficiência dos micronutrientes também acarreta problemas de déficit de crescimento em crianças, sendo as de maior importância as deficiências de vitamina A, C, D, E e de minerais tais como a de cálcio, ferro, magnésio e zinco. ${ }^{4}$

\section{Aspectos Epidemiológicos}

Segundo a FAO, a desnutrição na população mundial, sob o aspecto da insuficiência alimentar, declinou entre 2005 e 2015 e, a partir daí, apresentou um aumento, retornando aos valores de $2011^{3}$. Decorrente desta insuficiência, a desnutrição proteico-energética (DPE), especialmente em crianças, tem sido considerada um importante problema de saúde pública em diversos países do mundo ${ }^{4-7}$. No Brasil, a partir do Estudo Nacional de Despesa Familiar - Endef ${ }^{8}$ até a Pesquisa de Orçamento familiar (POF) de 2008-2009', a desnutrição entre crianças de 5 a 9 anos (altura/idade) reduziu de $29,3 \%$ em para $7,2 \%$. Neste trajeto, outra informação importante diz respeito à prevalência de deficiência de micronutrientes na América Latina e no Caribe. Resultados mostraram que a deficiência de vitamina A pareceu reduzir-se em vários países, a de folato é atualmente quase inexistente e o status de B12 é deficiente na maior parte das regiões. A anemia ferropriva continua sendo um problema de saúde pública para crianças menores de 6 anos e mulheres em idade fértil2.

Dados recentes divulgados pela Pesquisa Nacional por Amostra de Domicílios (Pnad Contínua) do Instituto Brasileiro de Geografia e Estatística (IBGE) $)^{5}$ sinalizam um aumento da extrema pobreza no país em cerca de $11 \%$, de 2016 para 2017 (13,3 para 14,8 milhões de pessoas). Tal incremento da pobreza extrema poderá, sim, refletir-se no aumento do número de pessoas que passam fome no país. No Brasil, os números apontam que, em 2017, mais de 5,2 milhões de pessoas passaram um dia ou mais sem consumir alimentos, o que corresponde a 2,5\% da população. Isso nos coloca em alerta sobre a possibilidade de a fome voltar a assolar as famílias brasileiras mais vulneráveis ${ }^{6}$. 
Com relação às doenças associadas às deficiências de micronutrientes, a Pesquisa Nacional de Demografia e Saúde da Criança e da Mulher, realizada em 20067, reafirmou que as deficiências de ferro e vitamina A ainda persistiam como problemas de saúde pública no Brasil, ou seja, $17,4 \%$ das crianças e $12,3 \%$ das mulheres em idade fértil apresentavam hipovitaminose A, enquanto $20,9 \%$ e $29,4 \%$ desses grupos populacionais, respectivamente, apresentavam anemia por deficiência de ferro ${ }^{8}$. Estes achados classificaram o país segundo os critérios da Organização Mundial de Saúde (OMS) de 1996 em um problema moderado de saúde pública.

\section{Segurança e insegurança alimentar e nutricional - SAN}

Entende-se por política de SAN um conjunto de ações planejadas para garantir a oferta e o acesso aos alimentos a toda a população, promovendo a nutrição e a saúde. Deve ser uma estratégia sustentável, ou seja, desenvolver-se articulando condições que permitam sua manutenção em longo prazo. Requer o envolvimento tanto do governo quanto da sociedade civil organizada, em seus diferentes setores ou áreas de ação- saúde, educação, trabalho, agricultura, desenvolvimento social, meio ambiente, entre outros- e em diferentes esferas (produção, comercialização, controle de qualidade, acesso e consumo) 9,10.

O direito humano à alimentação adequada (DHAA) é reconhecido internacionalmente como uma prerrogativa fundamental da pessoa humana desde 1947. O DHAA é o princípio fundamental da SAN9 Esse direito é violado sempre que pessoas, grupos ou comunidades não têm acesso a alimentos em quantidade e qualidade adequadas para atender suas necessidades nutricionais, o que afeta diretamente o estado nutricional do indivíduo ${ }^{11}$.

Para o Conselho Nacional de Segurança Alimentar e Nutricional (CONSEA), situações de insegurança alimentar e nutricional podem ser detectadas a partir de diferentes tipos de problemas, como a fome, obesidade, doenças associadas à má alimentação e ao consumo de alimentos de qualidade duvidosa ou prejudicial à saúde. A produção predatória de alimentos em relação ao ambiente, os preços abusivos e a imposição de padrões alimentares que não respeitem a diversidade cultural também são provocadores de insegurança alimentar. 
A insegurança alimentar geralmente relaciona-se com a vulnerabilidade social, sendo resultado também de uma combinação de situações que influenciam negativamente na qualidade de vida como desemprego, renda familiar insuficiente, produção e distribuição dos alimentos de forma inadequada, dentre outros aspectos ${ }^{10}$.

Inicialmente, nos anos 2000, a conjuntura motivou não somente a construção de políticas públicas de transferência de renda para combater à fome, mas também políticas focadas no fortalecimento da soberania alimentar, dentre elas o desenvolvimento da produção agrícola familiar e inclusão da mesma no sistema de abastecimento agroalimentar brasileiro. Apesar de alguns avanços, a atual conjuntura ainda revela problemas de SAN com desafios relacionados à elaboração de programas, projetos e ações inovadores ${ }^{11}$.

Para promover a SAN pelos governos existem aparatos legais e estruturas materializadas num Sistema Nacional de Segurança Alimentar e Nutricional denominado SISAN. Por meio desse sistema, instituído pela Lei Nacional $n^{\circ}$ $11.346 / 2006$, a política de SAN é projetada para ser operacionalizada em todas as esferas de governo (Federal, Estadual e Municipal) ${ }^{11}$.

A Comissão Intersetorial de Alimentação e Nutrição é uma das comissões do Conselho Nacional de Saúde (CNS) prevista na Lei $n^{\circ} 8.080 / 90$ e tem por objetivo acompanhar, propor e avaliar a operacionalização das diretrizes e prioridades da Política Nacional de Alimentação e Nutrição (PNAN) e promover a articulação e a complementaridade de políticas, programas e ações de interesse da saúde, cujas execuções envolvem áreas não compreendidas no âmbito específico do Sistema Único de Saúde (SUS). O planejamento das ações que garantam a inocuidade e a qualidade nutricional dos alimentos, controlando e prevenindo riscos à saúde, se faz presente na agenda da promoção da alimentação adequada e saudável e da proteção à saúde. ${ }^{12}$. Implementar e utilizar as boas práticas agrícolas, boas práticas de fabricação, boas práticas nutricionais e o Sistema Análise de Perigos e Pontos Críticos de Controle (APPCC), na cadeia de produção de alimentos, potencializa e assegura as ações de proteção à saúde do consumidor. A rotulagem nutricional dos alimentos constitui-se em instrumento central no aperfeiçoamento do direito à informação ${ }^{12}$. 
A abordagem da segurança alimentar e nutricional contemporânea permite ampliar o estreito quadro dos programas sociais tradicionais, reconhecendo que a população em situação de risco pode ser mais numerosa do que aquela normalmente identificada. Além disso, as políticas de segurança alimentar e nutricional devem trabalhar a necessidade de dar acesso aos alimentos para os grupos inseguros, atendendo às dimensões da quantidade, qualidade e regularidade no consumo de alimentos ${ }^{10}$.

O estudo de Rocha, em 2017 avaliou a anemia e insegurança alimentar e nutricional de famílias de crianças em idade pré-escolar, assim como buscou identificar os padrões alimentares e a sua relação com segurança alimentar e estado nutricional, investigando a relação entre a insegurança alimentar e concentração de hemoglobina de pré-escolares. As famílias apresentaram maior risco de consumo alimentar inadequado, propiciando problemas nutricionais a longo prazo ${ }^{13}$.

A SAN passou a constar da agenda pública do Brasil ocupando de forma crescente lugar de destaque nos debates e nos programas e ações intersetoriais. No entanto, isso se verifica num processo em que convivem diferentes compreensões sobre o tema, cada qual com implicações específicas nos desenhos de investigação, na definição de indicadores de monitoramento e avaliação e na construção de políticas públicas. ${ }^{10}$ Deste modo, a instituição da SAN como uma política nacional, regional e local tem sido um dos focos das ações dos governos em diferentes níveis articulados com a sociedade civil, na formulação, execução, monitoramento e controle de suas ações ${ }^{13}$.

\section{Vigilância alimentar e nutricional}

No setor de saúde, a Vigilância Alimentar e Nutricional (VAN) deve ser entendida como produto de um conjunto de ações que buscam, em última instância, o diagnóstico, a promoção da saúde, a prevenção e a reabilitação de morbidades que tenham, direta ou indiretamente, relação com a alimentação, seja individual ou coletivamente. Dessa forma, inserem-se, nesse escopo, as ações preconizadas pela OMS, como a Atenção Integrada às Doenças Prevalentes na Infância (AIDPI) ${ }^{14}$, as ações de monitoramento do crescimento e desenvolvimento infantil ${ }^{15-17}$, as ações relativas à atenção 
materna ${ }^{18} \mathrm{e}$ as doenças agudas ou crônico-degenerativas preconizadas pelo Ministério da Saúde para todas faixas etárias.

A vigilância alimentar e nutricional consiste na descrição contínua e na predição de tendências das condições de alimentação e nutrição da população e seus fatores determinantes ${ }^{12}$. Assim, entende-se por atitude de vigilância a abordagem e a subsequente intervenção no indivíduo ou na coletividade, derivada da percepção que a equipe de saúde desenvolveu acerca dos determinantes e dos fatores envolvidos no estado de saúde ou nutricional da sua população ou indivíduo-alvo, além da capacidade de transformar dados em ações, anseios em informações coadjuvantes ao diagnóstico e a própria intervenção. A VAN, portanto, permite fornecer dados desagregados para os distintos âmbitos geográficos, categorias de gênero, idade, raça/etnia, populações específicas (como indígenas e povos e comunidades tradicionais) e outras de interesse para um amplo entendimento da diversidade e dinâmicas nutricional e alimentar da população brasileira ${ }^{12}$. A atitude de vigilância pressupõe identificação e reconhecimento de realidades individuais ou coletivas.

Subsidiando o planejamento da atenção nutricional e das ações relacionadas à promoção da saúde e da alimentação adequada e saudável e à qualidade e regulação dos alimentos, nas esferas de gestão do SUS, o SISVAN (Sistema de Vigilância Alimentar e Nutricional), operado a partir da VAN, tem como objetivo principal monitorar o padrão alimentar e o estado nutricional dos indivíduos atendidos pelo SUS, em todas as fases do curso da vida $^{12}$, sendo um processo permanente e regular de coleta, análise e distribuição de informação necessária para manter o conhecimento atualizado da produção, qualidade e consumo dos alimentos e do estado nutricional da população, capaz de identificar suas causas e tendências, prever suas possíveis variações e decidir, oportunamente, as ações preventivas ou corretivas que o caso demande.

É importante salientar também que não cabe ao setor de saúde, isoladamente, a resolução de problemas alimentares nos quais a origem está localizada em outra esfera de determinação. Geralmente, as prescrições medicamentosas para o tratamento de carências de micronutrientes não consideram uma série de fatores, como a biodisponibilidade, as interações entre medicamentos e suplementos vitamínicos, especialmente o 
acesso alimentar e, portanto, o custo-benefício dessa prática. Sendo assim, questiona-se a real necessidade de tais práticas e, ao mesmo tempo, a substituição do alimento como veículo natural de satisfação das necessidades nutricionais e alimentares.

\section{Políticas públicas e Programas Institucionais}

A alimentação e nutrição estão presentes na legislação recente do Estado Brasileiro, com destaque para a Lei 8.080, de 19/09/1990, que entende a alimentação como um fator condicionante e determinante da saúde e que as ações de alimentação e nutrição devem ser desempenhadas de forma transversal às ações de saúde, em caráter complementar e com formulação, execução e avaliação dentro das atividades e responsabilidades do sistema de saúde ${ }^{12}$.

Os novos desafios para a alimentação na América latina e Caribe levam em consideração os novos Objetivos de Desenvolvimento Sustentável (ODS) são, em grande parte, um reflexo de mudanças sociais e econômicas vividas no mundo nos últimos anos. Em particular, o objetivo relativo ao êxito da segurança alimentar e nutricional da Agenda 2030 é exatamente o ODS, no sentido de acabar com a fome, alcançar a segurança alimentar e melhorar a nutrição e promover a agricultura sustentável. Entre as 8 metas e os 15 indicadores, existem 2 metas que fazem referência direta à erradicação da fome e à desnutrição ${ }^{12}$.

Embora a composição de uma dieta saudável dependa das particularidades culturais de cada país ou região, há um consenso de que deve conter uma combinação equilibrada de macronutrientes, como carboidratos, proteínas e gorduras, e micronutrientes essenciais, tais como vitaminas e minerais. Isso se refletiu no estabelecimento de guias alimentares baseados em alimentos (GABAs) na maioria dos países do mundo, que recomendam como base de uma dieta adequada o consumo de alimentos frescos, incluindo variedades de cereais, especialmente os integrais, legumes, frutas e vegetais, bem como alimentos de origem animal ${ }^{19}$.

Todas as iniciativas destinadas a mudar a dieta do ponto de vista do consumo passam por aspectos ligados às políticas que visam estimular a adoção de dietas saudáveis, como as ações propositivas relativas a 
orientações alimentares, de educação nutricional, também por meio de ações regulatórias, como a definição de normas para a publicidade de alimentos, a rotulagem dos produtos alimentares ou a implementação de instrumentos fiscais (impostos ou subsídios) para incentivar a compra de alimentos saudáveis, ou mesmo desencorajar a compra de produtos com alto conteúdo calóricos, açúcar, sal ou gordura, dependendo do caso ${ }^{19}$.

Entre esses instrumentos estão os guias alimentares baseados em alimentos, que são uma das políticas mais amplamente utilizadas para promover a alimentação saudável na região, estando atualmente presente em 28 dos 33 países da América Latina e do Caribe, que são a base para a implementação de políticas que, neste momento, têm se concentrado principalmente nos setores de saúde e educação, frente a uma presença menor em políticas agropecuárias ou de desenvolvimento social. Cabe destacar que, de qualquer forma, os guias alimentares têm sido considerados na elaboração das políticas de segurança alimentar e nutricional da Costa Rica, Brasil, Argentina, El Salvador, Belize e Guiana ${ }^{19}$.

Para enfrentar os efeitos negativos da publicidade sobre alimentos, alguns países da região começaram a gerar leis e/ou regulamentos para regular a geração da publicidade de alimentos e bebidas não alcoólicas para crianças. Em particular, seis países da região têm estabelecido por meio de leis nacionais a regulação da publicidade de alimentos, dentre eles o Brasil ${ }^{19}$.

Com relação à política de fortificação alimentar, os seus custos são extraordinariamente baixos, comparados com os custos sociais da deficiência. A estratégia de educação nutricional, que visa o consumo quantitativo e qualitativo adequado de alimentos, fontes dos diversos nutrientes, é uma alternativa que possui baixo custo e não produz efeitos indesejáveis.

No Brasil, em 2001, o Ministério da Saúde determinou como obrigatória a adição de ferro e ácido fólico às farinhas de milho e trigo. A fortificação deixou de ser facultativa e passou a ser obrigatória. Vários tipos de alimentos e também diferentes sais de ferro têm sido utilizados para o combate da deficiência nutricional, conforme ilustrado na tabela 1. A Estratégia de fortificação da alimentação infantil com micronutrientes em pó também é importante e consiste na adição nos alimentos de uma mistura de vitaminas e minerais, acondicionados em um sachê, os quais são distribuídos em creches 
participantes do Programa Saúde na Escola (PSE), abrangendo todas as crianças matriculadas, com foco na faixa etária entre 06 e 48 meses.

A Lei $n^{\circ}$ 11.346, de 15 de setembro de 2006, conhecida como Lei Orgânica de Segurança Alimentar e Nutricional (LOSAN), criou o Sistema Nacional de Segurança Alimentar e Nutricional (SISAN) e estabeleceu definições, princípios, diretrizes e objetivos do Sistema. Por meio do SISAN, o poder público (órgãos e entidades da União, dos Estados, do Distrito Federal e dos Municípios), com a participação da sociedade civil organizada, deve formular e implementar políticas, planos, programas e ações com vistas a assegurar o direito humano à alimentação adequada ${ }^{15}$.

Mesmo que o exercício do DHAA exija ações imediatas em saúde e em alimentação e nutrição, estas ações demonstram a dificuldade, ao longo de décadas, de nossa sociedade eliminar a fome oculta. Para um país caracterizado como um dos principais produtores e exportadores de alimentos, a cronificação das carências nutricionais demonstra que o principal problema ainda é o acesso físico/financeiro para o consumo de alimentos. 
Tabela 1 - Fortificação alimentar com ferro no Brasil

\begin{tabular}{|c|c|c|c|c|}
\hline Autor / Ano & $\begin{array}{l}\text { Veículo } \\
\text { alimentar }\end{array}$ & Sal de ferro & $\begin{array}{l}\text { Redução de } \\
\text { anemia }\end{array}$ & $\begin{array}{l}\text { Duração } \\
\text { do estudo }\end{array}$ \\
\hline $\begin{array}{l}\text { Nogueira et } \\
\text { al. (1992) }\end{array}$ & Galletas & $\begin{array}{l}\text { Hemoglobina } \\
\text { bovina }\end{array}$ & $75 \%$ para $0 \%$ & 3 meses \\
\hline $\begin{array}{l}\text { Dutra de } \\
\text { Oliveira et al. } \\
\text { (1994) }\end{array}$ & Agua & Sulfato ferroso & $58 \%$ para $3 \%$ & 8 meses \\
\hline $\begin{array}{l}\text { Torres et al. } \\
\text { (1995) }\end{array}$ & $\begin{array}{l}\text { Leite em } \\
\text { pó }\end{array}$ & $\begin{array}{l}\text { Sulfato ferroso } \\
+ \text { vitamina C }\end{array}$ & $\begin{array}{l}66,4 \% \text { para } 20,6 \% \\
72,8 \% \text { para } 18,0 \%\end{array}$ & 6 meses \\
\hline $\begin{array}{l}\text { Torres et al. } \\
\text { (1996) }\end{array}$ & Leite & $\begin{array}{l}\text { ferro } \\
\text { aminoácido } \\
\text { quelato }\end{array}$ & $62,3 \%$, para $26,4 \%$ & 12 meses \\
\hline $\begin{array}{l}\text { Fisberg ET al. } \\
\text { (1998b) }\end{array}$ & $\begin{array}{l}\text { Biscoitos e } \\
\text { pães }\end{array}$ & $\begin{array}{l}\text { Ferro } \\
\text { aminoquelato }\end{array}$ & $32 \%$ para $11 \%$ & 2 meses \\
\hline $\begin{array}{l}\text { Ferreira } \\
(2000)\end{array}$ & Leite & $\begin{array}{l}\text { Sulfato ferroso } \\
+ \text { vitamina C }\end{array}$ & $\begin{array}{l}63,24 \% \text { para } \\
33,82 \%\end{array}$ & 6 meses \\
\hline $\begin{array}{l}\text { Giorgini et al. } \\
(2001)\end{array}$ & Pães & Ferro quelato & $62 \%$ para $22 \%$ & 6 meses \\
\hline $\begin{array}{l}\text { De Paula } \\
\text { e Fisberg } \\
(2001)\end{array}$ & Açúcar & $\begin{array}{l}\text { Triglicinato } \\
\text { quelato }\end{array}$ & $\begin{array}{l}38,1 \% \text { para } 19,7 \% \\
29,4 \% \text { para } 19,6 \%\end{array}$ & 6 meses \\
\hline $\begin{array}{l}\text { Tuma et al. } \\
\text { (2003) }\end{array}$ & $\begin{array}{l}\text { Farinha de } \\
\text { mandioca }\end{array}$ & $\begin{array}{l}\text { Ferro } \\
\text { aminoquelato }\end{array}$ & $22,7 \%$ para $8,0 \%$ & 4 meses \\
\hline $\begin{array}{l}\text { Fisberg ET al. } \\
(2003)\end{array}$ & $\begin{array}{l}\text { Feijão } \\
\text { em pó }\end{array}$ & $\begin{array}{l}\text { Pirofosfato } \\
\text { férrico }\end{array}$ & $13 \%$ para $0 \%$ & 4 meses \\
\hline $\begin{array}{l}\text { Almeida et } \\
\text { al. (2003) }\end{array}$ & $\begin{array}{l}\text { Suco de } \\
\text { laranja }\end{array}$ & Sulfato ferroso & $60 \%$ para $20 \%$ & 4 meses \\
\hline $\begin{array}{l}\text { Beinner ET al. } \\
\text { (2005) }\end{array}$ & Água & Sulfato ferroso & $43,2 \%$ para $21 \%$ & 8 meses \\
\hline $\begin{array}{l}\text { de Almeida } \\
\text { et al. (2005) }\end{array}$ & Agua & $\begin{array}{l}\text { Sulfato ferroso } \\
+ \text { vitamina } C\end{array}$ & $45,9 \%$ para $31,1 \%$ & 6 meses \\
\hline
\end{tabular}

Fonte: Lamounier et al., $2010^{23}$. 
Ressalta-se que no Brasil, existem ações integradas como a Estratégia Amamenta e Alimenta Brasil (promoção de alimentação saudável), o Programa Nacional de Suplementação de Ferro para populações de risco, a fortificação das farinhas de trigo e milho e a recente Estratégia de Fortificação da Alimentação Infantil com Micronutrientes em pó (NutriSUS) para crianças em ambiente escolar².

Na última década, nota-se que o principal avanço foi a incorporação da alimentação como um direito social. Nesse sentido, o Estado Brasileiro, ocupado com a construção de uma nova abordagem para atuar no combate à fome, à pobreza e na promoção da alimentação adequada e saudável, publicou a Lei 11.346/2006 - Lei Orgânica de Segurança Alimentar e Nutricional e o Decreto 7.272/2010 - Política Nacional de Segurança Alimentar e Nutricional. Tanto a Lei como o Decreto apresentam, entre as suas bases diretivas, o fortalecimento das ações de alimentação e nutrição no sistema de saúde. O Brasil também adota as recomendações internacionais, orientando o aleitamento materno exclusivo até o sexto mês e continuado até o segundo ano de vida. Segundo a Pesquisa Nacional de Demografia e Saúde (PNDS), realizada em 2006, 95\% das crianças brasileiras foram alguma vez amamentadas, mas esse número cai drasticamente ao longo dos dois primeiros anos de vida12.

A sintonia do governo brasileiro com as recomendações internacionais se intensificou por meio da proposta, em maio de 1999, do "Compromisso Social para Redução da Anemia por Carência de Ferro, culminando posteriormente no desenvolvimento na fortificação de farinhas de trigo e milho. Essa estratégia foi aprovada pelo Governo federal e obrigava a fortificação com ferro a partir da utilização de sulfato ferroso desidratado, fumarato ferroso, ferro reduzido e ferro eletrolítico, etilenodiaminotetracetato de ferro e sódio e ferro bisglicina quelato nas farinhas de milho e trigo fabricadas ou importadas. ${ }^{16}$ Neste sentido, as ações de suplementação ocorrem desde 1983, mas sofreram descontinuidade e desestruturação entre 1998 e 2000, em função da extinção do órgão gestor nacional. A partir do ano 2000, o programa de suplementação passou a ter mais regularidade, ampliando sua cobertura e aperfeiçoando os processos ${ }^{13}$.

Neste momento, é importante enfatizar algumas políticas e programas importantes no cenário brasileiro. 


\section{PNAE}

O Programa Nacional de Alimentação Escolar (PNAE) é o programa social mais antigo do país na área de Segurança Alimentar e Nutricional, sendo caracterizado, desde seus primórdios, por grandes quantitativos em termos de cobertura populacional.

O objetivo do PNAE é atender às necessidades nutricionais dos alunos durante sua permanência no ambiente escolar, contribuindo para o desenvolvimento biopsicossocial, aprendizagem e rendimento escolar dos mesmos e promover a construção de hábitos alimentares corretos.

\section{PNAN}

A Política Nacional de Alimentação e Nutrição (PNAN), aprovada no ano de 1999, como parte integrante da Política nacional de saúde, integra os esforços do Estado Brasileiro que, por meio de um conjunto de políticas públicas, propõe respeitar, proteger, promover e prover os direitos humanos à saúde e à alimentação ${ }^{12}$.

O propósito da PNAN é exatamente garantir a qualidade dos alimentos colocados para consumo no País, a promoção de práticas alimentares saudáveis e a prevenção e o controle dos distúrbios nutricionais, bem como o estímulo às ações intersetoriais que propiciem o acesso universal aos alimentos.

Nesse sentido a PNAN resgata a vigilância nutricional como uma "atitude" de monitoramento nutricional e alimentar, ou seja, impõe-nos uma abordagem epidemiológica proativa, identificando tanto os fatores causais das doenças, quanto suas tendências temporais e, desta forma, propiciando a proposição de indicadores para o planejamento, execução e autoavaliação de políticas para o setor.

\section{PNSAN}

O Decreto $n^{\circ} 7.272$, de 25 de agosto de 2010, definiu as diretrizes e objetivos da Política Nacional de Segurança Alimentar e Nutricional (PNSAN), dispôs sobre a sua gestão, mecanismos de financiamento, monitoramento e avaliação, no âmbito do SISAN, e estabeleceu os parâmetros para a elaboração do Plano Nacional de Segurança Alimentar e Nutricional (PLANSAN) ${ }^{15}$. Assim, a PNAN deve interagir com a PNSAN e outras políticas de desenvolvimento econômico e social, ocupando papel importante na estratégia de 
desenvolvimento das políticas de SAN, principalmente em aspectos relacionados ao diagnóstico e vigilância da situação alimentar e nutricional e à promoção da alimentação adequada e saudável ${ }^{12}$.

\section{PNSF}

Existem os programas que podemos chamar de "medicamentalizados" como o Programa Nacional de Suplementação de Ferro (PNSF), o Programa Nacional de Suplementação de Vitamina A (VITA A MAIS), e mais recentemente implantado, a Estratégia de fortificação da alimentação infantil com micronutrientes em pó (NutriSUS) ${ }^{7}$ para o combate às carências de micronutrientes.

De acordo com a gravidade do problema e o compromisso que a PNAN tem para melhorar as condições de alimentação, nutrição e saúde da população brasileira, foram estabelecidas ações de prevenção e controle da anemia ferropriva dentro do âmbito do SUS, como o PNSF, onde são utilizados suplementos com ferro e alimentos, como farinha rica em ferro. Neste programa, a suplementação profilática com sulfato ferroso vem sendo desenvolvida desde 2005, pois é uma medida com boa relação de custo e efetividade. É disponibilizado para todas as crianças de 6 a 24 meses $^{20}$. Embora todos os esforços, de acordo com os dados da PNDS, a anemia ainda apresenta elevada prevalência na população; indicando o baixo impacto alcançado pelas intervenções nacionais no controle da deficiência de ferro, mesmo com melhoras isoladas (BRASIL, 2009)16.

No Brasil, políticas públicas inovadoras no campo da segurança alimentar e nutricional demonstram que, em articulação com outras políticas, foi possível reduzir a fome e a desnutrição e ao mesmo tempo estimular a produção e consumo de alimentos saudáveis. No entanto, a fome ainda afeta muita gente, e a má nutrição, sobretudo a deficiência de micronutrientes, e do aumento do sobrepeso e obesidade, que se tornam cada vez mais presentes. ${ }^{11}$ Situação paradoxal da transição epidemiológica e nutricional caracterizada nas últimas décadas. Portanto, podemos estar em um país no qual os dois extremos da má nutrição - desnutrição pela carência e obesidade pelo excesso - compartilham do mesmo cenário. Uma situação denominada de paradoxo nutricional, típico da transição nutricional ${ }^{21-23}$. 
O combate à fome tem justificativa, visto que ainda existem bolsões de pobreza com desnutrição. Por outro lado, famílias tendem a incluir na alimentação alimentos de elevado valor calórico, em geral de menor custo. A questão poderia ser vista sob o ângulo de falta de informação nutricional, o que requer enfoque na promoção da educação e não na distribuição de alimentos. Outra questão também é a distribuição de renda de forma cruel, concentrada a maior parte nas mãos de uma pequena parcela da população. Estes são fatores que devem ser considerados numa análise mais profunda da questão nutricional e de suas implicações na saúde da população brasileira. Fome zero e obesidade zero devem ser parte de uma mesma política que passa por um programa de educação nutricional e melhor distribuição de renda, para que as famílias possam ter melhor conhecimento e mais acesso aos alimentos de qualidade nutricional.

\section{Referências}

1. SILVA LSV, THIAPÓ AP, SOUZA GG, et al. Micronutrientes na gestação e lactação. Rev Bras Saúde Matern Infant. 2007;3:237-44.

2. OMS. Diretriz: Uso de formulações em pó de múltiplos micronutrientes para fortificação caseira de alimentos consumidos por gestantes. Genebra: Organização Mundial da Saúde; 2013.

3. LEME A, ALMEIDA A, RODRIGUES A, et al. Micronutrientes nos primeiros 6 anos de vida. ILSI Brasil. 2019;9.

4. DE SOUZA M, DAS FLORES R, SOARES P, et al. Avaliação nutricional e dietética de pré-escolares de Montes Claros, Minas Gerais. Journal Health. 2019;4(1):166-81.

5. IBGE. PNAD. Pesquisa Nacional por Amostra de Domicílios (Pnad Contínua). Instituro Brasileiro de Geografia e Estatística.

$6 . \quad$. Plano estadual de Segurança Alimentar e Nutricional Sustentável de Minas Gerais 2018/2019. Belo Horizonte/MG: Câmara Governamental Intersetorial de Minas Gerais- CAISANS; 2018. p. 118.

7. BRASIL. Pesquisa Nacional de Demografia e Saúde da Criança e da Mulher - PNDS 2006: dimensões do processo reprodutivo e da saúde da criança / Ministério da Saúde, Centro Brasileiro de Análise e Planejamento. Brasília: Ministério da Saúde; 2009. p. 300 p.: il. - (Série G. Estatística e Informação em Saúde).

8. BRASIL. Política Nacional de Alimentação e Nutrição- PNAN. Brasília/DF: Ministério da Saúde. Secretaria de Atenção à Saúde. Departamento de Atenção Básica. Básica; 2013. p. 84. 
9. TEIXEIRA R. Deficiência de Vitamina A e fatores associados em crianças e adolescentes em dois municípios do semiárido de Minas Gerais [Tese de Doutorado]: Universidade Federal de Minas Gerais; 2010.

10. BONOMO E. Segurança alimentar e perfil de consumo alimentar e antropométrico de escolares e seus fatores associados em dois municípios do semiárido de Minas Gerais: contribuição à política local de segurança alimentar e nutricional [Tese de Doutorado]. Belo Horizonte/MG: Universidade Federal de Minas Gerais; 2010.

11. PIMENTA F. Perfil antropométrico e avaliação da insegurança alimentar de adolescentes de Itinga, Vale do Jequitinhonha, MG. [Dissertação de Mestrado]: Universidade Federal de Ouro Preto. Escola de Nutrição. Programa de Pós Graduação em Saúde e Nutrição; 2018.

12. PEIXOTO M. Segurança Alimentar e Nutricional. Brasília/DF: Senado Federal. Núcleo de Estudos e Pesquisas- Consultoria Legislativa- Senado Federal; 2012.

13. ROCHA E. Anemia e Segurança Alimentarem Crianças em Idade Escolar [Tesed de Doutorado]. São Paulo/SP: Universidade de são Paulo; 2017.

14. BENGUIGUI Y. Investigaciones operativas sobre Atención Integrada a las Enfermedades Prevalentes de la Infancia (Aiepi). Washington DC: OPS (Serie HCT/ AIEPI-27.E); 2001. p. 642p.

15. BRASIL. Atendimento à saúde e desenvolvimento da criança: cartão da criança. In: Saúde Md, editor. Brasília: Ministério da Saúde; 1993.

16. BRASIL. Aleitamento materno e orientação alimentar para o desmame. Brasília: Ministério da Saúde; 1994.

17. BRASIL. Saúde da criança: acompanhamento do crescimento e desenvolvimento infantil. Brasília/DF: Ministério da Saúde. Caderno de Atenção Básica; 2002.

18. BRASIL. Assistência pré-natal: manual técnico. Brasília/DF: Ministério da Saúde; 2000.

19. FAO. Panorama da segurança alimentar e Nutricional . sistemas Alimentares sustentáveis para acabar com a fome e a má nutrição. Santiago do Chile: Organização das Nações Unidas para a Alimentação e a Agricultura (FAO) e Organização Pan- Americana da Saúde (OPAS); 2017.

20. BRASIL. Manual de Condutas Gerais. Programa Nacional de Suplementação de Ferro. Brasília/DF: Ministério da Saúde; 2013. p. 24.

21. LAMOUNIER JA. Transição epidemiológica nutricional em crianças e adolescentes argentinos de áreas carentes. Editorial. Rev Paul Pediatr. 2009;27(2):124-6.

22. BATISTA FILHO M, SOUZA AI, MIGLIOLI TC, et al. Anemia e obesidade: um paradoxo da transição nutricional Brasileira. Cad Saúde Pública. 2008;24(Sup 2):S247-S57.

23. LAMOUNIER JA, VIEIRA EC, LEAO E. Desnutriçao versus obesidade: o paradoxo nutricional. Rev Med MG. 2004;14(4):215-90. 


\section{Capítulo 5}

\section{POLÍTICAS DE COMBATE À POBREZA INFANTIL NA AMÉRICA LATINA E NO CARIBE}

\section{Matilde Peguero ${ }^{1}$, Amarilis Then-Paulino ${ }^{2}$}

${ }^{1}$ Bioanálista. Maestra y Doctora en Salud, Pública. Docente de la Escuela de Salud Pública de la Universidad Autónoma de Santo Domingo. República Dominicana.

${ }^{2}$ Médica. Maestra en Salud Pública. Docente de la Facultad de Ciencias de la Salud; Escuela de Salud Pública, Universidad Autónoma de Santo Domingo. República Dominicana.

Resumo:

Na América Latina, os países comprometidos com a melhoria da saúde infantil, inclusive como ponto fundamental a redução da pobreza, estabeleceram Políticas Públicas que se implementadas contribuiriam em muito para o bem estar da infância e adolescência nos países da América Latina e o Caribe. Entretanto, apesar dos esforços empreendidos, muitas dessas políticas servem apenas como cartão de visita nas páginas governamental de muitos países, que preferiram por motivos diversos aderir a política neoliberal ditatorial de países e governos externos. Nesse capítulo são apresentadas as principais políticas relacionadas ao marco legal da proteção aos direitos da infância e adolescência. Em função da localização de poucos ou nenhum estudos em alguns países, padronizou- se a coleta das informações, de modo quase na íntegra (com citação da referência), no site relacionado a "Política Nacional de Primeira Infância", que contempla a maioria dos países da América Latina, com descrição das políticas, seu início de criação e implementação e definição de objetivos e marcos políticos. Infelizmente, a Guatemala e o Haiti aparecem como países de alta vulnerabilidade social para a infância, enquanto o Chile figura como país de maior bem estar para crianças e adolescentes.

Palavras-chave: Pobreza; Política Pública; Igualdade de Oportunidades; Marginalização social. 


\section{Introdução}

A Convenção sobre os Direitos da Criança consagra o direito de todas as crianças ao pleno desenvolvimento de suas potencialidades ${ }^{1}$, por isso é necessário avançar nas políticas de desenvolvimento infantil. Desta forma, existe o compromisso e grande esforço de todos os países para o cumprimento dessas políticas. A infância é um período em que as pessoas necessitam de cuidados e apoios especiais, pois é a fase em que se lançam as bases para o desenvolvimento das suas capacidades, aptidões e potencialidades. Portanto, a criança durante seu desenvolvimento e crescimento deve ter um sistema público adequado de proteção social².

Políticas e programas equitativos para a primeira infância são cruciais para alcançar os Objetivos de Desenvolvimento Sustentável (ODS). Além disso, sua implementação ajuda as crianças a desenvolverem habilidades intelectuais, criatividade e o bem-estar necessários para se tornarem adultos saudáveis e produtivos ${ }^{3}$. Crianças menores de 5 anos que vivem em países de baixa renda estão expostas a múltiplos riscos: pobreza, desnutrição, ambientes domésticos inseguros e estimulantes que afetam negativamente seu desenvolvimento cognitivo, motor e socioemocional2; bem como seu impacto no desenvolvimento social e econômico em geral ${ }^{4}$. Além disso, existem evidências neurocientíficas que relacionam situações adversas na infância com deficiências nutricionais e com o mau desenvolvimento das funções cerebrais que repercutem ao longo da vida5; a aplicação de políticas voltadas para a primeira infância é insuficiente para reverter a situação na grande maioria dos países de baixa renda ${ }^{3}$.

Eliminar os riscos para o desenvolvimento integral na primeira infância é um desafio que requer o conhecimento do estado de desenvolvimento das crianças na primeira infância. Assim, o ODS número 1 expressa o compromisso de "Erradicar a pobreza em todas as suas formas no mundo"; e seu objetivo 1.1 enfatiza a erradicação da pobreza extrema para todas as pessoas no mundo até 2030; já a meta 1.2 propõe, até 2030 , reduzir para menos da metade a proporção de homens, mulheres e crianças de todas as idades que vivem na pobreza em todas as suas dimensões. A pobreza extrema é medida por quem recebe US \$1,25 por dia6. 
O ODS 1, se refere a um conceito multidimensional de pobreza e menciona explicitamente as crianças como uma parte fundamental da população-alvo. Para atingir esse objetivo, os governos e a sociedade civil devem considerar a ampliação dos programas de desenvolvimento da primeira infância, tornando-os econômicos e de alta qualidade ${ }^{7}$. A população infantil é mais vulnerável à pobreza, devido à alta dependência de cuidados por parte dos adultos e por sofrer as maiores consequências biopsicossociais dela derivadas.

O número de crianças e adolescentes obesos aumentou dez vezes nas últimas quatro décadas. As linhas estratégicas de ação propostas para ajudar os países da região a enfrentar a crescente epidemia de sobrepeso e obesidade são: a) atenção primária à saúde; b) promoção do aleitamento materno e alimentação saudável; c) melhoria dos ambientes nutricionais e de saúde; d) atividade física escolar; e) políticas fiscais; f) regulamentação da comercialização e rotulagem de alimentos, entre outras ações multissetoriais ${ }^{8}$.

\section{Principais políticas de combate à pobreza infantil na América Latina e no Caribe}

Na América Latina, os países comprometidos com a melhoria da saúde infantil, inclusive como ponto fundamental de redução da pobreza, têm desenvolvido diversas iniciativas que, apesar de estabelecerem objetivos comuns, variam em escopo e metodologia de desenvolvimento.

As principais políticas públicas de desenvolvimento infantil foram compiladas por Aulicino e Langou (2016) ${ }^{9}$ e são as seguintes: Brasil Cariñoso (Brasil); Estadias Infantis (México), Estratégia Integral de Atenção à Primeira Infância de "Cero para Siempre" (Colômbia), Plano Integral de Atenção à Primeira Infância - PAIPI (Panamá), Plano Nacional de Ação pelos Direitos da Criança e do Adolescente (Argentina), Plano Nacional de Atenção Integral Desenvolvimento da Primeira Infância (Paraguai), Política Integral de Desenvolvimento da Infância (Equador), Política Nacional de Educação da Primeira Infância e Desenvolvimento Integral (El Salvador), Política Nacional da Primeira Infância da Infância Amor por los Pequeninos" (Nicarágua), Política Pública para o Desenvolvimento Integral da Primeira Infância (Guatemala), Política Pública para o Desenvolvimento Integral da Primeira 
Infância (Honduras), Quisqueya Começa com você (República Dominicana), Rede Nacional de Puericultura e Desenvolvimento (Costa Rica), Sistema de Atenção Integral a Crianças e Adolescentes (Peru), Subsistema de Proteção Integral à Criança Chile Cresce com você (Chile) e Uruguai cresce com você (Uruguai).

A implementação de políticas, como estratégia de redução das iniquidades no desenvolvimento da primeira infância, voltada para o atendimento à criança de forma integrada e intersetorial nesta fase, ainda que parcialmente implementada, tem potencial para reduzir as iniquidades. Essa prática de implementação deve incluir os seguintes mecanismos: a) articulação intersetorial em conformidade com as políticas previamente delineadas para a infância, por meio da rede intersetorial de serviços, como saúde, educação e desenvolvimento social; b) criação de espaços de discussão sobre a viabilidade local, formação de lideranças e continuidade dos programas; c) a formação sistemática de recursos humanos que atuam na primeira infância, utilizando metodologias de educação em saúde; d) monitorar as ações políticas com indicadores específicos, indicando as barreiras relacionadas à organização dos sistemas e serviços, além daquelas localizadas no campo da cultura e das representações sociais ao nível de pacientes / indivíduos, tomadores de decisão, trabalhadores de saúde, organização de serviços e sistemas de saúde. Nesse contexto, serão listadas as políticas implementadas nos países da América Latina e do Caribe.

\section{Plano Nacional de Ação pelos Direitos da Criança e do Adolescente (Argentina)}

O plano na Argentina foi elaborado em 2012, com o objetivo de criar condições para o efetivo cumprimento dos direitos da criança e do adolescente, na sua qualidade de cidadão, por meio do desenvolvimento de políticas públicas integrais, de implementação interinstitucional e intersetorial e com enfoque territorial. O plano buscou: 1) garantir os direitos da criança e do adolescente como política prioritária do Estado; 2) aumentar os graus de igualdade, principalmente territorial e de gênero; 3) garantir o acesso a bens e serviços de igual qualidade? 
A Argentina experimentou alguns avanços na proteção da primeira infância, entre eles o Salário Familiar Universal por Criança e na Gravidez, o Plano SUMAR (cobertura universal de saúde), a educação pré-escolar obrigatória em quatro anos, passando de 57,3\% (2003) para 86,2 (2013)); mas os avanços nessas políticas foram incompletos, devido à desarticulação entre setores e níveis de governo e às dificuldades de gestão do federalismo argentino, incluindo as relações entre níveis de governo com diferentes capacidades técnicas e fiscais ${ }^{10}$. Da mesma forma, o Centro de Implementação de Políticas Públicas para Equidade e Crescimento (CIPPEC), propôs a construção institucional para a primeira infância, que incluiu:

a) definição de órgão vinculado à presidência do país, para acompanhamento orçamentário dos órgãos executores setoriais de políticas estratégicas para a primeira infância;

b) preparação de um pacto federal para políticas e investimentos na primeira infância nos diferentes niveis de governo;

c) investir em 2019 1,82\% do PIB em saúde e nutrição, educação inicial e puericultura;

d) garantir mecanismos de gestão em todos os níveis da gestão governamental;

e) treinamento contínuo de funcionários públicos sobre o tema ${ }^{11}$.

\section{Programa Brasil Carinhoso (Brasil)}

O programa Brasil carinhoso é um projeto desenvolvido pelo Governo Federal do Brasil, criado EM 2011, pela Medida Provisória $n^{\circ}$ 570, de 14 de maio de 2012. Está vinculado ao Ministério do Desenvolvimento Social e representa a transferência de renda para financiar o desenvolvimento da educação. Contribuir com as ações de atenção integral, segurança alimentar e nutricional, além de garantir o acesso e permanência da criança na educação infantil, para alunos de zero a 18 meses, matriculados em creches públicas ou em convênio com o poder público, cujas famílias são beneficiários do Programa Bolsa Família (BRASIL) ${ }^{12}$. 


\section{Chile cresce com você (Chile)}

É um sistema abrangente de proteção à criança, criado desde 2006 e em constante evolução. Consiste no monitoramento e proteção abrangente de todas as crianças mais vulneráveis da população e suas famílias, por meio de ações e serviços universais, além de apoio especial aos mais vulneráveis. $O$ acompanhamento do crescimento e desenvolvimento é realizado no sistema público de saúde, de forma personalizada, desde o pré-natal até o ingresso na rede de ensino no primeiro nível de transição ou pré-educação infantil; A partir de 2016, houve uma expansão gradativa até os 8 ou 9 anos de idade, ou o fim do primeiro ciclo básico ${ }^{13}$, a política possui três linhas de atuação:

1. Programa de educação massiva: dirigido a toda a população nacional com o objetivo de gerar um ambiente social com ambientes familiares e comunitários favoráveis à primeira infância, por meio de ações de conscientização, promoção e educação.

2. Programa de apoio ao desenvolvimento do recém-nascido: entrega de elementos práticos e educativos às famílias atendidas em estabelecimento pertencente à Rede de Assistência aos Serviços de Saúde.

3. Benefícios diferenciados para famílias em situação de vulnerabilidade. A política integral de proteção à criança continua a ser implementada e os indicadores são atualizados ${ }^{13}$.

\section{De Zero a Sempre (Colômbia)}

Criado em 2012, com a missão de promover e garantir o desenvolvimento das crianças na primeira infância, por meio de um trabalho unificado e intersetorial, na perspectiva dos direitos. É dirigido a todas as crianças do zero aos 5 anos e respectivas famílias. Busca garantir o cumprimento de seus direitos, definir uma política de qualidade técnica e financeiramente sustentável de longo prazo, sensibilizar a sociedade colombiana e fortalecer o papel da família como ator fundamental. Entende-se que o desenvolvimento integral enfoca as necessidades da criança a partir de cinco elementos estruturais: cuidado e educação; saúde, alimentação e nutrição; educação 
inicial; lazer; exercício da cidadania e participação. Esses cinco eixos estruturantes devem ser trabalhados em quatro ambientes: domicílio, saúde, educação e espaços públicos ${ }^{14}$.

\section{Rede Nacional de Assistência e Desenvolvimento Infantil (RNADI) (Costa Rica)}

Estabelece o sistema de atenção e desenvolvimento infantil de acesso público universal e financiamento solidário, que articula as diferentes modalidades de atendimento público e privado, na área de atenção e desenvolvimento infantil, para fortalecer e ampliar alternativas integrais de atenção à criança. Os serviços da RNADI são complementares e não substitutos dos serviços pré-escolares prestados diretamente pelo Ministério da Educação. Garante a todas as crianças de zero a seis anos o direito de participarem do Programa na busca de seu desenvolvimento integral, de acordo com as diferentes necessidades e de acordo com os diferentes tipos de assistência de que necessitem ${ }^{15}$.

O programa RNADI, mesmo durante a pandemia provocada pelo COVID-19, continua atendendo a população infantil, por meio de suas três unidades executoras: Centros de Educação e Nutrição-Centros de Puericultura (CEN-CINAI). National Board for Children (PANI) e o Joint Institute for Social Aid (IMAS); e coordenação com outras instituições do estado por meio de provedores de serviços dentro dele. Isso permite que o atendimento à população que dele necessita continue a ser mantido na modalidade de Puericultura (API) e o serviço de refeições servidas e distribuição de alimentos ${ }^{16}$.

\section{Programa Educa Seu Filho (Cuba)}

O Programa Educa Seu Filho busca o desenvolvimento integral das crianças e o fortalecimento da formação pessoal, cognitiva, física, afetiva e social, para permitir sua inserção no contexto cultural; onde serão reconhecidos como sujeitos diversos e únicos, desde o nascimento até a entrada na escola. Possui caráter comunitário e intersetorial e mantém a família como núcleo básico. Busca transmitir conhecimentos essenciais às famílias para preparar seus filhos para o ingresso na escola. A concepção deste modelo não institucional, prioriza entre os seus objetivos fundamentais a formação 
dos seus principais protagonistas, constituindo uma modalidade de ensino equivalente à realizada através do canal institucional e não como meio de transmissão de conteúdos selecionados a grupos populacionais específicos. Portanto, o sistema de educação inicial em Cuba caracteriza-se por ser patrocinado, coordenado e regulamentado pelo Ministério da Educação por meio do subsistema de "educação pré-escolar" em duas modalidades: institucional e não institucional ${ }^{17}$.

\section{Estratégia de Infância Integral (Equador)}

En acción desde 2012, para promover el desarrollo integral de los niños menores de 5 años, considerando que las condiciones de vida, estimulación temprana, educación, alimentación y afectividad en la primera infancia, condicionan el futuro de las personas. La estrategia está alineada con el Plan Nacional del Buen Vivir (2013-2017), y busca reducir las inequidades abordando el punto de partida del proceso de desarrollo humano, desde el momento del embarazo. Así, una educación adecuada de las madres, padres y cuidadores, además de una intervención de calidad y oportuna por parte del Estado y el apoyo comunitario, permitirá la erradicación permanente de la pobreza, fortaleciendo capacidades y generando mayores oportunidades en la población. La Constitución de Ecuador establece el derecho de las personas y de las comunidades al acceso seguro y permanente a alimentos saludables, suficientes y nutritivos; reconoce el derecho de la población a vivir en un entorno sano y ecológicamente equilibrado, que garantice la sostenibilidad y el buen vivir. Afirma que el Estado, la sociedad y la familia promoverán prioritariamente el desarrollo integral de la niñez y la adolescencia y garantizarán el pleno ejercicio de sus derechos, y estos derechos prevalecerán sobre los de otras personas; asume que la educación, con acceso universal, es un deber ineludible e inexcusable del Estado. Los niños menores de seis años tienen la garantía de su alimentación, salud, educación y cuidado diario, en un marco de protección integral de sus derechos, garantizando el derecho a la salud y sus condiciones como el derecho al agua, alimentación, educación, cultura física, trabajo de adultos, seguridad social, ambientes saludables y otros que apoyen el buen vivir $^{18}$. 


\section{Sistema Universal de Proteção Social (El Salvador)}

Este é considerado um instrumento de política social baseado na abordagem dos direitos humanos que melhora o desenvolvimento humano das pessoas e busca garantizar a todos los ciudadanos, especialmente a la población viviendo en peores condiciones de pobreza y exclusión social. Los componentes del programa son: suministro de uniformes, útiles y calzado, comidas escolares, leche, casa para todos, agricultura familiar, programa de apoyo temporal a la renta, pensión básica universal ${ }^{23}$. A pesar de la perspectiva de buscar el bienestar social, es necesario alinear la oligarquía, las fuerzas armadas, el clero, las intervenciones externas en la economía y la política, así como intereses geopolíticos que han generado graves conflictos políticos y sociales, como han sido guerra civil y profunda crisis social en el país.

\section{Política Pública para o Desenvolvimento Integral da Primeira Infância (Guatemala)}

Apresenta uma política cujo objetivo é garantir que os homens e mulheres guatemaltecos, desde o momento em que começam a viver no ventre materno até os seis anos de idade, desfrutem de seus serviços básicos. Promove a construção de um sistema que garanta atenção à saúde e desenvolvimento integral, respeitando a diversidade cultural do país. Define as áreas de intervenção e estabelece as ações de acordo com as etapas do ciclo de vida.

Apesar das informações contidas no site do governo, o direito à alimentação e o combate à fome e à pobreza extrema continuam sendo um desafio para a Guatemala, que busca cumprir as metas estabelecidas em acordos internacionais e garantir o direito à alimentação estabelecido em seu Conselho Federal Constituição e que afeta principalmente a infância maia. A participação popular é necessária para exigir políticas públicas que ajudem a avançar na luta pela segurança alimentar e a quebrar a cadeia intergeracional da desnutrição e da fome. Essas políticas devem respeitar a cultura do povo maia e garantir condições sociais e de saúde adequadas ${ }^{19}$. Políticas específicas podem ser encontradas em: https: // www. siteal.iiep. unesco.org/pt/politicas ${ }^{20}$. Decreto Legislativo $n^{\circ} 12$ - Lei Nacional da Educação; Decreto $n^{\circ} 27$ - Lei de Proteção Integral à Criança e ao Adolescente 
(PINA); Plano Estratégico de Educação 2016-2020; Plano de Desenvolvimento K'atun: Nossa Guatemala 2032 e o Plano Operacional Anual e Ano Fiscal e Mundial 2021-2025.

\section{Programa de Proteção Social (Haiti)}

A revisão realizada sobre a proteção social da criança na primeira infância, no caso particular do Haiti, da informação disponível na web encontra-se em diversos documentos que tratam do tema da proteção e promoção da saúde. Também em documentos regionais como a produção da CEPAL: Sistemas de proteção social na América Latina e Caribe (2013), bem como Promoção e proteção social de crianças e adolescentes no Haiti (2014), ambos documentos da CEPAL ${ }^{21,22}$. Isso limita uma descrição mais detalhada da proteção social das crianças na primeira infância,

\section{Política Pública para o Desenvolvimento Integral da Primeira Infância (Honduras)}

O Programa PAIPI foi aprovado em 2012, atende todas as crianças menores de 6 anos e tem como objetivo promover o cumprimento dos direitos da primeira infância, a formação do capital humano do futuro, com foco nos direitos e na corresponsabilidade com essa população. grupo. Reconhece que o ambiente familiar da criança é essencial para o desenvolvimento de suas capacidades e que a intervenção precoce, visando remediar algumas diferenças entre as famílias, contribui para a redução da desigualdade ${ }^{23}$.

O plano estratégico do PAIPI 2014-2025 estabelece a meta de que a primeira infância em Honduras receba atenção integral, para garantir o cumprimento de seus direitos. Na área da saúde, garante que a gravidez e a primeira infância se desenvolvam em um ambiente saudável: a) assistência materno-infantil (educação domiciliar, maternidade, atendimento personalizado durante o parto, vacinação, redução da mortalidade infantil, atendimento odontológico); b) acesso a água potável e saneamento; c) atendimento à população vulnerável (doenças sexualmente transmissíveis, equipes multidisciplinares itinerantes, coordenação de programas de capacitação). 
$\mathrm{Na}$ educação, dois componentes são estabelecidos para oferecer serviços educacionais de qualidade: a) educação para educadores da primeira infância (formação, documentação e certificação de apoio, plano de informação, educação e comunicação sobre a importância da atenção integral à primeira infância); b) qualidade e cobertura da formação inicial (currículo, fortalecimento institucional e ampliação de programas alternativos).

$\mathrm{Na}$ área de segurança alimentar e nutricional, define dois componentes para garantir o acesso a alimentos e nutrição ideais e seguros: a) segurança alimentar (institucionalizar os padrões de crescimento da OPAS/OMS, espaço para articulação e coordenação de políticas); b) fortalecimento institucional (prevenção de problemas futuros) ${ }^{24}$.

$\mathrm{Na}$ área de proteção, são estabelecidos dois componentes para a criação de condições sociais que contribuam para o bem-estar da infância vulnerável: a) garantia dos direitos fundamentais (cadastro e Sistema Nacional de Cadastro da Primeira Infância - RENPI); b) serviços de proteção (acolhimento comunitário temporário, centros de atenção integral compatíveis com o horário de trabalho e proteção especial). Por fim, na área de recreação e formação de valores, definem-se duas componentes para promover as condições necessárias ao desenvolvimento do lazer, da participação e dos valores com o contributo da família e da comunidade: a) espaços culturais e recreativos (construção e fica melhor); b) formação em valores para famílias e trabalhadores dedicados à puericultura ${ }^{24}$.

\section{Programa de apoio ao bem-estar de meninos e meninas (México)}

É um programa de apoio a mães, pais solteiros, tutores ou cuidadores primários que trabalham, procuram emprego ou estudam, cuja renda per capita por domicílio não ultrapasse o Limite Previdenciário (LP) e declaram não ter acesso a creches serviços para através de instituições públicas de segurança social ou outros meios. O valor de $\$ 900$ pesos mexicanos por mês é oferecido para cada criança menor de três anos e onze meses e $\$ 1.800$ pesos por mês para crianças menores de seis anos com necessidades especiais (deficiência) certificadas por um médico do serviço público de saúde ${ }^{25}$. 


\section{Política Nacional da Primeira Infância "Amor pelos Pequenos" (Nicarágua)}

A política nicaraguense "Amor aos Pequenos" foi criada em 2011 com o objetivo de fortalecer as articulações interinstitucionais das ações realizadas em relação à primeira infância, além de apresentar todos os programas voltados para este segmento da população. Em particular: 1) restaurar os direitos humanos das crianças menores de 6 anos, mulheres grávidas e lactantes, bem como promover seu pleno desenvolvimento humano; 2) apresentar todos os programas, centros e ações do Estado para que sejam universais, gratuitos, de qualidade, equitativos, com cordialidade humana, relevância cultural e social. A política inclui os seguintes componentes: a) Educação: universalidade da educação inicial e acesso a centros préescolares de qualidade; b) Saúde: garantia de saúde completa para o binômio mãe-filho (saúde pré-natal, parto e recém-nascido), com atendimento especializado e promoção da saúde preventiva; c) Estimulação precoce: consolidar a organização municipal e comunitária por meio da formação de promotores de solidariedade para chegar às famílias. Fortalecer o papel da família com base em um modelo parental responsável; d) Identidade: cadastramento de meninos e meninas e promoção de sua autoestima e participação; e) Segurança alimentar: redução do déficit nutricional de crianças menores de 6 anos, promoção do aleitamento materno, garantia da disponibilidade alimentar; f) Prevenção da violência contra a criança: atendimento às vítimas e sanções aos agressores: programas socioeducativos e atendimento integral; g) Restrição de direitos: proteção de crianças em situação de risco, filhos de mães e pais com problemas de dependência, adolescentes, migrantes, infratores e privados de liberdade, crianças com necessidades especiais (com deficiência), vivendo com HIV ou AIDS e crianças indígenas; h) Moradia segura: garantia do direito à moradia digna e segura ${ }^{26}$.

\section{O Plano Integral de Atenção à Primeira Infância - PAIPI (Panamá)}

Iniciado em 2011, para facilitar a adoção de políticas públicas voltadas para a primeira infância no Panamá. Inclui programas e linhas de ação que 
garantem o desenvolvimento integral de meninos e meninas de 0 a 6 meses de idade, na busca das seguintes estratégias: 1) estabelecer uma perspectiva estratégica que coloque meninos e meninas no centro; 2) estabelecer e implementar padrões de qualidade na atenção integral à primeira infância em seu contexto; 3) garantir atendimento oportuno, pertinente e abrangente; 4) maximizar a eficácia dos recursos técnicos e econômicos investidos; 5) fortalecer as capacidades das instituições para responder de forma eficaz e sustentável ao desafio de fornecer atenção integral à primeira infância; 6) facilitar o fortalecimento do contexto familiar para que possa prestar atenção integral às crianças de 0 a 6 anos, de forma equilibrada, comprometida e informada; 7) promover o fortalecimento comunitário que garanta às crianças de 0 a 6 anos de idade que possam se desenvolver em um ambiente seguro, que lhes permita ter acesso a serviços básicos, institucionais e recreativos que facilitem seu desenvolvimento integral ${ }^{27}$.

\section{O Plano Nacional de Desenvolvimento Integral da Primeira Infância (Paraguai)}

Criado em 2011, a ser implementado até 2020 com o apoio do UNICEF, com o objetivo de consolidar as políticas públicas em prol da primeira infância no país (definidas até 8 anos) em todos os níveis de governo, junto a famílias, comunidades, organizações, sociedade civil e cooperação internacional. O plano visa: a) elevar a qualidade de vida da primeira infância, garantindo o pleno acesso aos serviços de saúde e nutrição, à documentação necessária e ao ingresso e permanência no sistema educacional; b) proteger e incluir crianças em situação de vulnerabilidade social, promovendo integralmente seus direitos; c) proporcionar a proteção jurídica necessária à primeira infância, por meio da articulação de todas as instituições responsáveis; d) gerar consciência, a partir de ações de comunicação e visibilidade. O Plano criou a Comissão Nacional da Primeira Infância (CONPI), que é o órgão gestor, em conjunto com as comissões departamentais e municipais da primeira infância, dos Conselhos da Infância e da Adolescência, no âmbito do Sistema Nacional de Proteção e Promoção da Infância e Adolescência Integral28. 


\section{Sistema de Atenção Integral à Criança e ao Adolescente SNAINA (Peru)}

Criada em 1995 e entrou em vigor em 1996 por meio da Lei $n^{\circ}$ 26.518, em atendimento ao Código da Infância e Adolescência, com a finalidade de orientar, integrar, estruturar, coordenar, supervisionar e avaliar políticas, planos, programas e ações em âmbito nacional, voltada para o atendimento integral à criança e ao adolescente. Em 2002, foi lançado o Plano Nacional de Ação da Criança e do Adolescente 2002-2010, documento histórico das políticas públicas nacionais a favor da criança e do adolescente ${ }^{29}$.

\section{Quisqueya começa com você (República Dominicana).}

Criado em 2013 com o objetivo de estabelecer um sistema integral de proteção e cuidado à primeira infância, buscando organizar, articular, integrar e regular a oferta de serviços no país, bem como ampliar a oferta de cobertura e qualidade por meio de um conjunto de Serviços. Estratégias de atenção integral para crianças de 0 a 5 anos, suas famílias e comunidades. A política possui oito linhas de ação: 1) educação inicial; 2) saúde e nutrição; 3) detecção precoce e atendimento de necessidades educacionais especiais e deficiência; 4) proteção contra abuso e violência; 5) registro de nascimento e identidade; 6) participação da família e da comunidade; 7) sensibilização e mobilização em favor da primeira infância; e 8) treinamento de recursos humanos. Como parte dos objetivos do Plano, previa-se um aumento considerável na cobertura de serviços para a primeira infância por meio dos seguintes programas: 1) Programa de Centros de Atenção Integral à Primeira Infância (Estância Infantil), executado diretamente por órgãos governamentais. São centros que oferecem serviços de educação, saúde e nutrição para crianças de 45 dias a 4 anos e 11 meses; 2) Programa Integral de Atenção à Primeira Infância Familiar e Comunitária (Centros Comunitários), que é executado com a gestão de organizações da sociedade civil. O programa consiste em quatro estratégias para sua implementação: 1) formação de famílias em Educação Oportunidade (estimulação precoce); 2) atendimento integral às crianças de 3 e 4 anos; 3) atendimento domiciliar integral; e 4) formação de famílias por meio de uma rede organizada e articulada de prestação de serviços ${ }^{26}$. 


\section{Uruguai cresce com você UCC (Uruguai)}

Criado em 2012 com o objetivo de consolidar um sistema integral de proteção à primeira infância por meio de uma política que garanta atenção e proteção adequadas às gestantes e o desenvolvimento integral dos menores de 4 anos, na perspectiva da criança. Combina ações focadas e universais. Inclui as seguintes ações: a) ações socioeducativas: campanhas na mídia, welcome pack (material educativo e didático que é entregue a todos os hospitais públicos e privados participantes do país e às famílias participantes; b) geração de conhecimento: realização do inquérito nacional saúde, nutrição e desenvolvimento infantil, convênio com a Universidade da República para apuração de temas prioritários do UCC e avaliação externa; c) Fortalecimento das capacidades institucionais: apoio técnico para a revisão das normas e critérios de atenção à saúde e para a construção de um projeto curricular comum para a educação inicial de crianças de 0 a 6 anos, contratando 30 recursos humanos para fortalecer os graduados no controle da gravidez e nutrição, fortalecimento dos sistemas de informação; d) apoio familiar e trabalho próximo: fortalecer as capacidades das famílias para o desenvolvimento de boas práticas parentais, por meio do trabalho nos domicílios mais vulneráveis, realizado por 211 técnicos da área social e da saúde. As Equipes Técnicas de Proximidade (ETC) acompanham famílias com gestantes e crianças menores de 4 anos que apresentam situação de risco biológico e social ${ }^{30}$.

\section{Conclusão}

A revisão documental mostra que a grande maioria dos países latinoamericanos tem se esforçado para definir políticas voltadas para a primeira infância, com o lançamento de planos integrais ou massivos de atendimento a essa população. No entanto, subsistem desafios importantes para que as iniciativas de garantia do direito da criança à saúde se traduzam em melhorias concretas na situação dos mais jovens, permitindo assim o gozo do direito de todas as crianças ao pleno desenvolvimento das suas potencialidades. 
Entre os desafios a serem enfrentados está a falta de articulação das políticas para a primeira infância com as demais políticas implementadas. Desta forma, entende-se que os governos dos países que compõem a América Latina devem promover iniciativas que demonstrem um papel mais inclusivo na sociedade, bem como que atuem como articuladores do sistema evitando a duplicação de esforços nos serviços, garantindo melhor uso dos recursos. Vencer a batalha contra a pobreza infantil deve ser considerado um desafio para os países, a fim de alcançar eficiência econômica e poder alcançar a cobertura universal dos programas implementados. Isso é necessário em parte porque as deficiências sofridas na infância podem repercutir ao longo de suas vidas, expressando-se na perda de oportunidades na formação integral de crianças com acesso limitado à escola, o que por sua vez contribui para a perpetuação da pobreza na região.

\section{Referencias}

1. Abud S. Infancia, niñez en riesgo, vulnerabilidad infantil, ¿Qué reflejan estos conceptos? Derecho y Soc. 2018;1:51-62.

2. Infancia-UNICEF FDLNUP La convención sobre los derechos del niño.

3. Black PMM, Walker PSP, Fernald LCH, Andersen CT, Digirolamo AM, Lu C, et al. HHS Public Access. 2018;389(10064):77-90.

4. Grantham-McGregor S, Cheung YB, Cueto S, Glewwe P, Richter LSB. International Child Development Steering Group. Developmental potential in the first 5 years for children in developing countries. Lancet. 2007;369(9555):60-70.

5. Children G, Walker SP, Chang SM, Wright A, Osmond C, Grantham-mcgregor SM. Early Childhood Stunting Is Associated with Lower Developmental Levels in the Subsequent. 2015.

6. Lu C, Black MM, Richter LM. HHS Public Access. 2018;4(12).

7. PNUD. Apoyo del PNUD a la implementación del Objetivo de Desarrollo Sostenible 13. 2016;1-16. Disponible en: file:///C:/Users/user/Downloads/SDG_1_Spanish.pdf

8. Engle PL, Black MM, Behrman JR, Cabral de Mello M, Gertler PJ, Kapiriri L, Martorell R YM. International Child Development Steering Group. Strategies to avoid the loss of developmental potential in more than 200 million children in the developing world. Lancet. 2007;369(9557):229-42.

9. OPAS/Brasil. Determinantes Sociais e Riscos para a Saúde, Doenças Crônicas Não Transmissíveis e Saúde Mental [Internet]. 2020 [citado 24 de agosto de 
2020]. Disponible en: hhttps://www.paho.org/bra/index. php?option=com_ content\&view=articlectid=5957:no-brasil-paises-das-americas- definem-proximos-passos-para-o-enfrentamento-da-epidemia-de-obesidade- infantil\&ltemid=839

10. Aulicino C, Documento L. Políticas públicas de desenvolvimento infantil en América Latina. Levantamento e análise de experiências. 2016;

11. Ministerio da Saude. Síntese de evidências para políticas de saúde: promovendo o desenvolvimento na primeira infância / Ministério da Saúde, Secretaria de Ciência, Tecnologia e Insumos Estratégicos, Departamento de Ciência e Tecnologia. 2016;

12. Educacao TP. Plano nacional da ação pelos direitos das crianças e adolescentes [Internet]. [citado 24 de agosto de 2020]. Disponible en: https://www.todospelaeducacao.org.br/primeirainfancia/pais_argentina.html

13. Gobierno de México. Programa de Estancias para Apoyar a Madres Trabajadoras [Internet]. 2016 [citado 24 de agosto de 2020]. Disponible en: https://www.gob. $\mathrm{mx} /$ bienestar/acciones-y-programas/estancias-infantiles-para-apoyar-a-madres-trabajadoras

14. Dipres. Sistema de Protección Integral a la Infancia2020 [Internet]. [citado 24 de agosto de 2020]. Disponible en: http://www.dipres.gob.cl/597/w3- multipropertyvalues-24543-25190.html

15. Presidencia de la República de Costa Rica PI. Equidad para la primera infancia, De cero a Siempre [Internet]. 2012. Disponible en: http://www.deceroasiempre. gov.co/Prensa/CDocumentacionDocs/Equidad-Primera-Infancia.pdf

16. REDCUDI. Red Nacional de Cuido y Desarrollo Infantil [Internet]. [citado 24 de agosto de 2020]. Disponible en: https://redcuidoinfantil.go.cr/

17. Latina A de PI para A. Plan de atención integral a la primera infancia - PAIPI [Internet]. Experiencias de los Países. 2015 [citado 24 de agosto de 2020]. Disponible en: https://www.todospelaeducacao.org.br/primeirainfancia/es-pais_panama.html

18. Gobierno de Ecuador. Estrategia Nacional Intersectorial para la primera infancia-infancia plena [Internet]. [citado 24 de agosto de 2020]. Disponible en: https:// www.todaunavida.gob.ec/primera-infancia/

19. Latina A de PI para A. Política pública de desarrollo integral de la primera infancia Guatemala [Internet]. 2016 [citado 24 de agosto de 2020]. Disponible en: https://www.todospelaeducacao.org.br/primeirainfancia/es-pais_guatemala. html\#:-:text=

20. UNESCO. Políticas y regulaciones [Internet]. [citado 24 de agosto de 2020]. Disponible en: https://siteal.iiep.unesco.org/pt/politicas?pais=8\&eje=2

21. Lamaute-brisson NC. Sistema de Protección Social en América Latina y el Caribe, Haití [Internet]. 2013. Disponible en: https://repositorio.cepal.org/bitstream/ handle/11362/4050/1/S2013067_es.pdf

22. CEPAL. Fortalecimiento de la protección social de Haití [Internet]. 2015 [citado 24 de agosto de 2020]. Disponible en: https://www.cepal.org/pt-br/noticias/discuten-fortalecimiento-del-sistema-de-proteccion-social-de-haiti-en-conferencia-en-puerto 
23. Honduras G de la R de. Ricardo Cardona [Internet]. Segunda. Tegucigalpa; 2015. 19-25 p. Disponible en: https://ceniss.gob.hn/PoliticasPublicas/PAIPI.pdf

24. UNESCO/HONDURAS. Política pública para el Desarrollo Integral de la Primera Infancia. 2018; Disponible en: https://siteal.iiep.unesco.org/sites/default/files/ sit_accion_files/hn_0307.pdf

25. Brasil G de. Brasil cariñoso [Internet]. Fondo Nacional de Desarrollo Educativo. 2016 [citado 25 de agosto de 2020]. Disponible en: https://www.fnde.gov.br/index.php/ programas/brasil-carinhoso/sobre-o-plano-ou-programa/sobre-o-brasil-carinhoso

26. El Diálogo, Fundación María Cecilia, Todos por la educación R. política nacional de primera infancia «amor para los más chiquitos y chiquitas» Nicaragua [Internet]. 2016 [citado 25 de agosto de 2020]. Disponible en: https://www.todospelaeducacao.org.br/primeirainfancia/es-paises.html

27. UNESCO/SITIAL/PANAMÁ. Plan de Atención Integral de la Primera Infancia, PAIPI [Internet]. 2018 [citado 27 de agosto de 2020]. Disponible en: https://siteal.iiep. unesco.org/sites/default/files/sit_accion_files/siteal_panama_0067.pdf

28. Paraguay $\mathrm{M}$ de E y C. Plan nacional de atención integral [Internet]. Paraguay; 2011. Disponible en: https://www.unicef.org/paraguay/media/1756/file/resumen-primera-infancia.pdf

29. Cisneros SP, Social D. Sistema Nacional de Atención Integral al Niño y al Adolescente - SNAINA Plan Nacional de Acción por la Infancia y Adolescencia PNAIA 2002 - 2010 Visión : [Internet]. 2008. Disponible en: https://www2.congreso.gob. pe/Sicr/Comisiones/2007/ComRevNinAdo.nsf/34069c3bb71c123b05256f47006 2fea7/200F3DC04DE2CA7405257466007BC363/\$FILE/SNAINA-PNAIA.pdf

30. Social M de D. Uruguay Crece Contigo. Disponible en: https://www.gub.uy/ ministerio-desarrollo-social/uruguay-crece-contigo-ucc 


\section{Capítulo 6}

\section{POLÍTICAS PÚBLICAS DE NUTRIÇÃO NA AMÉRICA LATINA E CARIBE: REFLEXX̃̃ES SOCIAIS E ANTROPOLÓGICAS}

\section{María Elena Díaz Sánchez ${ }^{1}$}

${ }^{1}$ Antropóloga. Doutora em Ciências da Saúde e Pós-Graduação em Antropologia Sociocultural e Gestão da Informação. Pesquisadora titular e chefe do Laboratório de Antropologia Nutricional do Centro de Nutrição e Higiene Alimentar do Instituto Nacional de Higiene, Epidemiologia e Microbiologia de Havana e professor da Universidade Médica de Havana.

Resumo:

Este capítulo discute a questão das políticas públicas no contexto da Nutrição para a Região da América Latina e Caribe a partir de uma perspectiva antropológica, fornecendo ferramentas metodológicas e teóricas para explorar o significado das políticas, suas implicações culturais a partir de uma perspectiva holística. Discutem-se os obstáculos à formulação de políticas públicas que contemplem processos sociais, práticas culturais, aplicadas a situações de conflito a partir dos fundamentos do estudo antropológico, da linguagem e dos discursos dos formuladores de políticas, ecos do regime socioeconômico vigente. impactos na sociedade vitimada pela política neoliberal exigida pelos dominadores, reforçando a crise econômica, política e social da Região, aumentando a pobreza, a fome e a desnutrição, com o aumento do sobrepeso e da obesidade de forma alarmante, além das deficiências de micronutrientes. Chama a atenção para a existência de normas, aspectos jurídicos, acordos e garantias sobre direitos sociais que os programas devem considerar e não violar, mas que nem sempre são cumpridos, permitindo a permanência da insegurança alimentar das crianças na América Latina e no Caribe.

Palavras-chave: Alimentação Infantil; Políticas de Saúde; Antropologia Cultura. 
Quando passamos a discutir a questão das políticas públicas no contexto da Nutrição para a Região da América Latina e do Caribe sob uma perspectiva antropológica, é relevante considerar alguns esclarecimentos.

A formulação de políticas públicas hoje se tornou uma atividade imersa em processos sociais, práticas culturais, aplicadas a situações de conflitos e isso implica decisões, ações, acordos, instrumentos com a participação do poder público e outros atores sociais para prevenir ou solucionar um problema. Tem sido afirmado na literatura que, se este trabalho de formulação de políticas é definido como práticas socioculturais e formas organizacionais para gerá-las, já estamos nos alicerces do estudo antropológico $0^{1,2}$.

A resposta a várias questões sobre a análise de uma política pública realizada por Shore ${ }^{1}$ passa pela consideração do seu objeto de estudo, das ações que gera, dos contextos institucionais e socioculturais em que são implementadas, da linguagem e do discurso dos formuladores, das decisões que são tomadas, as regras que as originam, o impacto que têm sobre os beneficiários e a forma como respondem. Este autor reafirma que a Antropologia oferece abordagens próprias para o estudo das políticas públicas, nas quais, além dos elementos conceituais e metodológicos, ajudam a compreender o seu funcionamento e fornecem uma compreensão crítica dos processos que estruturam a sociedade. São os regimes de poder e suas relações com os demais atores sociais, para citar alguns, os dirigentes, administradores, facilitadores e, sobretudo, o último elo da cadeia, que são os sujeitos para os quais se dirige a ação política. Diante de tal pluralidade de situações, podem ser identificadas lacunas nas descrições das políticas entre pessoas de fora do processo, como acadêmicos e analistas com os participantes que as projetam, além do impacto que esses contrastes podem gerar nas pessoas que as recebem.

Mas as políticas refletem concepções de mundo, que são ecos do regime socioeconômico predominante representado pelos estados; por exemplo, na maioria dos países da América Latina e do Caribe, segue-se uma linha neoliberal no desenvolvimento de suas políticas sociais. Portanto, quando as políticas se constituem como instrumentos de intervenção e ação social, elas podem impor sua ordem, pois dentro de suas funções é legitimar as decisões da mais alta autoridade administrativa, que é o aparelho do Estado, então exerce-se uma vontade política, de acordo com visões e interesses e está relacionada à 
complexidade cultural em que a sociedade civil está imersa, mas nem sempre são bem-sucedidos. Essas estratégias dependem da instabilidade do ciclo político dos países, portanto sua projeção pode ser temporária e decrescente.

As abordagens antropológicas permitem analisar a racionalidade das políticas públicas, que são práticas culturais situadas, atravessadas por atores sociais como o Estado, agências humanitárias, o Banco Mundial, as Nações Unidas, a sociedade civil, etc. e em seu desenho as relações de poder se manifestam, mas seu propósito é tentar resolver um problema social.

Segundo Huerta ${ }^{3}$, o processo político se diferencia pela esfera pública, pelo alcance de seus objetivos e por um poder diferenciado. Segundo essa abordagem, o poder está em uma relação que obtém obediência da outra parte interagente, mas com um pedido de obrigações subsequentes e, nesse sentido, constitui um meio simbólico que legitima o governamental ${ }^{4}$. Há uma relação aqui onde o setor empoderado tem o controle dos recursos econômicos e busca o domínio do social e do simbólico ${ }^{5}$, sobre a população silenciada, articulando um discurso hegemônico e nessa interação os sujeitos assumem identidades coletivas ${ }^{2}$. É por isso que a análise de políticas públicas requer uma abordagem antropológica, etnográfica, multisituacional para compreender os diferentes pontos de vista dos atores envolvidos em sua relação, desde uma perspectiva global (Estado x populações), ou local, com a interpretação da comunidade, o que nos permite perceber a complexidade desses processos.

A antropologia, em uma de suas linhas de trabalho, trata da análise de categorias de complexidade sociocultural, úteis para analisar as políticas públicas que os Estados desenvolvem com outros atores sociais e que atuam efetivamente para os beneficiários que delas necessitam. A antropologia constitui assim um instrumento de aplicação, do ponto de vista acadêmico e da prática, que pode contribuir com os seus métodos de trabalho para as estratégias organizacionais e avaliação de impacto, entre outros, na missão do Estado e das instituições humanitárias para a execução de políticas públicas, dirigidas ao cidadão.

O estado é uma instituição gerada por pessoas, que tem dentro de suas funções administrar, priorizar e distribuir recursos, definir e implementar políticas sociais, que visem a melhoria da qualidade de vida da população 
vulnerável, que em termos de direitos humanos corresponde a ser protegida e nesta ação são criadas novas categorias para descrever às pessoas (por exemplo: cidadão, camponês, estudante, mulher, etc.).

A antropologia fornece ferramentas metodológicas e teóricas para explorar o significado das políticas, suas implicações culturais de uma perspectiva holística; Pode auxiliar na implementação de estratégias, verificando se as ações beneficiariam real e diretamente os grupos de cidadãos mais vulneráveis com uma abordagem de direitos, respeitando suas crenças e imaginações sociais. Mas, mesmo numa fase anterior, pode contribuir para a análise da construção da própria política (seja ela adequada ou não), das dificuldades da sua aplicação, das características dos atores diretos responsáveis pela sua implementação, em termos de honestidade, eficácia de suas funções e liderança como facilitadores, entre outros aspectos importantes para seu desenvolvimento.

Finalmente, pode-se afirmar que as diversas técnicas antropológicas, baseadas em pesquisas qualitativas ${ }^{6}$, também estão preparadas para avaliar o impacto das intervenções, a partir dos planos e programas gerados pelas políticas, por meio de um trabalho interpretativo que pode ser realizado em pesquisas, entrevistas, grupos de discussão, estudos de caso e em algumas ocasiões, dependendo do tipo de ações realizadas, também é possível uma avaliação física ou antropométrica dos indivíduos.

Uma velha crítica à abordagem antropológica tem sido a limitação do trabalho em áreas ou comunidades específicas, embora proporcionem um maior acervo de conhecimentos da complexidade sociocultural. Porém, há algum tempo, a etnografia "multilocal"” tem sido reconhecida nestes espaços, o que implica a aplicação de estudos em diferentes lugares, áreas ou cidades, proporcionando mais informação sobre um determinado tema, com instrumentos menos extensos para trabalho de campo.

Os elementos levantados contribuem para saber, juntamente com aspectos que podem ser de ordem econômica, jurídica, entre outros, se determinada política pública cumpria a finalidade para a qual foi concebida e, caso contrário, permitiria nortear quais seriam as modificações ou novas linhas de trabalho para fazer. Ou seja, obteríamos conhecimento coletivo como feedback de uma ou de certas políticas públicas aplicadas a uma população ou 
populações-alvo, por isso é muito importante saber com certeza o argumento de quem tem seus direitos humanos e cidadãos violados.

Dentre as políticas públicas desenvolvidas nos países da América Latina e do Carie, as relacionadas à alimentação e nutrição têm sido muito frequentes, devido ao grande problema de insegurança alimentar existente, causada pela desigualdade no acesso aos alimentos, principalmente entre as populações mais empobrecidas.

Isso vem ocorrendo desde o século passado no contexto de acordos neoliberais e mudanças de governos que têm esse modelo, em paralelo às dificuldades do mercado de trabalho, com queda de salários, desemprego, entre tantas outras situações. Essas políticas na América Latina são bem conhecidas, pois foram replicadas em diferentes países da Região e estão publicadas em diversos relatórios ${ }^{8-11}$.

As políticas alimentares são consideradas bem-estar a partir de seus objetivos, critérios de seleção e segmentação da população beneficiária ${ }^{10}$. Essa conceituação em sua adaptação aos tempos modernos se baseia, como apontam Soldano e Adrenacci ${ }^{12}$, no fato de que a política de previdência entregou bens e serviços a uma parcela da sociedade que não se integrava ao mercado de trabalho, ou que sua situação irregular não atendia às necessidades básicas da vida nas sociedades de mercado. Outras abordagens dizem respeito às relações de poder hegemônicas, com as desigualdades sociais se tornando cada vez mais tangíveis.

No desenvolvimento de políticas públicas, também ao nível da alimentação, do Estado ou com abordagem setorial, impõe-se um conjunto de decisões, conflitos ou situações dos diversos atores na sua complexidade que devem ser analisados. Por outro lado, também existem normas, aspectos jurídicos, acordos e garantias sobre os direitos sociais que os programas devem considerar e não violar, portanto, não basta que sejam firmados acordos em relação aos direitos, mas que sejam cumpridos. Os vínculos entre a ordem pública e o direito não são claros e, portanto, não são necessariamente concebidos de acordo com ele ${ }^{10}$. No que diz respeito às necessidades alimentares, apesar de constituírem um fator de sobrevivência, as políticas nem sempre se aprofundam para obter um resultado positivo, de forma a satisfazer as carências dos grupos sociais mais precários, violando assim a abordagem legal. 
Na América Latina, foram desenvolvidos inicialmente programas nacionais de assistência alimentar, como medidas compensatórias em contextos de privação, acompanhados de políticas de inclusão social, relacionadas à renda, trabalho assalariado, educação, saúde e outros, posteriormente destacando alguns países para abastecimento e doações de produtos alimentares, subsídios, bem como intervenções diretas de programas de alimentação complementar, suplementação e educação em aspectos da nutrição, dirigidos aos mais vulneráveis, nem sempre bem selecionados. A mudança para outras estratégias com programas de complementação e suplementação mais seletivos favoreceu uma implementação de curto prazo, benéfica para os implementadores da política no que diz respeito aos custos, mas difícil de medir o impacto, sem monitoramento e avaliação, prevalecente nos setores urbanos ${ }^{10}$; Também se deu atenção à vigilância nutricional na Região.

Outro aspecto muito importante discutido foi a falta de racionalidade na gestão organizacional dos benefícios em territórios com diferentes cenários de gravidade e a existência ao mesmo tempo de grande número de programas em funcionamento. Dada a complexidade das situações alimentares, os especialistas argumentam que os programas de assistência, que criam um quadro de melhoria, tornaram-se programas de assistência, relacionados com a continuidade e manutenção de esquemas de desigualdade ${ }^{13}$. No decorrer dos eventos na Região, essas intervenções alimentares de base assistencial foram se ampliando, até se tornar o espaço de ação do Estado por excelência, em comparação com outros setores, como a indústria agroalimentar.

Por sua vez, o direito à alimentação está refletido na Declaração Universal dos Direitos Humanos ${ }^{14}$ e o Estado como fiador deles junto à população deve cumprir essa máxima mas, o neoliberalismo existente na maioria dos países da América Latina e do Caribe limita a função do Estado de garantir o desenvolvimento do mercado livre, sem realizar ações que gerem um benefício global para os cidadãos. Isso tem reforçado a crise econômica, política e social da Região, aumento da pobreza, fome e desnutrição, com aumento do sobrepeso e da obesidade de formas alarmantes, manifestando também estados de deficiência de micronutrientes. 
Não foi abordada a necessidade de uma universalidade de ações para assumir o direito das pessoas a uma alimentação adequada em termos de cultura e nutrição. As violações são graves e estão longe de serem vencidas. Estes ocorrem durante a cadeia do processo alimentar, que inclui a produção e obtenção de alimentos da natureza, transformação, troca, consumo e nutrição ${ }^{15}$, impactando nas relações sociais e no meio ambiente.

O papel das agências das Nações Unidas e outras organizações não governamentais (ONGs) tem sido representado na implementação de programas de ajuda humanitária ${ }^{16}$, que têm servido para aliviar situações de crise alimentar, entre outros, mas de forma alguma resolver o problema. A situação social desfavorável que atravessa a Região é reconhecida por diversos relatórios técnicos e administrativos e publicações científicas ${ }^{17,18,19}$.

Vários relatos tratam da evolução do problema alimentar-nutricional na região, por meio das confirmações obtidas pelos programas de assistência alimentar ${ }^{15,20,21}$. Recentemente, foi reiterado que a fome e a desnutrição tiveram um alto impacto na qualidade de vida da população, os custos de saúde, sociais e econômicos aumentaram e há fortes evidências de um duplo fardo da desnutrição.

Embora tenha sido relatada uma rápida redução nas prevalências de nanismo e desnutrição atual em crianças, os números alcançados podem mascarar as desigualdades nos países da Região22. Os dados atualizados no observatório de nutrição da Organização Mundial da Saúde (OMS) para crianças menores de cinco anos de idade confirmam esta abordagem (retardo de crescimento, ano 2020: 6,3\% [3,7-10,0]; desnutrição, ano 2019: 0,8\% [0,5-1,4]), destacando-se também os valores de excesso de peso nessas idades (ano 2019: 7,3\% [6,1-8,7]). Da mesma forma, indica-se que as Américas já são consideradas a região com maior sobrepeso e obesidade do mundo, com prevalência em maiores de 18 anos de 63,4\% [61,3-65,3] para sobrepeso (ano 2016) e quase uma em 3 pessoas com obesidade (ano de 2016: 29,0\% [27,1-31,0]). A anemia (dados de 2016) está presente em $19,1 \%$ [13,9-26,5] das mulheres em idade reprodutiva e em crianças pequenas atinge valores de $22,7 \%[16,8-30,1]$, tudo isso acompanhado de aumento das doenças crônicas não transmissíveis ${ }^{23}$.

Para reverter esse cenário, é necessária uma transformação dos Sistemas 
Alimentares em outros modelos sustentáveis que garantam uma nutrição adequada. Para isso, devem ser formuladas políticas públicas alimentares, onde o Estado e demais atores sociais garantam a Segurança Alimentar e o bem-estar nutricional em todas as idades e grupos de cidadãos.

Nosatuaisregimespolítico-econômicosqueprevalecemnaRegião,aaliment ação, antes de cumprir seu papel de satisfação das necessidades da população, é percebida como mercadoria, tem um preço e é consumida enquanto houver poder aquisitivo. Se não há possibilidades para os indivíduos identificados como consumidores, então há uma lacuna que deve ser preenchida, não com intervenções alimentares assistenciais, mas com uma profunda transformação intersetorial dos Sistemas Alimentares; na verdade, estes são responsáveis por fornecer alimentos à população, aumentando a disponibilidade, o acesso e o consumo, com diversidade na alimentação, segura e culturalmente adequada.

O modelo neoliberal vigente em muitos países da Região considera um sistema alimentar de tipo corporativista, com interesses e métodos de gestão econômica voltados para o exercício de uma estratégia de desapropriação, com mudanças culturais e de consumo a partir do empoderamento das corporações que monopolizam a todos na cadeia alimentar, restringindo as alternativas de pequenos produtores e consumidores ${ }^{15}$. Por outro lado, quando se insiste que o campesinato tem práticas produtivas obsoletas, impondo o uso de sementes certificadas em vez das originais, seu pensamento modernizador leva à destruição da agricultura tradicional. Assim, recomendam a globalização dos sabores e do consumo, e manifestam o controle ao difundir as junk food de diferentes formas, estabelecendo competição com relação aos alimentos tradicionais. Apesar dos inegáveis problemas alimentares atuais, eles defendem o mercado livre como fonte de riqueza e progresso. Este sistema alimentar corporativo intervém nas decisões sobre a produção, transformação e consumo de alimentos, reduzindo a capacidade dos demais atores sociais que deveriam participar nessas disposições. Em suas ações, também ganham a participação multilateral de agências de cooperação e organismos regionais, tornando-se doadores financeiros.

Nessa situação complexa ocorre o abuso de alimentos ultraprocessados, pobres em nutrientes, mas ricos em açúcar, sal ou gordura ${ }^{24,25}$, que estão as- 
sociados ao aumento das doenças crônicas não transmissíveis, com destaque para a obesidade.

Ao contextualizar a assistência alimentar, por meio de políticas públicas nos diversos países da Região no combate à pobreza, no marco de um enfoque de direitos, desde o século passado, a Segurança Alimentar é invocada em acordos, regulamentos, convenções para a implementação dos programas ${ }^{10}$ e foram publicadas evidências da situação, planejamento e resultados a esse respeito, com diferentes perspectivas de análise ${ }^{26-30}$.

O conceito de Segurança Alimentar sofreu muitas mudanças ${ }^{31}$; considerando que algumas dessas modificações têm dificultado ações concretas de políticas alimentares. A consolidação conceitual que vem ocorrendo é consequência do agravamento dos problemas apresentados no mundo; tem evoluído de forma holística e com maior rigor devido à sua utilização em cenários díspares, com a contribuição dos diferentes atores ligados ao processo, podemos citar, entre outros, governos, sociedade civil, investigação científica e também têm sido agências multinacionais relevantes. Nesse contexto de situações, foram identificados os fatores que influenciam a insegurança alimentar presente no mundo contemporâneo.

Grande parte das definições de Segurança Alimentar contém como objetivo primordial a conquista de uma vida saudável e ativa, que permita o desenvolvimento integral das pessoas e da sociedade. Nesse sentido, uma abordagem de direitos é invocada ao considerar que as pessoas devem ter acesso físico, social e econômico permanente a alimentos seguros e nutritivos em quantidade suficiente para satisfazer suas necessidades nutricionais e poder desenvolver uma vida ativa e saudável, (publicado em documentos da FAO, 2011) ${ }^{32}$. Relacionado a este marco conceitual, nas políticas de Segurança Alimentar, os aspectos macro e microeconômicos são tocados em três eixos, que envolvem a disponibilidade e acesso aos alimentos, consumo, uso e aproveitamento biológico desses, bem como qualidade e segurança.

Nesse sentido, vale destacar os argumentos do fórum de ONGs durante a Cúpula Mundial da Alimentação de 2002. Os documentos disponíveis dessa reunião ${ }^{33}$ mostram a rejeição dos movimentos sociais aos problemas não resolvidos para a erradicação da fome e o fracasso da políticas aplicadas nos países; Ficou abertamente exposta a monopolização e concentração 
desenfreada de recursos e processos produtivos nas mãos de poucas grandes empresas, bem como o aumento da produtividade de curto prazo com o uso de organismos geneticamente modificados, entre outras abordagens, motivos pelos quais a insegurança aumentou Comida.

Nesse sentido, vale destacar os argumentos do fórum de ONGs durante a Cúpula Mundial da Alimentação de 2002. Os documentos disponíveis dessa reunião ${ }^{33}$ mostram a rejeição dos movimentos sociais aos problemas não resolvidos para a erradicação da fome e ao fracasso das políticas aplicadas em. os países; ficou abertamente exposta a monopolização e concentração desenfreadas de recursos e processos produtivos nas mãos de poucas grandes empresas, bem como o aumento de produtividade a curto prazo com o uso de organismos geneticamente modificados, entre outras abordagens, motivos pelos quais a insegurança aumentava os alimentos.

A Soberania Alimentar apresenta uma conceituação mais ampla ao incluir uma posição de direitos em seu enunciado, considerando as práticas culturais dos cidadãos e respeitando o meio ambiente, tomando os diferentes movimentos sociais como marco estratégico. Foi desenvolvido pela Via Campesina (LVC), discutido durante a Cúpula da FAO de 1996 e posteriormente modificado até a Declaração de Nyéléni no fórum de Soberania Alimentar de $2007^{34}$. Assim, a definição declara o direito dos povos de obter alimentos saudáveis e produtos culturalmente adequados produzidos com métodos ecológicos e sustentáveis, bem como definindo seus próprios Sistemas Alimentares e Agrícolas.

Foram apontados aspectos comuns entre Segurança Alimentar e Soberania Alimentar, mas, também diferentes perspectivas entre sistemas agroalimentares com enquadramentos alternativos, sendo esses contrastes as visões epistémicas correspondentes a cada definição ${ }^{35}$. A partir dessas abordagens é que propõem que a Segurança Alimentar esteja relacionada com a agronomia e as ciências naturais, concentrando conhecimentos a nível individual ou doméstico para identificar culturas consideradas eficientes de acordo com conteúdo nutricional, condições e custos de produção, mas esta participação local é oficialmente reduzida por modos de produção com conhecimento técnico, acompanhando avanços agrícolas, sementes melhoradas, novos produtos, dentre outros. 
Por sua vez, a Soberania Alimentar está mais associada à ecologia e às ciências sociais, tende a suscitar uma visão multidisciplinar dos sistemas agrícolas, que se complementa ao nível local, considerando métodos de cultivo, produção camponesa, hábitos e preferências alimentares; propõe mudanças nos padrões de consumo, transporte e processamento e outros, a fim de melhorar os processos agrícolas, defender a pequena e média agricultura, em oposição à indústria.

As estimativas mais atualizadas da FAO para o período 2012-2014 indicam que 37 milhões de pessoas passam fome na América Latina, 15\% a menos que no triênio 1990-1992, mas a situação está longe de ser controlada, apesar de ter sido reduzida à metade, em correspondência com a meta estabelecida pelos Objetivos de Desenvolvimento do Milênio (ODM). Para reverter esta situação, foi proposto o desenvolvimento de várias políticas públicas com grande impacto nas populações mais vulneráveis, afirmando que na Região há alimentos suficientes para cobrir as necessidades, mas o acesso é difícil ${ }^{36}$.

A Agenda 2030 para o Desenvolvimento Sustentável propõe um limite de 15 anos para eliminar a pobreza e a fome, para o qual todos os países são chamados a trabalhar em coordenação e eliminar as causas que mantêm as pessoas em situação de insegurança alimentar e desnutrição, com o compromisso da FAO com ações de acompanhamento ${ }^{37}$.

Para compreender o impacto dos Sistemas Alimentares ao nível da concepção e implementação de políticas, programas, monitoria e avaliação, governação e apoio financeiro, são necessárias mais informações sobre as intervenções que promovem o bem-estar nutricional, bem como estudos multissetoriais estilos de vida saudáveis. Para tanto, foram considerados dados de 33 países membros da CELAC ${ }^{21}$. A partir da análise das intervenções, observou-se a promoção e uso de alimentos nutritivos, o uso de guias alimentares, diversidade alimentar, cultura culinária tradicional, rotulagem nutricional e regulamentação publicitária de alimentos ultraprocessados. Da mesma forma, foram identificadas atividades de benefício direto à população (entrega periódica de alimentos, transferências de dinheiro, educação nutricional, dentre outras.), atividades para garantir o funcionamento do programa (comissões técnicas, treinamento, monitoramento, supervisão, avaliação do estado nutricional, e outros) e atividades de fortalecimento de programas 
(articulação entre programas, gestão de políticas públicas, resgate de tradições, empoderamento de cidadãos e outros).

Esses resultados permitem vislumbrar que os países da América Latina e do Caribe estão trabalhando para promover comportamentos alimentares mais adequados, ao mesmo tempo em que vêm ampliando suas políticas públicas, havendo potencial para melhorar o bem-estar nutricional, apesar da fardos de desnutrição combinados existentes.

Em relação às políticas públicas para melhorar o bem-estar nutricional na infância, embora persistam várias formas de desnutrição $0^{38}$ na atualidade, destaca- se o sobrepeso e a obesidade ${ }^{39}$ devido ao aumento das prevalências na Região ${ }^{23}$, com uma abordagem multissetorial que combina o consumo de alimentação saudável, atividade física e diminuição do tempo de tela devido ao uso abusivo de produtos de informática, limitação de publicidade e outros fatores negativos do Ambiente Alimentar, que caracterizam o ambiente obesogênico em que se insere.

Para que as políticas públicas de combate à obesidade sejam efetivas, por exemplo, na escola e na adolescência, é preciso estudar as percepções e representações das crianças e suas famílias sobre o problema no imaginário coletivo. A intervenção educativa sobre alimentação e nutrição é imprescindível, dentro da abordagem dos direitos, acompanhada da existência e legitimidade de produtos saudáveis para consumo. Mas avaliar o impacto no crescimento e no estado nutricional a curto, médio e longo prazo por meio do monitoramento ajudará a mostrar o sucesso dos programas. 0 estudo da complexidade cultural da família é importante na abordagem das políticas públicas de nutrição na infância, para promover práticas alimentares seguras baseadas em orientações alimentares e, nos primeiros 1000 dias de vida, promover o aleitamento materno exclusivo. De uma perspectiva hegemônica, a infância constitui a transição para a vida adulta e requer um modelo de família; é uma fase de grande plasticidade pelo crescimento e desenvolvimento, onde se incutem hábitos, costumes, enfim, estilos de vida com os quais o indivíduo irá evoluir para um resultado final já mais difícil de transformar.

Atualmente, o flagelo da pandemia COVID-19 está afetando os sistemas alimentares, há interrupções no processo produtivo, afetando a distribuição 
e o acesso aos alimentos. A longo prazo, a segurança alimentar terá um impacto de enormes proporções, que se fará sentir nos países mais afetados pelas crises, os marginalizados e os vulneráveis ${ }^{40}$. Assim, compromete-se o cumprimento da meta para 2030, por isso propõe-se atuar fortemente na mobilização de governos, sociedade civil e demais atores sociais para a formulação de políticas públicas adequadas que promovam a Segurança Alimentar.

\section{Referências}

1. Shore C. La antropología y el estudio de la política pública: Reflexiones sobre la “formulación” de las políticas. Antípoda 2010;10 (enero-junio):21-49.

2. Ramírez, MC. La antropología de la política pública. Antípoda 2010;10 (enerojunio):13-17.

3. Huerta MG. Procesos interculturales y construcciones sociales: apuntes para una antropología de las políticas públicas. Iberoamérica Social: revista-red de estudios sociales, 2016; VI, pp. 118-134. [citado 16 de mayo 2020]; Disponible en: http://iberoamericasocial.com/procesos-interculturales-construcciones-sociales-apuntes-una-antropologia-las-politicas-publicas.

4. Swartz M, Turner V, Tuden, A. Antropología política: una introducción. Alteridades, 1994;4(8):101-126.

5. Huerta MG. Los múltiples sentidos de las políticas públicas. Una propuesta etnográfica para su análisis, VII Jornadas Santiago Wallace de Investigación en Antropología Social. Sección de Antropología Social. Instituto de Ciencias Antropológicas. Facultad de Filosofía y Letras, UBA, Buenos Aires, 2013. [citado 29 de mayo 2020]; Disponible en: https://www.aacademica.org/000-063/219.

6. Fick, U. Introducción a la Investigación Cualitativa. 3ra Ed. Madrid: Ediciones Morata. 2012.

7. Marcus G. Ethnography in/of the World System: The Emergence of Multi-sited Ethnography", Ann Rev Anthropol 1995;24:95-117.

8. Barquera S, Rivera-Dommarco J, Gasca-García A. Políticas y programas de alimentación y nutrición en México. Salud Publica Mex 2001;43:464-77.

9. Vivero Pol JL, Ramírez P. Leyes, políticas e instituciones contra el hambre en el contexto latinoamericano. En: Vivero JL, Erazo J, editores. Derecho a la Alimentación, Políticas Públicas e Instituciones contra el Hambre. Santiago: Ediciones LOM; 2009. p. 123-171.

10. Sartasiero LH. Las políticas sociales en el caso de la satisfacción de necesidades alimentarias. Trabajo y Sociedad 2012;159-176. 
11. Pereyra I. Políticas públicas em Uruguay y la autonomía de las personas, Rev. Cubana Salud Púb. 2019;45(1):e1238.

12. Soldano D, Andrenacci L. Aproximación a las teorías de la política social a partir del caso argentino. En: Andrenacci L (compilador). Problemas de política social en la Argentina contemporánea. Buenos Aires: Editorial Prometeo. 2005. p. 21-89

13. Álvarez, S. Los discursos minimistas sobre las necesidades básicas y los umbrales de ciudadanía como reproductores de la pobreza. En: ÁLVAREZ, Sonia (Compilador.) Trabajo y producción de la pobreza en Latinoamérica y el Caribe: estructuras, discursos y actores. Buenos Aires: CLACSO; 2005. p. 239-273.

14. Naciones Unidas. Declaración universal de los derechos humanos. Naciones Unidas. [Actualización 2020; citado 15 de junio 2020]; Disponible en: https://www. un.org/es/udhrbook/.

15. Morales González JC, Salcedo Fidalgo H, Medina Bernal JL, Rodríguez Navarro SA, Romero Niño IP, Holguín Reyes P. Perspectivas sobre Derecho a la Alimentación y Nutrición Adecuadas. Colombia, FIAN. Año 1, Número 1, 2018. 111p.

16. Martínez-Mauri M. Una mirada antropológica a las Organizaciones no gubernamentales. En: Antropología Social. Algunos debates actuales. Editorial UCO. 2010; 141-202.

17. Martínez R, Palma A, Atalah E, Pinheiro AC. Inseguridad alimentaria y nutricional en América Latina y el Caribe. Comisión Económica para América Latina y el Caribe (CEPAL). Programa Mundial de Alimentos (PMA). Naciones Unidas. 2009.

18. Jiménez-Benítez $D$, Rodríguez-Martín A, Jiménez-Rodríguez R. Análisis de determinantes sociales de la desnutrición en Latinoamérica. Nutr Hosp 2010; 25(Supl 3):18-25.

19. Comisión Económica para América Latina y el Caribe (CEPAL), "Ruralidad, hambre y pobreza en América Latina y el Caribe", Documentos de Proyectos (LC/S.2018/119), Santiago, 2018.65p

20. González M, Pasarin L, Malpeli A. Políticas sociales de alimentación. X Jornadas de Sociología. Facultad de Ciencias Sociales, Universidad de Buenos Aires, Buenos Aires, 2013. [citado 13 de junio 2018]; Disponible en: http://www.aacademica. org/000-038/498.

21. Molina Barrera V, Mejicano Robles G, Alfaro Villatoro N, Rivas Siliézar RM, Hernández-Garbanzo Y, Rapallo Fernández R, et al. Intervenciones de Fomento al Bienestar Nutricional en América Latina y el Caribe: oportunidades para fortalecer las políticas y programas de alimentación y nutrición. Rev Esp Nutr Comunitaria 2018;24(4):1-16.

22. Grajeda R, Hassell T, Ashby-Mitchell K, Uauy R, Nilson E. Regional Overview on the Double Burden of Malnutrition and Examples of Program and Policy Responses: Latin America and the Caribbean. Ann Nutr \& Metab 2019; 75:139-143. DOI: 10.1159/000503674. 
23. WHO Global Health Observatory data repository. Global and regional trends by WHO Regions, 1990-2025 [updated 2020; [cited 2020 Jun 27]; Available from https://apps.who.int/gho/data/view.main.

24. Pan American Health Organization. Ultraprocessed food and drink products in Latin America: Trends, impact of obesity, policy implications. Washington: PAHO. 2015.

25. Ezzahra Housni F, Magaña González CR, Macías Macías A, Aguilera Cervantes VG, Bracamontes del Toro H. La Antropología Nutricional y el estudio de la dieta. Actualización en Nutrición 2016;17(3):87-93.

26. Zamora Valdés $P$, Rodríguez Oisiac L, Pinheiro Fernandes A, Ivanovic Willumsen AC, Cofre Sasso C, Pizarro Quevedo T. Política Nacional de Alimentación y Nutrición. Ministerio de Salud. Santiago. Chile. 2017.

27. CEPAL (Comisión Económica para América Latina y el Caribe), CAC/SICA (Consejo Agropecuario Centroamericano del Sistema de la Integración Centroamericana) y SIECA (Sistema de Integración Económica de Centroamérica). Seguridad alimentaria y nutricional en Centroamérica y la República Dominicana: Explorando los retos con una perspectiva sistémica, LC/MEX/TS.2017/29, Ciudad de México. 2017. 185p.

28. Leavy MP, Szulc AP, Anzelin I. Niñez indígena y desnutrición Análisis antropológico comparativo de la implementación de programas alimentarios en Colombia y Argentina. Cuadernos de Antropología Social 2018;48:39-54.

29. Sistema de información de tendencias educativas en América Latina (SITEAL). Política de Seguridad Alimentaria y Nutricional 2011-2021. [Actualización 2018; citado 21 de junio, 2020]; Disponible en: www.siteal.iiep.unesco.org.

30. FAO, OPS, WFP y UNICEF. Panorama de la seguridad alimentaria y nutricional en América Latina y el Caribe 2019. Santiago. 135 p.

31. Cárcamo Mallen RW, Álvarez Macías A. La Seguridad Alimentaria y las Políticas Públicas. Una visión conceptual. Sociedades Rurales. Producción y Medio Ambiente 2014;14(27):97-126.

32. Organización de Naciones Unidas para la Agricultura y la Alimentación. La Seguridad Alimentaria: Información para la toma de decisiones. 2011. [citado 26 de junio 2020]; Disponible en: .http://www.fao.org/docrep/ 014/al936s/al936s00. pdf.

33. Organización de Naciones Unidas para la Agricultura y la Alimentación. Cumbre Mundial sobre la alimentación. Anexo III. FAO, junio 2002. [citado 28 de junio 2020]; Disponible en: .http://www.fao.org/3/Y7106s/Y7106S02. htm\#P516_72987.

34. Nyéléni Forum. Declaración de Nyéléni 2007. [citado 29 de junio, 2020]; Disponible en: https://nyeleni.org/spip.php?article291.

35. Waldmueller JM, Rodríguez Avalos L. La soberanía alimentaria más allá de la técnica: Una aproximación global hacia su monitoreo intercultural. Rev Centro Andino Est Internacionales 2015;15:253-286. 
36. Organización de Naciones Unidas para la Agricultura y la Alimentación. Seguridad alimentaria y nutricional en América Latina y el Caribe. 2020. [Actualización 2020; citado 27 de junio 2020]; Disponible en: 36.http://www.fao.org/americas/ prioridades/. seguridad-alimentaria/es/

37. Naciones Unidas (UN). Objetivos de Desarrollo Sostenibles 2015. Agenda 2030 para el Desarrollo Sostenible. [citado 29 de junio 2020]; Disponible en: https:// www..un.org/sustainabledevelopment/es/development-agenda/.

38. Programa Mundial de Alimentos (PMA). Política em materia de Nutrición. Tema 4. Primer período de sesión extraordinaria de la Junta Ejecutiva directiva. Roma, 20-23 de febrero, 2017.

39. Araneda J, Pinheiro AC, Rodríguez L. Una mirada actualizada sobre los Ambientes Alimentarios y obesidad. Rev Chil Salud Pública 2020;24(1): 67-71.

40. Johnsen JT, Buckner L, Ray S. Knowledge synthesis and translation in global food and nutrition security to evaluate and accelerate priority actions. bmjnph 2020;0:1- 2. doi:10.1136/bmjnph-2020-000104. 


\section{Capítulo 7}

\section{MORTALIDADE INFANTIL NA AMÉRICA LATINA E CARIBE: INTERFACE COM AS POLITICAS PÚBLICAS E SOCIAIS}

Maressa Cristiane Malini de Lima'; Janine Pereira da Silva², Eugenia de las Mercedes Aguilar Lema ${ }^{3}$, Faride E. Rodríguez Díaz ${ }^{4}$, Helder Gomes ${ }^{5}$, Valmin Ramos-Silva ${ }^{6}$

Bióloga. Doutora em Genética e Biologia Molecular pela Universidade Estadual de Londrina (UEL). Docente do Programa de Pós-Graduação em Políticas Públicas e Desenvolvimento Local da Escola Superior de Ciências da Santa Casa de Misericórdia de Vitória (EMESCAM). E-mail: maressa.lima@emescam.br.

${ }^{2}$ Nutricionista. Doutora em Ciências da Saúde/Saúde da Criança e do Adolescente. Universidade Federal de Minas Gerais (UFMG). Docente do Programa de Pós-Graduação em Políticas Públicas e Desenvolvimento Local da Escola Superior de Ciências da Santa Casa de Misericórdia de Vitória (EMESCAM). E-mail: janine.silva@emescam.br.

3 Doutora em Medicina e Cirurgia. Universidad Central del Ecuador, Diplomado Superior en Políticas de Salud y Género. Facultad Latino Americana de Ciencias Sociales (FLACSO); Diplomado Superior en Salud y Nutrición Humana. Instituto de Post Grado de la Universidad Central del Ecuador. E-mail: euge28051204@gmail.com.

${ }^{4}$ Nutricionista-Dietista. Mestre em Saúde Pública, com ênfase em Epdemiologia. Pesquisadora. Instituto Conmemorativo Gorgas de Estudios de la Salud. Docente en la Facultad de Medicina de la Universidad de Panamá. e-mail: faridesther@hotmail.com.

Economista. Mestre em Ciências Econômica. Doutor em Política Social. Pós-Doutorado em Política Social. Universidade Federal do Espírito Santo. Docente do Programa de PósGraduação em Políticas Públicas e Desenvolvimento Local da Escola Superior de Ciências da Santa Casa de Misericórdia de Vitória (EMESCAM). E-mail: helder.gomes@emescam.br.

${ }^{6}$ Biólogo. Médico Pediatria. Mestre em Biologia Vegetal. Universidade Federal do Espírito Santo (UFES). Doutor em Pediatria. Universidade Federal de Minas Gerais (UFMG). Pós-Doutorado em Educação (UFES)Docente do Programa de Pós- Graduação em Políticas Públicas e Desenvolvimento Local da Escola Superior de Ciências da Santa Casa de Misericórdia de Vitória (EMESCAM). E-mail: valmin.silva@gmail.com.

Resumo:

Introdução. A mortalidade infantil, representada pelo número de óbito em menores de um ano de vida, por mil nascidos vivos é um indicador social reflete e reflete em nível global, as condições de vida e saúde, vinculadas à situação socioeconômica, de um país. Objetivo: descrever a evolução da mortalidade infantil na América Latina e Caribe nos últimos 18 anos. Método: Consultas a Bases de Dados da América Latina, seguido pela organização e análise descritiva dos dados. 
Resultados: Cuba é o país que sempre teve taxas de Mortalidade Infantil muito inferiores às recomendadas pela OMS, enquanto o Haiti, embora tenha reduzido as taxas em mais de $50 \%$ ao longo dos anos, ainda permanece com taxas extremamente altas. Conclusão: Percebe-se que as políticas neoliberais implantadas na América Latina, contribuíram para o aumento da pobreza e para a piora das condições de vida da população. Países que recorreram ao FMI têm o pior desempenho no indicador mortalidade infantil.

Palavras-chave: Indicadores básicos de saúde, Políticas de saúde, Mortalidade Infantil, Criança.

\section{Introdução}

A taxa de mortalidade infantil é um indicador social representado pelo "número de óbitos de menores de um ano de idade, por mil nascidos vivos, em determinado espaço geográfico, no ano considerado", sendo utilizada para "analisar variações geográficas e temporais de mortalidade infantil; contribuir na avaliação dos níveis de saúde e de desenvolvimento socioeconômico da população, além de subsidiar processos de planejamento, gestão e avaliação de políticas e ações de saúde voltadas para a atenção pré-natal, o parto e a proteção da saúde infantil"1.

O óbito neonatal ( 0 ao $27^{\circ}$ dia de vida), importante componente da mortalidade infantil, tem alta prevalência global e pode estar associado a baixos índices de APGAR (<7) no quinto minuto pós-nascimento, a complicações durante o nascimento, a defeitos congênitos ou a infecções, baixa escolaridade materna, prematuridade (<37 semanas de gestação), menos de três consultas no pré-natal, baixo peso ao nascer $(<2500 \mathrm{~g})$ e raça/cor preta e parda ${ }^{2,3}$.

Recém-nascidos são mais vulneráveis durante e imediatamente após o parto, e estima-se que a mortalidade nesse grupo seja de 2,8 milhões a cada ano, principalmente de causas evitáveis. Contudo, desde 2000, houve queda na taxa de mortalidade infantil (50,0\%) e materna (30,0\%), associada, em especial, a melhoria do acesso a serviços de saúde de qualidade. Ainda, segundo meta proposta na Agenda 2030 sobre o Desenvolvimento 
Sustentável, os Estados-membros se comprometeram em reduzir a taxa de mortalidade materna para menos de 70 casos para cada 100 mil recémnascidos vivos até 2030. Quanto aos recém-nascidos, o objetivo é ter menos de 12 casos para cada mil nascimentos ${ }^{4}$.

Desta forma, a mortalidade infantil é um importante indicador para o bem-estar ${ }^{5}$, de qualidade de vida e dos serviços de saúde, de saneamento básico e de educação de uma cidade, país ou região 4 . Altas taxas de mortalidade infantil assolam a América Latina e Caribe há longo tempo e vêm decrescendo lentamente, contudo, em alguns países da região, poucas melhorias foram observadas nos últimos 20 anos $^{6,7}$.

Nesse capítulo, será apresentada a taxa de mortalidade infantil nos países da América Latina e Caribe no período de 2000, 2006, 2012 e 2018, discutindo o papel político e social na gênese do problema, valorizando as perspectivas políticas propostas e implementadas ao longo deste período para enfrentar esta questão de notória relevância para evolução dos países e dos povos desta região.

Busca-se, ainda, aproximar e fundamentar a nova tendência na produção de conhecimento para integrar as necessidade sociais à pesquisa, no sentido de fortalecer o processo de discussão de políticas públicas e sociais na América Latina e Caribe, fomentando o processo democrático e os espaços para interação equitativa na região ${ }^{8}$. Em especial, pois esta região ainda está na luta pelo desenvolvimento e fortalecimento dos processos das práticas democráticas, vinculados a eleições, participação e expansão dos programas sociais, melhoria da capacidade administrativa dos países, o que exige se apoderar do conhecimento para reduzir as taxas de mortalidade infantil e contribuir para o desenvolvimento humano ${ }^{5,9}$.

A América Latina e Caribe engloba 33 países: Antígua e Barbuda, Argentina, Bahamas, Barbados, Belize, Bolívia, Brasil, Chile, Colômbia, Costa Rica, Cuba, Dominica, Equador, El Salvador, Granada, Guatemala, Guiana, Haiti, Honduras, Jamaica, México, Nicarágua, Panamá, Paraguai, Peru, República Dominicana, São Cristóvão e Névis, San Vicente e Granadinas, Santa Lúcia, Suriname, Trindade e Tabago, Uruguai e Venezuela?.

Nessa região, a expectativa de vida e a mortalidade infantil são muito variáveis, evidenciando contrastes entre os países e dentro dos países, principalmente quando se considera as diferenças regionais, rurais e urbanas 
nas grandes cidades ${ }^{10}$. Apesar disso, os países da América Latina e do Caribe apresentaram progresso substancial em termos de redução das desigualdades nas intervenções de saúde reprodutiva, materna, neonatal e infantil, mortalidade infantil e nutrição. No entanto, os $20,0 \%$ mais pobres da população na maioria desses países ainda não têm qualidade de vida mínima, sendo necessárias novas ações para melhorar a equidade ${ }^{11}$.

Historicamente, a mortalidade infantil sempre foi maior nas áreas rurais, vinculada ao grau de escolaridade materna, a pobreza e entre povos indígenas. Isto porque na América Latina, esses grupos não se beneficiam integralmente dos recursos tecnológicos e do conhecimento em saúde $\mathrm{e}^{12}$, o que pode contribuir para a maior ocorrência da mortalidade infantil. Há evidências crescentes apoiando a existência de um vínculo entre desigualdades de renda e resultados de saúde ${ }^{13-16}$. Em muitos países, ao se controlar a renda nacional bruta per capita, a taxa de alfabetização e os gastos com saúde, o índice de Gini é independentemente associado aos piores resultados de saúde. O índice de Gini representa uma escala que varia de zero, indicando a inexistência de desigualdade a um, representando a desigualdade máxima ${ }^{17}$. $O$ resultado da desigualdade resulta em altas taxas de mortalidade infantil, que são ainda piores nos países devedores do Fundo Monetário Internacional (FMI). Na América Latina, para cada aumento de ponto percentual no índice de Gini, a taxa de mortalidade infantil cresce 0,467 mortes por 1.000 nascidos vivos, mantendo todas as outras variáveis constantes. Portanto, é necessário combater as desigualdades de renda e repensar o papel das instituições financeiras internacionais que ditam as políticas externas ${ }^{14}$.

Desde os primeiros anos do século XXI, o aprofundamento da crise econômica mundial acabou explicitando problemas estruturais crônicos, nem sempre visíveis, especialmente após as políticas de controle da inflação promovidas amplamente no continente nos anos 1990, a partir do chamado Consenso de Washington.

O Consenso de Washington foi um movimento de um grupo de economistas de diversos países que, motivado pelas agências Multilaterais (BIRD, FMI etc.), formulou um modelo de estabilização monetária, no final dos anos 1980, cuja base era a paridade fixa das moedas nacionais dos países endividados 
com o dólar dos Estados Unidos. O modelo exigia a abertura comercial às importações e o endividamento público para o acúmulo de reservas em dólares. Como consequência, a orientação era adotar medidas de ajuste fiscal, privatização de empresas e serviços estatais e a desregulação dos fluxos de capital. Na verdade, estava em marcha uma nova divisão internacional do trabalho, com a imposição imperialista de um novo estágio de especialização produtiva para as nações dependentes ${ }^{18}$.

Mais recentemente, estão em alta falar de Política sociais, austeridade fiscal, recessão, crise econômica e requalificação do Estado, todos com o objetivo de reduzir a demanda e o direito da maior parcela da sociedade ao acesso e funcionamento do Estado em todos os aspectos, em particular no que tange ao bem-estar social ${ }^{19}$.

Apesar de todos os ataques às políticas Sociais, para a perda de direitos é inegável que vem ocorrendo uma redução da mortalidade infantil, e esta pode ser atribuída, dentre outros fatores, ao acesso da população à atenção primária e secundária à saúde, além das reformas no sistema de saúde público e melhorias nas condições sanitárias. Isso reforça a importância da luto e do enfrentamento para a manutenção de políticas públicas que contribuam para redução da desigualdade social, acesso a moradia de qualidade, saneamento básico e incentivo ao aleitamento materno, que são imprescindíveis para a redução da mortalidade infantil na América Latina e Caribe 10,20,21.

Outrossim, as doenças diarreicas foram importantes causas de mortalidade, e a adoção das vacinas contra rotavírus contribuíram em muito para a redução destas enfermidades e, em consequência, da mortalidade infantil, mesmo entre os países com baixa cobertura vacinal ${ }^{22,23}$. Também, a aplicação de protocolos da Organização Mundial da Saúde (OMS) para o tratamento da desnutrição aguda grave entre crianças hospitalizadas contribuiu para a redução da mortalidade infantil por essa causa ${ }^{13,15,24}$.

Apesar da contribuição de estudos sobre taxa de mortalidade infantil na ALC, existe a limitação associada a confiabilidade dos dados divulgados pelos países, gerando grandes diferenças quando se avaliam dados entre países centrais e periféricos ${ }^{12}$. Assim, o objetivo deste capítulo é analisar 
as taxas de mortalidade infantil na América Latina e Caribe e sua interface com as políticas públicas e sociais, com o intuito de contribuir com subsídios teórico-práticos para o (re)planejamento de políticas e programas para o enfretamento da mortalidade infantil na região. Trata-se de pesquisa descritiva, exploratória e documental, a partir da análise das taxas de mortalidade infantil dos países da América Latina e Caribe, nos anos de 2000, 2006, 2012 e 2018, disponíveis no banco de dados da Comissão Econômica para a América Latina e Caribe?.

\section{Desenvolvimento}

A África Subsaariana, o Sul da Ásia e o Oriente Médio, figuravam entre as regiões de maiores taxas de mortalidade infantil do mundo, entre os anos de 1970 e $2003^{25}$. América Latina e o Caribe, por outro lado, representaram em média, 48,8\% da taxa de mortalidade infantil mundial no período de 2000 a 2018. Apesar dessa alta taxa de mortalidade, os dados também revelam uma tendência de queda nesta região e no mundo (Figura 1).

Figura 1 - Comparação da taxa de mortalidade infantil na América Latina e Caribe em relação ao Mundo, entre 2000 e 2018.

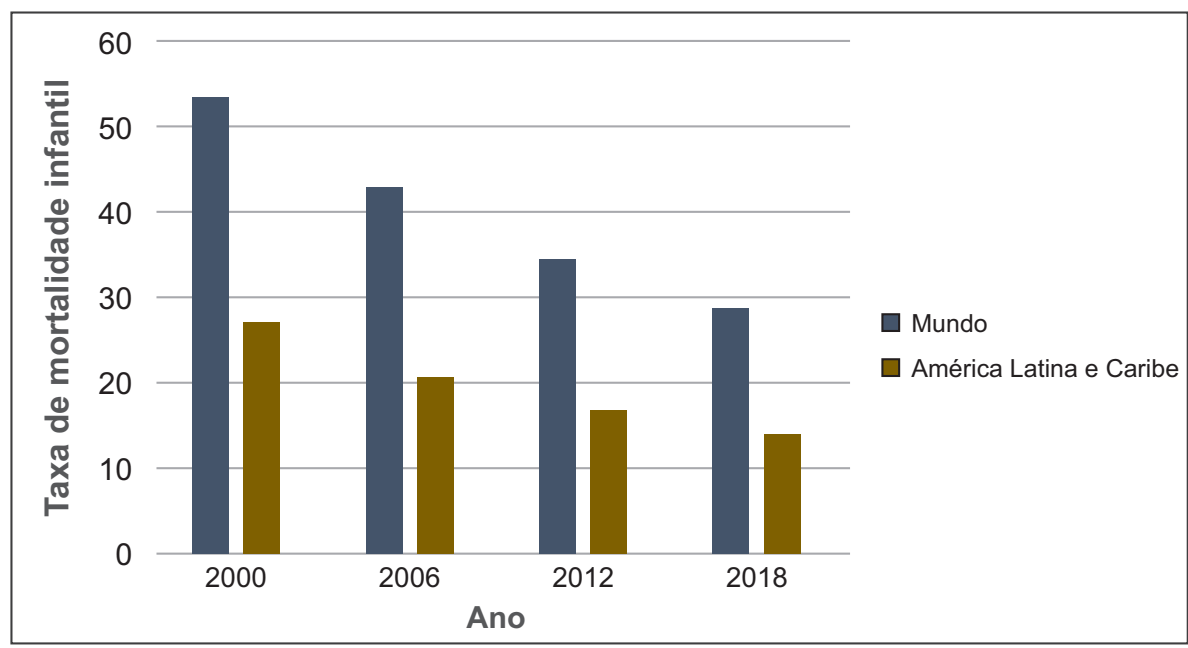

Fonte: Health Nutrition and Population Statistics, 2020. 
No ano de 2000, os seis países de maior risco para uma criança morrer na América Latina e Caribe eram representados pelo Haiti (74,2\%), Bolívia (55,7\%), Guatemala (40,6\%), Guiana (37,1\%), República Dominicana $(33,1 \%)$ e Brasil (30,4\%) enquanto os de menor risco eram Cuba (6,8\%), Chile (9,2\%), Costa Rica (11,1\%), Dominica (12,7\%), Bahamas (13,0\%) e Antígua e Barbuda (13,1\%).

Após um período de 18 anos (2000-2018) foi possível observar que a mortalidade infantil permaneceu alta nos países como, Haiti (49,5\%), República Dominicana (que não deve ser confundida com Dominica) e Bolívia (21,8\%), correspondendo, ainda, a lugares que apresenta grandes riscos para o nascimento de crianças. Uma mudança expressiva é observada na taxa de mortalidade do Brasil, que conseguiu chegar a uma taxa de mortalidade infantil de 12,8 em 2018.

Outro aspecto importante observado neste estudo foi com relação ao comportamento das taxas de mortalidade infantil da Venezuela, Dominica e Granada. Nestes países essas taxas se comportaram na contramão dos demais países da América latina e do Mundo, ou seja, foi observado um aumento de mortalidade infantil. No ano de 2018, todos os países de menor mortalidade infantil em 2000, foram mantidos com taxas de mortalidade menores que 10,0 (Tabela 1).

Tabela 1 - Taxa de mortalidade infantil na América Latina e Caribe, nos anos de 2000, 2006, 2012 e 2018.

\begin{tabular}{|l|r|r|r|r|c|}
\hline \multicolumn{1}{|l|}{ TAXA DE MORTALIDADE INFANTIL / AÑO } & \multicolumn{3}{c|}{ \% REDUÇÃO } \\
\hline PAísES & $\mathbf{2 0 0 0}$ & \multicolumn{1}{c|}{$\mathbf{2 0 0 6}$} & $\mathbf{2 0 1 2}$ & $\mathbf{2 0 1 8}$ & $\mathbf{( 2 0 0 0 - 2 0 1 8 )}$ \\
\hline Antígua e Barbuda & 13,1 & 9,7 & 6,7 & 5,0 & 61,8 \\
\hline Argentina & 17,5 & 14,4 & 11,8 & 8,8 & 49,7 \\
\hline Bahamas & 13,0 & 11,9 & 9,9 & 8,3 & 36,2 \\
\hline Barbados & 13,7 & 14,2 & 13,1 & 11,3 & 17,5 \\
\hline Belize & 20,0 & 17,6 & 15,2 & 11,2 & 44,0 \\
\hline Bolívia & 55,7 & 40,6 & 29,2 & 21,8 & 60,9 \\
\hline Brasil & 30,4 & 20,7 & 15,4 & 12,8 & 57,9 \\
\hline Chile & 9,2 & 7,6 & 7,2 & 6,2 & 32,6 \\
\hline Colômbia & 21,1 & 17,8 & 14,9 & 12,2 & 42,2 \\
\hline Costa Rica & 11,1 & 8,9 & 8,4 & 7,6 & 31,5 \\
\hline Cuba & 6,8 & 5,4 & 4,4 & 3,7 & 45,6 \\
\hline
\end{tabular}




\begin{tabular}{|c|c|c|c|c|c|}
\hline \multicolumn{4}{|c|}{ TAXA DE MORTALIDADE INFANTIL / AÑO } & \multicolumn{2}{|c|}{ \% REDUÇÃO } \\
\hline PAÍSES & 2000 & 2006 & 2012 & 2018 & $(2000-2018)$ \\
\hline Dominica & 12,7 & 14,5 & 22,7 & 32,9 & $-159,1^{\#}$ \\
\hline Equador & 24,3 & 18,6 & 14,4 & 12,2 & 49,8 \\
\hline El Salvador & 27,2 & 20,0 & 15,0 & 11,8 & 56,6 \\
\hline Granada & 13,3 & 12,5 & 12,9 & 13,7 & $-3,0^{*}$ \\
\hline Guatemala & 40,6 & 33,0 & 26,8 & 22,1 & 45,6 \\
\hline Guiana & 37,1 & 32,9 & 29,4 & 25,1 & 32,4 \\
\hline Haiti & 74,2 & 63,8 & 56,8 & 49,5 & 33,3 \\
\hline Honduras & 30,3 & 23,6 & 18,6 & 15,1 & 50,2 \\
\hline Jamaica & 19,0 & 16,9 & 14,9 & 12,4 & 34,7 \\
\hline México & 22,2 & 16,9 & 14,1 & 11,0 & 50,5 \\
\hline Nicarágua & 29,9 & 21,1 & 16,6 & 15,7 & 47,5 \\
\hline Panamá & 21,8 & 19,0 & 16,0 & 13,1 & 39,9 \\
\hline Paraguai & 27,9 & 24,4 & 20,7 & 17,2 & 38,4 \\
\hline Peru & 29,6 & 19,5 & 14,3 & 11,1 & 62,5 \\
\hline República Dominicana & 33,1 & 29,6 & 27,5 & 24,1 & 27,2 \\
\hline São Cristóvão e Névis & 19,0 & 13,7 & 11,4 & 9,8 & 48,4 \\
\hline San Vicente e Granadinas & 19,4 & 19,7 & 17,6 & 14,8 & 23,7 \\
\hline Santa Lúcia & 15,4 & 16,1 & 16,3 & 14,9 & 3,3 \\
\hline Suriname & 30,1 & 24,9 & 20,4 & 16,9 & 43,9 \\
\hline Trinidad e Tabago & 25,4 & 23,2 & 19,7 & 16,4 & 35,4 \\
\hline Uruguai & 14,8 & 11,7 & 8,5 & 6,4 & 56,8 \\
\hline Venezuela & 18,4 & 15,4 & 14,8 & 21,4 & $-16,3^{\#}$ \\
\hline América Latina e Caribe ${ }^{*}$ & 27,2 & 20,5 & 16,6 & 14,0 & 61,8 \\
\hline
\end{tabular}

Fonte: CEPAL, 2020. *Estimativa baseada em 33 países. \# $\mathrm{O}$ índice negativo indica o percentual de piora da taxa de mortalidade infantil.

A alta mortalidade infantil persistente na América Latina e no Caribe é fortalecida por crises econômicas que geraram desemprego e inflação ${ }^{27}$. Também, o baixo investimento em infraestrutura, a deficiência de abastecimento de água e sistema de esgotamento sanitário, que garantiriam a melhoria na qualidade de vida da população, foram negligenciados e contribuíram para a permanência de doenças que foram associadas ao aumento da mortalidade infantil no século XXI. Outro fator importante está associado 
ao baixo empenho na implantação de políticas públicas para melhorar os níveis de aleitamento materno exclusivo, pelo menos até os quatro meses de vida, nessa região ${ }^{28}$.

Todo esse processo pode ser justificado pela política neoliberal, que defende uma orientação contrária ao investimento em políticas sociais que, por exigência do FMI, foi implantada em países da América Latina e Caribe para a negociação da dívida externa desses países. Essa política, como esperada, resultou em impactos negativos nos indicadores socioeconômicos e altos custos sociais (Tabela 2), como prejuízo no acesso a serviços básicos de infraestrutura, aumento das desigualdades sociais, desemprego e precarização do emprego, interferindo, por conseguinte, nos indicadores de desenvolvimento humano 29 .

Nesse sentido, o acirramento da armadilha da dívida pública acabou envolvendo a reprodução ampliada de problemas fiscais internos em cada país. Paradoxalmente, a busca por soluções desses graves problemas, com base na austeridade fiscal, ao contrário de promover a possibilidade de novas fontes de financiamento das políticas sociais, acabou gerando uma presença ainda mais marcante da lógica privada na gestão dos serviços públicos ${ }^{18}$.

Tabela 2 - Total das despesas correntes com saúde como proporção do PIB nos anos de 2000, 2006, 2012 e 2018.

\begin{tabular}{|l|c|c|c|c|}
\hline \multicolumn{5}{|c|}{ GASTO COM SAÚDE (\% PIB) } \\
\hline PAísES & $\mathbf{2 0 0 0}$ & $\mathbf{2 0 0 6}$ & $\mathbf{2 0 1 2}$ & $\mathbf{2 0 1 8}$ \\
\hline Antígua e Barbuda & 4,5 & 4,7 & 5,2 & 4,5 \\
\hline Argentina & 8,5 & 7,6 & 8,5 & 9,1 \\
\hline Bahamas & 4,0 & 5,4 & 6,0 & 5,8 \\
\hline Barbados & 5,3 & 6,6 & 7,8 & 6,8 \\
\hline Belize & 4,1 & 4,6 & 5,4 & 5,6 \\
\hline Bolívia & 4,4 & 4,8 & 5,4 & 6,4 \\
\hline Brasil & 8,3 & 8,3 & 7,7 & 9,5 \\
\hline Chile & 7,0 & 6,0 & 7,0 & 9,0 \\
\hline Colômbia & 5,7 & 6,4 & 6,8 & 7,2 \\
\hline Costa Rica & 6,6 & 7,0 & 7,9 & 7,3 \\
\hline Cuba & 6,6 & 8,3 & 9,3 & 11,7 \\
\hline Dominica & 5,2 & 5,2 & 5,8 & 5,9 \\
\hline
\end{tabular}




\begin{tabular}{|l|c|c|c|c|}
\hline \multicolumn{5}{|c|}{ GASTO COM SAÚDE (\% PIB) } \\
\hline PAíSES & $\mathbf{2 0 0 0}$ & $\mathbf{2 0 0 6}$ & $\mathbf{2 0 1 2}$ & $\mathbf{2 0 1 8}$ \\
\hline Equador & 3,3 & 5,7 & 8,5 & 8,3 \\
\hline El Salvador & 8,9 & 7,9 & 7,5 & 7,2 \\
\hline Granada & 5,3 & 6,0 & 5,9 & 4,8 \\
\hline Guatemala & 5,7 & 6,6 & 6,0 & 5,8 \\
\hline Guiana & 3,9 & 5,0 & 4,9 & 4,9 \\
\hline Haiti & 6,9 & 5,5 & 9,7 & 8,0 \\
\hline Honduras & 6,4 & 8,1 & 8,6 & 7,9 \\
\hline Jamaica & 5,8 & 4,5 & 5,0 & 6,0 \\
\hline México & 4,4 & 5,7 & 5,8 & 5,5 \\
\hline Nicarágua & 5,2 & 6,0 & 7,6 & 8,6 \\
\hline Panamá & 7,0 & 6,6 & 6,6 & 7,3 \\
\hline Paraguai & 5,5 & 4,2 & 6,5 & 6,7 \\
\hline Peru & 4,5 & 4,5 & 4,8 & 5,0 \\
\hline República Dominicana & 4,9 & 4,0 & 5,9 & 6,1 \\
\hline São Cristóvão e Névis & 4,7 & 4,9 & 5,2 & 5,0 \\
\hline San Vicente e Granadinas & 4,3 & 3,8 & 4,7 & 4,5 \\
\hline Santa Lúcia & 5,4 & 5,7 & 5,6 & 4,5 \\
\hline Suriname & 6,3 & 6,3 & 4,6 & 6,2 \\
\hline Trinidad e Tabago & 4,2 & 4,2 & 4,9 & 7,0 \\
\hline Uruguai & 10,0 & 8,4 & 8,8 & 9,3 \\
\hline Venezuela & 7,3 & 8,1 & 6,4 & 1,2 \\
\hline
\end{tabular}

Fonte: CEPAL, 2020. * Estimación basada en 33 países. \# El índice negativo indica el porcentaje de empeoramiento de la tasa de mortalidad infantil

Assim, os anos iniciais da década de 1990 foram marcados por políticas neoliberais, enquanto na década seguinte houve predominância de avanços sociais, com pequena redução das desigualdades sociais. Houve redução da exportação de manufaturados e aumento da exportação de produtos primários, de baixa composição tecnológica e baixo valor econômico, que contribuíram para prejudicar a economia e a manutenção econômica, política e social da região da América Latina e Caribe ${ }^{30}$.

Felizmente, observa-se que a difusão dos programas de transferência condicionada de renda, importante instrumento de combate à pobreza inter- 
geracional, tem sido adotada por quase todos os países latino-americanos ${ }^{31}$, o que traz benefícios imediatos, mas pode comprometer o fortalecimento de políticas eficazes e a permanência de governos indesejados, o que fortalece na região a manutenção de índices de mortalidade infantil acima do recomendado pela OMS.

Ressalta-se que desde o início do século XXI a crise do Estado do BemEstar Social ampliou o papel do mercado como o mecanismo para a satisfação das necessidades básicas, diminuindo os orçamentos públicos para as políticas sociais. Isso contribuiu para a manutenção de crises econômicas e políticas, resultando no aumento da vulnerabilidade social, abrindo espaço para políticas públicas que buscassem ultrapassar a lógica assistencialista, de dependência, produzindo o desenvolvimento e a emancipação social, refletindo, dentre outros, na melhoria dos índices de mortalidade infantili32.

A questão política é fundamental para o enfrentamento das questões sociais, que incluem o progresso para a infância e juventude e, consequentemente, para a evolução dos países latino-americanos. Assim, havia no início da década de 2000, a percepção pública da importância dos partidos na vida política da América Latina e, apesar do envolvimento das elites, os partidos algumas vezes continuam operativos legitimados, estruturando a competição e dando forma aos resultados eleitorais, orientando os cidadãos e as elites no que se refere à compreensão da realidade política, construindo acordos em torno de políticas governamentais e ações legislativas efetivas. Apesar das falhas, com algumas exceções, continuaram estruturando a dinâmica política latino- americana e mais da metade da população acreditava, na época, que a qualidade do voto mudaria as coisas no futuro, especialmente entre uruguaios e venezuelanos ${ }^{33}$.

Dentre os países analisados neste estudo, oito apresentaram redução maior que $50 \%$ na sua taxa de mortalidade infantil, conforme destacado na Figura 2. As médias de redução na taxa de mortalidade infantil para esses países foram de: Peru (62,50\%), Antígua e Barbuda (61,8\%), Bolívia (60,9\%), Brasil (57,9\%), Uruguai (56,8\%), El Salvador (56,6\%), México (50,5\%), Honduras (50,2\%). Estes resultados podem ser atribuídos, em parte, “à vontade política de melhorar o acesso a serviços de saúde de qualidade, investindo na força de trabalho em saúde, introduzindo atendimento gratuito para grávidas e crianças e apoiando o planejamento familiar"4. 
Figura 2 - Países da América Latina e Caribe que apresentaram redução maior que $50,0 \%$ na taxa de mortalidade infantil, no período de 2000 a 2018.

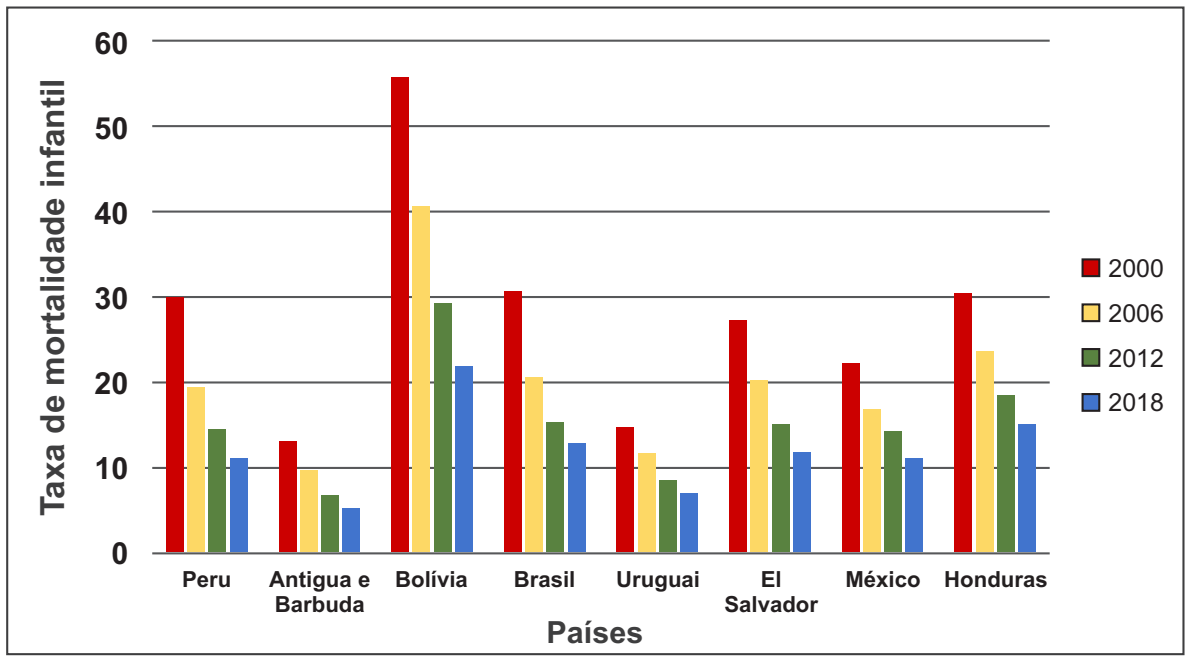

Fonte: Health Nutrition and Population Statistics, 2020.

O panorama social da América Latina continua refletindo desigualdade de renda, pobreza e redução de gasto social, com forte influência da migração, tema de grande relevância na agenda política e social da região. Percebe-se que a renda $(1,0 \%)$ dos mais ricos continua crescendo. A pequena melhora na renda da classe média não se refletiu na eliminação de vulnerabilidades para a maioria da população, que permaneceu com baixo nível educacional, desemprego ou emprego de baixa qualidade, baixa cobertura e insuficiência das prestações no sistema de aposentadoria e pensões. Para a efetividade da igualdade social é necessário estabelecer um pacto de equidade distributiva e sustentabilidade da proteção social para a prática da igualdade social? .

Instituições nocivas em muitos desses países contribuem para ampliar as desigualdades sociais, que impactam negativamente no processo de desenvolvimento econômico ${ }^{34}$. No Brasil, apesar da alta desigualdade social31, a redução da mortalidade infantil pode ser atribuída a programas de transferência condicional de renda aos mais pobres, aos investimentos na atenção primária à saúde, a redução das taxas de analfabetismo, baixos níveis de fecundidade e melhoria do acesso ao abastecimento de água e saneamento básico ${ }^{35}$. 
No início da década de 2000, os indicadores demográficos e epidemiológicos da América Latina indicaram semelhanças e contrastes em alguns países, percebidos como retrocesso social. Para reduzir a publicização da oposição, alguns organismos internacionais atribuíram as perdas de direitos sociais à transição demográfica, e não às políticas de corte neoliberal ${ }^{36}$.

Na Figura 3, é possível observar o retrato da disparidade que acontece na América Latina e Caribe. De um lado Cuba, com sua taxa de mortalidade muito pequena, mantida e com tendência a queda no período analisado e, do outro lado, o Haiti, que apesar de ter tido uma diminuição de 33,3\% ao longo deste período de 18 anos, ainda apresenta taxa de mortalidade próxima de 50.

Figura 3 - Comparação entre as taxas de mortalidade infantil de Cuba e Haiti, no período de 2000 a 2018

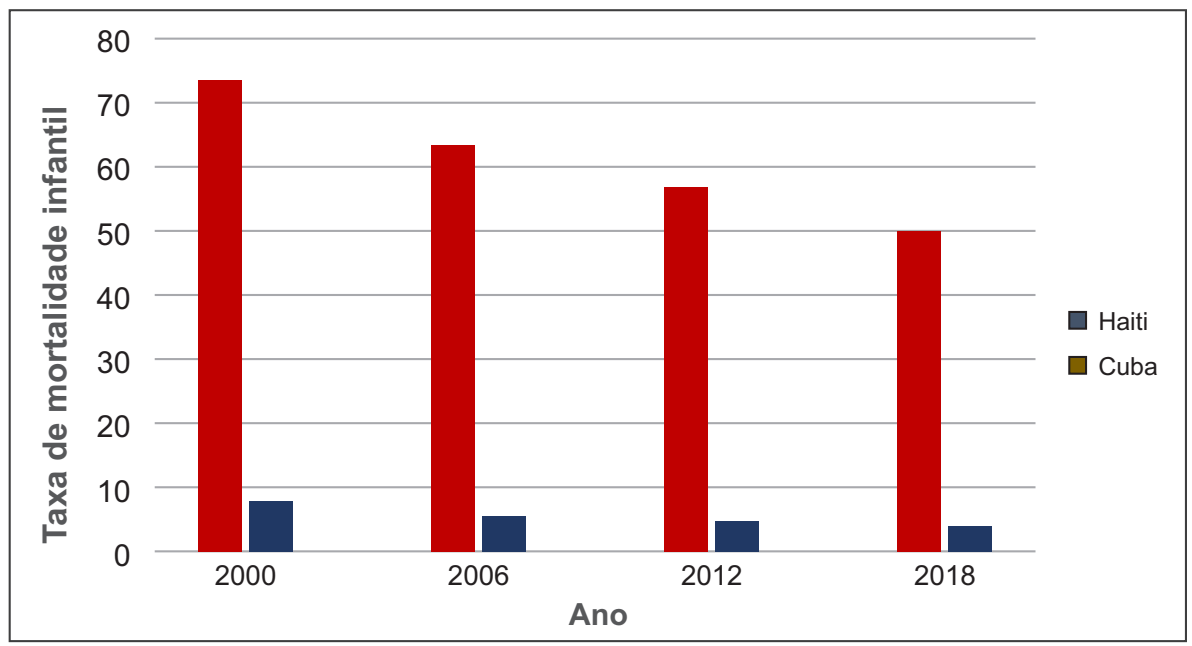

Fonte: Health Nutrition and Population Statistics, 2020

As consequências funestas da ação do imperialismo selvagem americano e do colonialismo predatório europeu, deixaram como herança para a região da América Latina e o Caribe, influências da opressão cultural para a implantação do racismos e a invisibilidade para todas as formas de preconceito, que reduzem a autoestima das pessoas, em todos os ciclos de vida. Implantou no inconsciente coletivo as bases para minimização da dependência eco- 
nômica, favorecendo a implantação de políticas públicas que resultaram no aumento da pobreza, da educação e saúde de baixa qualidade e da perda ou violação de direitos sociais ${ }^{37}$, que afetaram diretamente a infância na Região, reduzindo as chances de uma vida saudável, em um mundo altamente seletivo e competitivo.

\section{Considerações finais}

Em resumo, a crise econômica mundial explicitou problemas estruturais crônicos, às vezes invisíveis, em resposta às políticas públicas para controle da inflação a partir de 1990. Muitos países da região, inclusive, conseguiam esconder muitas de suas dificuldades em financiar os planos de desenvolvimento por trás da cantilena das agências multilaterais (FMI, BIRD etc.), que forçavam a ideia de converter artificialmente nações subdesenvolvidas em economias emergentes, diante do boom da demanda da China por produtos básicos. Interessante é que, mesmo com a ascensão de governos progressistas em alguns países da América Latina, no período, a exacerbação da armadilha da dívida travou qualquer possibilidade de avançar com os planos (neo) desenvolvimentistas que procuravam colocar em marcha. Assim, diferentes dos discursos formais, as políticas de austeridade fiscal deram a tônica da política macroeconômica.

Controlar gastos das políticas essenciais continuou sendo uma prioridade do modelo, uma vez que foi mantida a contínua conversão de dívida externa privada em dívida pública interna, cujos pagamentos parciais de juros crescentes destruíram a já precária capacidade de fomentar novos investimentos e de promover políticas públicas essenciais, que pudessem sustentar e avançar na qualidade de vida em geral. Assim, o acirramento da armaditha da dívida pública acabou envolvendo a reprodução ampliada de problemas fiscais internos em cada país. Paradoxalmente, a busca por soluções desses graves problemas, com base na austeridade fiscal, ao contrário de promover a possibilidade de novas fontes de financiamento das políticas sociais, acabou gerando uma presença ainda mais marcante da lógica privada na gestão dos serviços públicos. 
No caso das políticas de saúde, em particular, essa perspectiva proporcionou a terceirização de serviços a organizações sociais e fundações e, inclusive, o avanço da tramitação de propostas de privatização de unidades em favor do grande capital. dentro dessa lógica, o acesso aos serviços essenciais de saúde fica cada vez mais restritivo, desde à infraestrutura preventiva, como aquela vinculada ao saneamento ambiental, até à atenção básica e aos procedimentos mais intesivos de diagnóstico e de tratamento. Nesse contexto, os avanços obtidos na atenção preventiva e nos cuidados emergenciais, que vinham apresentando resultados positivos na redução da mortalidade infantil na América Latina e no Caribe, vão sendo obstaculizados. É preciso enfretnar essa tendência que aponta para um cenário camuflado de conversão definitiva do pré-natal e do pós-parto em privilégios para quem poder pagar por eles, de imediato, no momento da prestação desses serviços, como pressuposto para a mãe e a criança serem atendidas.

\section{Referências}

1. BRASIL. Ministério da Saúde/CENEPI: Sistema de Informações sobre Mortalidade (SIM) e Sistema de Informações sobre Nascidos Vivos (SINASC). Disponível em: http://tabnet.datasus.gov.br/cgi/idb2000/fqc01.htm. Acesso em: 10 ago. 2020.

2. CARVALHO, P. I. et al. Fatores de risco para mortalidade neonatal em coorte hospitalar de nascidos vivos. Epidemiol. Serv. Saúde, v.16, n. 3, p. 185-194, jul./ set. 2007. doi: 10.5123/S1679-49742007000300005

3. Mortalidade Materna e na Infância - Mulheres e crianças estão sobrevivendo cada vez mais.disponível em https://www.unicef.org/brazil/comunicados-de-imprensa/ mortalidade-materna-e-na-infancia-mulheres-e-criancas-estao-sobrevivendocada-vez-mais.

4. FUNDO DAS NAÇÕES UNIDAS PARA A INFÂNCIA (UNICEF); ORGANIZAÇÃO MUNDIAL DA SAÚDE (OMS). 2019. UNICEF e OMS dizem que taxas de mortalidade materno-infantil nunca foram tão baixas. Disponível em: https://news.un.org/pt/ story/2019/09/1687532. Acesso em: 10 ago. 2020.

5. GERRING, J. et.al. Electoral Democracy and Human Development. Paper prepared for presentation at the ECPR joint sessions of workshops, Pisa, April 24-28, 2016. Disponível em: https://ecpr.eu/Filestore/PaperProposal/0a4557bb-f171-42f3882a- cb6ba37456c9.pdf. Acesso em: 10 ago. 2020.

6. HEALTH NUTRITION AND POPULATION STATISTICS, 2020. Disponível em https:// databank.worldbank.org/source/health-nutrition-and-population-statistics. Acesso em 14 OUT 2020. 
7. Comissão Econômica para a América Latina e o Caribe (CEPAL), Panorama Social da América Latina, 2019. Resumo executivo (LC/PUB.2020/1-P), Santiago, 2020. Disponivel em: https://repositorio.cepal.org/bitstream/handle/11362/45090/1/ S1900909_pt.pdf. Acesso em: 10 ado. 2020.

8. PELLEGRINI FILHO, A. Pesquisa em saúde, política de saúde e eqüidade na América Latina. Ciência \& Saúde Coletiva [online], v. 9, n. 2, p. 339-350, 2004. doi: 10.1590/ S1413-81232004000200011.

9. TOUCHTON, M.; SUGIYAMA, N. B.; WAMPLER, B. DEMOCRACIA EM AÇÃO: indo além das eleições para melhorar o bem-estar. Caderno $\mathrm{CRH}$, Salvador, v. 33, p. 01-17, e020006, jul. 2020. doi: 10.9771/ccrh.v33i0.33273.

10. BÄHR, J.; WEHRHAHN, R. Life expectancy and infant mortality in Latin America. Soc Sci Med, v.36, n. 10, p. 1373-1382, mai. 1993. doi:10.1016/0277-9536(93)90230-2.

11. RESTREPO-MÉNDEZ, M. C. et al. Progress in reducing inequalities in reproductive, maternal, newborn, and child health in Latin America and the Caribbean: an unfinished agenda. Rev Panam Salud Publica, v. 38, n. 1, p. 9-16, 2015.

12. BEHM, H.; PRIMANTE, D. A. Infant and child mortality in Latin America. Notas Poblacion, v. 6, n. 16, p. 23-44, abr. 1978. doi: pubmed.ncbi.nlm.nih.gov/12335524/.

13. CHUANG, Y. C. et al. The inter-relationship among economic activities, environmental degradation, material consumption and population health in low-income countries: a longitudinal ecological study. BMJ Open, v. 5, n. 7, e006183, jul. 2015. doi:10.1136/ bmjopen-2014-006183.

14. FERRE, J. C. Economic Inequalities in Latin America at the Base of Adverse Health Indicators. Int J Health Serv, v. 46, n. 3, p. 501-522, jun. 2016. doi:10.1177/0020731416653428.

15. HOSSAIN, M. et al. Efficacy of World Health Organization guideline in facility-based reduction of mortality in severely malnourished children from low and middle income countries: A systematic review and meta-analysis. J Paediatr Child Health, v. 53, n. 5, p. 474-479, jan./mai. 2017. doi:10.1111/jpc.13443.

16. TEJADA, C. A. O. et al. Crises econômicas, mortalidade de crianças e o papel protetor do gasto público em saúde. Ciênc. saúde coletiva, Rio de Janeiro, v. 24, n. 12, p. 4395-4404, nov./dez. 2019. doi: 10.1590/1413-812320182412.25082019.

17. WOLFFENBÜTTEL, A. O que é? - Índice de Gini. Desafios do Desenvolvimento. Instituto de Pesquisa Econômica Aplicada. ed. 4, ano 1, 2004. Disponível em: https:// www.ipea.gov.br/desafios/index.php?option=com_content\&id=2048: catid=28. Acesso em: 10 ago. 2020.

18. GOMES, Helder. Endividamento, histórico de lutas e propostas alternativas nos países da América Latina e do Caribe. São Paulo: Jubileu Sul Américas. 2020.

19. Vieira, Fabiola Sulpino, et al. "Políticas sociais e austeridade fiscal: como as políticas sociais são afetadas pelo austericídio da agenda neoliberal no Brasil e no mundo." (2018). 
20. SANKAR, M. J. et al. Optimal breastfeeding practices and infant and child mortality: a systematic review and meta-analysis. Acta Paediatr, v.104, n. 467, p.3-13, dez. 2015. doi:10.1111/apa.13147.

21. NISHIMURA, F. Efeito da habitação sobre a mortalidade infantil: evidências de um desenho de regressão descontínua. Análise Econômica, Porto Alegre, v. 38, n. 76, p. 171-196, jun. 2020. doi: 10.22456/2176-5456.81890.

22. OLIVEIRA, L. H. et al. Impact and Effectiveness of 10 and 13-Valent Pneumococcal Conjugate Vaccines on Hospitalization and Mortality in Children Aged Less than 5 Years in Latin American Countries: A Systematic Review. PLoS One, v. 11, n. 12, e0166736, dez. 2016. doi: 10.1371/journal.pone.0166736.

23. CHAVERS, T. et al. Post-licensure experience with rotavirus vaccination in Latin America and the Caribbean: a systematic review and meta-analysis. Expert Rev Vaccines, v. 17, n. 11, p. 1037-1051, nov. 2018. doi:10.1080/14760584.2018.154 1409.

24. da Silva, Valmin Ramos. "Desnutrição em crianças internadas em Hospital Infantil de Vitória, ES: reflexão histórico-político-social.” Rev Med Minas Gerais 2017.26 (1818).

25. Victora, Cesar, and Fernando C. Barros. "A questão da sobrevivência infantil no mundo e sua relevância para as Américas” Cadernos ESP 1.1 (2005): 04-13.

26. Chuang YC, Huang YL, Hu CY, Chen SC, Tseng KC. The inter-relationship among economic activities, environmental degradation, material consumption and population health in low-income countries: a longitudinal ecological study. BMJ Open. 2015;5(7):e006183. Published 2015 Jul 15. doi:10.1136/bmjopen-2014-006183

27. Tejada, Cesar Augusto Oviedo, et al. “Crises econômicas, mortalidade de crianças e o papel protetor do gasto público em saúde." Ciência \& Saúde Coletiva 24 (2019): 4395-4404.

28. TEIXEIRA, J. C.; PUNGIRUM, M. E. M. C. Análise da associação entre saneamento e saúde nos países da América Latina e do Caribe, empregando dados secundários do banco de dados da Organização Pan-Americana de Saúde-OPAS. Rev. bras. epidemiol [online], v. 8, n. 4, p. 365-376, 2005. doi: 10.1590/S1415$790 \times 2005000400005$.

29. SILVA, G. F. O custo social das reformas neoliberais: impactos do consenso de Washington em pobreza e desigualdades na América Latina e o Caribe. Trabalho de Conclusão de Curso (Graduação) - Universidade Federal de Santa Catarina, Centro Socioeconômico. Santa Catarina, p. 94. 2019. Disponível em https:// repositorio.ufsc.br/handle/123456789/209690. Acesso em: 10 ago. 2020.

30. SANTOS, T. M. Estudo do desenvolvimento em países da América Latina a partir do comércio exterior (1990-2015). Dissertação (Mestrado) - Universidade Estadual de Campinas, Faculdade de Ciências Aplicadas. São Paulo, p. 122. 2018. Disponível em: http://repositorio.unicamp.br/handle/REPOSIP/332947. Acesso em: 10 ago. 2020. 
31. SANTOS, P. M. A. Mecanismos de difusão de políticas sociais: o caso dos programas de transferência condicionada de rendimentos na América Latina. Dissertação (Mestrado) - Universidade de Lisboa, Instituto Superior de Ciências Políticas. Portugal, p. 116. 2019. Disponível em https://www.repository.utl.pt/ handle/10400.5/18011. Acesso em: 10 ago. 2020.

32. ZAMBAM, N. J.; KUJAWA, H. A. As políticas públicas em Amartya Sen: condição de agente e liberdade social. Revista Brasileira de Direito, v. 13, n. 1, p. 60-85, 2017.

33. Alcántara Sáez, Manuel, and Flavia Freidenberg. "Partidos políticos na América Latina." Opinião Pública 8.2 (2002): 137-157.

34. FERREIRA, C. C.; SALLES, A. O. T. Desenvolvimento econômico e desigualdade social: uma análise a partir do princípio de causação circular cumulativa de Gunnar Myrdal. Revista da Sociedade Brasileira de Economia Política, n. 55, p. 82-116, jan./abr. 2020.

35. SILVA, E. S. A.; PAES, N. A. Programa Bolsa Família e a redução da mortalidade infantil nos municípios do Semiárido brasileiro. Ciênc. saúde coletiva [online], v. 24, n. 2, p. 623-630, 2019. doi: 10.1590/1413-81232018242.04782017.

36. Soares, Laura Tavares Ribeiro. "América Latina: transição epidemiológica ou retrocesso social?." Acta Paul Enferm. 13.special issue 1 (2000): 55-64.

37. VAL, Eduardo Manuel, BELLO, Enzo. O pensamento pós e descolonial no novo constitucionalismo latino-americano. Caxias do Sul, RS: Educs, 2014. https://www. ucs.br/site/midia/arquivos/pensamento_pos.pdf. 



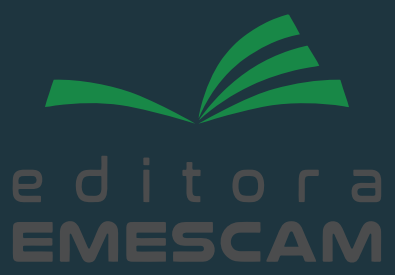

